Portland State University

PDXScholar

Summer 9-13-2019

\title{
Connecting Local-scale Heavy Precipitation to Large- scale Meteorological Patterns Over Portland, Oregon Using Observations and Climate Models
}

Christina Marie Aragon

Portland State University

Follow this and additional works at: https://pdxscholar.library.pdx.edu/open_access_etds

Part of the Meteorology Commons

Let us know how access to this document benefits you.

\section{Recommended Citation}

Aragon, Christina Marie, "Connecting Local-scale Heavy Precipitation to Large-scale Meteorological Patterns Over Portland, Oregon Using Observations and Climate Models" (2019). Dissertations and Theses. Paper 5174.

https://doi.org/10.15760/etd.7050

This Thesis is brought to you for free and open access. It has been accepted for inclusion in Dissertations and Theses by an authorized administrator of PDXScholar. Please contact us if we can make this document more accessible: pdxscholar@pdx.edu. 
Connecting Local-scale Heavy Precipitation to Large-scale Meteorological Patterns Over Portland, Oregon Using Observations and Climate Models

by

Christina Marie Aragon

A thesis submitted in partial fulfillment of the requirements for the degree of

\author{
Master of Science \\ in \\ Geography
}

\begin{abstract}
Thesis Committee:
Paul Loikith, Chair

Andrew Fountain

Andrew Martin

Justin Wettstein
\end{abstract}

Portland State University

2019 
C 2019 Christina Marie Aragon 


\begin{abstract}
Precipitation timing and magnitude is essential to human, ecological, and economic systems. Climate change may be altering the character of precipitation locally to globally, thus it is vital that resource managers, practitioners, and decision makers understand the nature of this change. This thesis was conducted in partnership with the City of Portland Bureau of Environmental Services (BES), and the Portland Water Bureau (PWB) in order to support resiliency planning around precipitation and precipitation extremes.
\end{abstract}

This work has two primary phases, which are discussed in chapter 2 and 3 of this thesis. The first phase of this research entails characterization of the large-scale meteorological patterns (LSMPs) associated with high hourly intensity and heavy daily accumulation of precipitation over Portland, OR. Heavy precipitation is associated with a multitude of impacts on urban environments, thus it is important to understand the meteorological drivers behind these events. This phase of work describes the range of meteorological patterns associated with heavy precipitation totals and high intensity precipitation days over the city of Portland, Oregon. The range of large-scale meteorological patterns (LSMPs) associated with high intensity precipitation days are clustered using the self-organizing map (SOM) approach and are defined using sea level pressure, $500 \mathrm{hPa}$ geopotential height, and $250 \mathrm{hPa}$ wind. Results show that an array of LSMPs are associated with heavy precipitation days, the majority of which occur in fall and winter, usually driven by extratropical cyclones and associated atmospheric rivers. Spring and summer heavy and high intensity precipitation days, while less common than in fall and winter, are typically related to upper level disturbances. Examination of two case studies, one occurring in summer and one in winter, supports the ability of the SOMs approach to realistically capture key observed storm types. Methods developed here 
may be extensible to other locations and results build an observational foundation for validating the ability of climate models to simulate the LSMPs associated with local extremes.

The second phase of this thesis involves evaluation of the fifth phase of the Coupled Model Intercomparison Project (CMIP5) to simulate wet season LSMPs and associated precipitation in the Pacific Northwest of North America. As in the first phase, LSMPs are identified using the self-organizing maps (SOMs) approach, except in this phase all wet season days are included, and defined with sea level pressure, $500 \mathrm{hPa}$ geopotential height, and $250 \mathrm{hPa}$ wind speed. Using SOMs, the range of LSMPs over the region is constructed with reanalysis, providing the target for the multi-model evaluation. Overall, the CMIP5 models are able to reproduce reference LSMPs with reasonable fidelity, though the low pressure LSMPs are generally captured better than the ridging patterns. Furthermore, there is a hierarchy in model ability to capture key LSMPs, with some models exhibiting overall higher fidelity than others. To further evaluate model fidelity, precipitation associated with the LSMPs is evaluated. In general, the observations, reanalysis, and CMIP5 models agree on the LSMPs associated with wet and dry days, but wet patterns are captured somewhat better than dry patterns. The LSMPs associated with the driest and wettest conditions in the PNW are generally overrepresented, while the LSMPs associated with light average daily precipitation across the pacific northwest are underrepresented in the models. Results provide a mechanistic perspective on model fidelity in capturing synoptic climatology and associated precipitation characteristics across the PNW.

This research focuses on Portland and the Pacific Northwest, but has helped to develop methodology that is extensible to any location. The first phase gives us target LSMPs to understand future extreme precipitation over Portland, and the second phase of 
work lays the groundwork for developing projections of future changes to precipitation and precipitation extremes. 


\section{Acknowledgements}

This thesis was supported in part by the Institute for Sustainable Solutions at Portland State University, and the City of Portland Water Bureau. I'd like to express my gratitude for my collaborators Beth Gilden, Nicholas McCullar, Arnel Mandilag, Kavita Heyn, Kristin Anderson, and Benjamin Beal.

I would like to express my sincerest gratitude to everyone who has supported me through this process. My advisor, Dr. Paul Loikith has been an exceptional mentor - thank you for providing me with endless opportunities, believing in me, challenging me to grow, and always being available for guidance. I am motivated by your dedication to your students, and your work. I additionally owe gratitude to my committee members, Dr. Andrew Martin, Dr. Andrew Fountain, and Dr. Justin Wettstein for providing insights and dialogue on my research, personal interests, and professional trajectory. Thank you also to Dr. Kelly Gleason for inspiring my scientific curiosity and for showing me it can be done - a scientist, a woman, a mother, a mountain beast, and a remarkable human being.

Thank you to the Climate Science Lab for the laughs, conversations, and comradery. I feel honored to have worked with such an outstanding group of individuals. Thank you, Arielle Catalano, Judah Detzer, Emily Slinskey, John Rogers, Valerie Thaler, and Dimitri Kalashnikov. I would like to acknowledge my lab mates Judah Detzer, and Dr. Arielle Catalano for going above and beyond to provide support and mentorship along the way.

Finally, I would like to express my gratitude for my family. To my sisters, Jen and Bear - you make me whole. To my parents - my lifelong mentors. Your relentless work ethic, your compassion for others, your devotion to your family, and your values are unparalleled. Thank you, dad, for teaching me to dream, and for showing me that anything is 
possible. Thank you, mom, for encouraging my inquisitiveness and for showing me strength comes in many shapes. Thank you to my husband Taylor, mi amor. Thank you for your boundless belief in me, and in our future. And thank you to the mountains - where my heart sings. 
Table of Contents

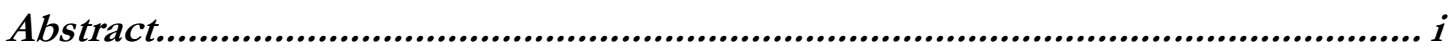

Acknowledgements ..........................................................................

Table of Contents ............................................................................... vi

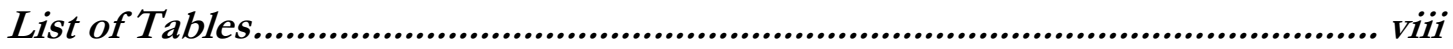

List of Figures ..................................................................................... ix

Chapter 1: Characterization of LSMPs associated with extreme precipitation over

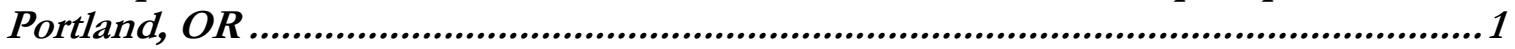

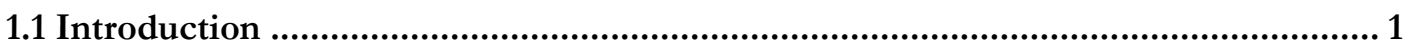

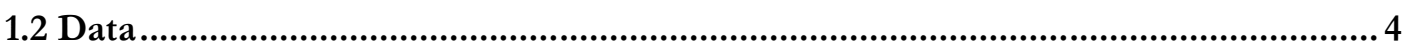

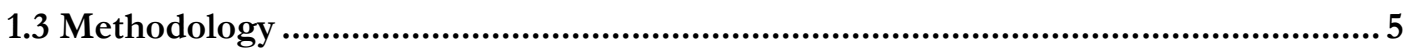

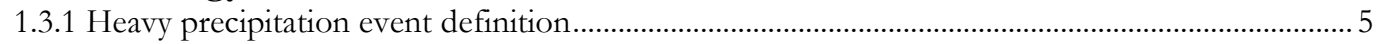

1.3.2 Self-organizing maps .........................................................................................................................

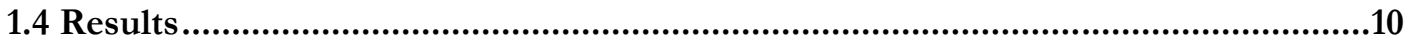

1.4.1 Climatology

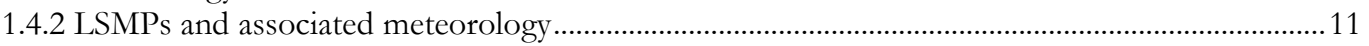

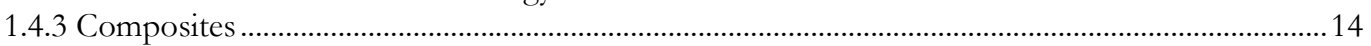

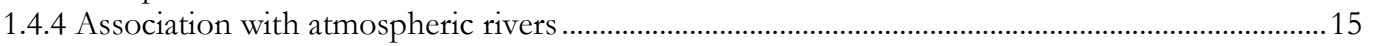

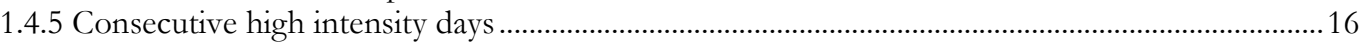

1.5 Individual Case Studies ...........................................................................17

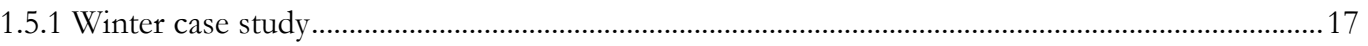

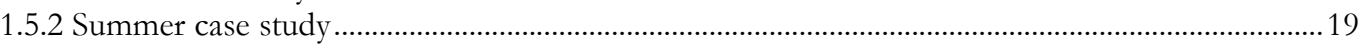

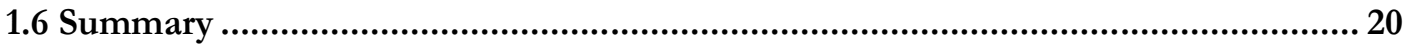

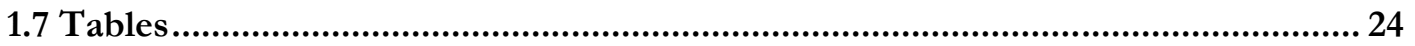

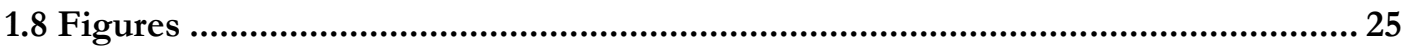

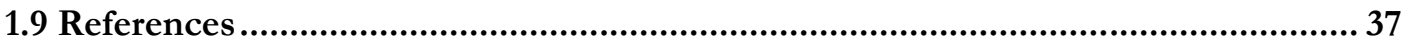

Chapter 2: Evaluation of CMIP5 fidelity at simulating wet season large-scale meteorological patterns and associated precipitation over the Pacific Northwest..... 42

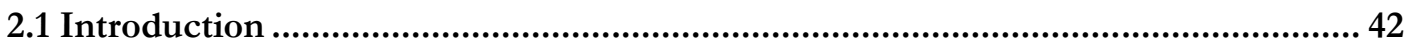

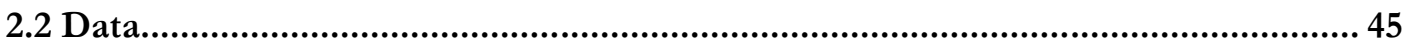

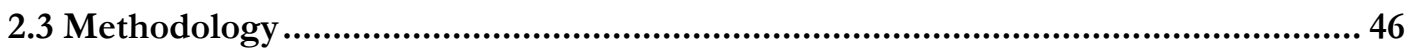

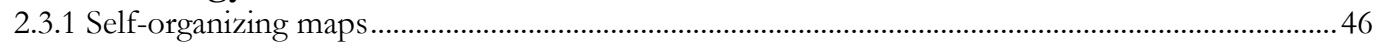

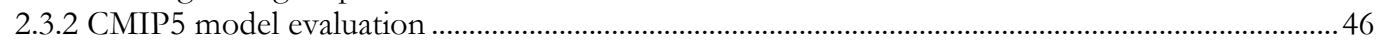

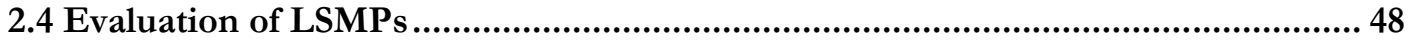

2.4.1 Evaluation of CMIP5 synoptic climatology.................................................................................. 48

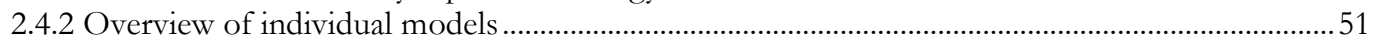

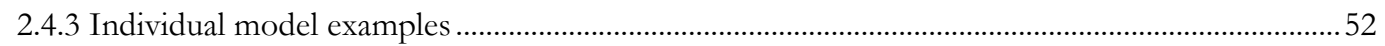

2.5 Evaluation of Associated Precipitation ......................................................................54

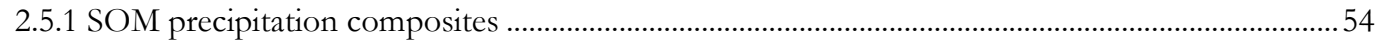




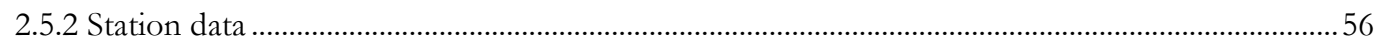

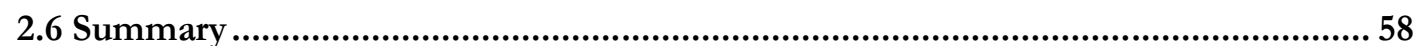

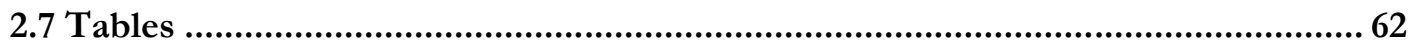

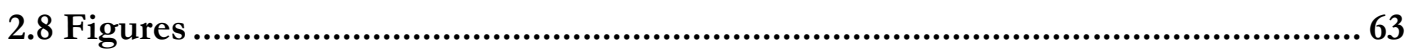

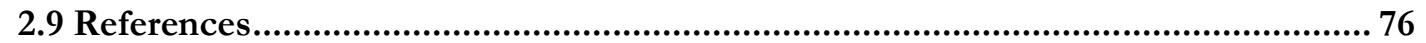

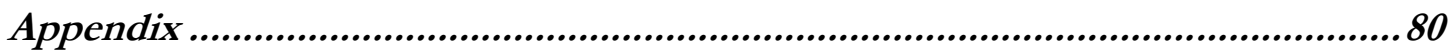

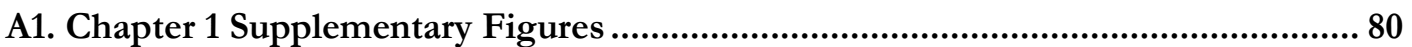




\section{List of Tables}

Table 1. 1 Fraction of heavy intensity days for nodes that are part of a consecutive string of

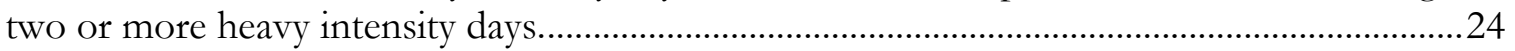

Table 2. 1 CMIP5 models used in this study (left) and the associated native resolution

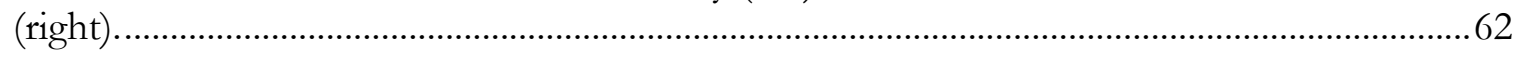




\section{List of Figures}

Figure 1. 1 (Upper left panel) Map of the state of Oregon with elevation shaded and study area outlined in red. (Right Panel) Detailed map of study area showing long-term (red) and shorter-term (green) HYDRA Network precipitation gauges.

Figure 1. 2 (a) Climatology of wet day precipitation $(>0 \mathrm{~mm}$ ) with left y-axis corresponding to the bar chart indicating the average fraction of wet days per month, and the right y-axis indicating the average wet day precipitation accumulation amount per month corresponding to line chart. (b) Climatology of heavy total days with the left y-axis corresponding to the bar chart indicating the average fraction of heavy total days per month, and the right $y$-axis indicating the average heavy total daily precipitation accumulation corresponding to line chart. Turquoise bars indicate the fraction of days per month that are heavy total days and cyan bars indicate the fraction of wet days per month that are heavy total days. (c) Same as center, but for high intensity days

Figure 1. 3 Composite averages of (left) SLP [hPa] (contours at $5 \mathrm{hPa}$ spacing), (center) Z500 [m](contours at $50 \mathrm{~m}$ spacing), and (right) V250 [ms-1](contours at $5 \mathrm{~m} \mathrm{~s}-1$ spacing) concurrent with high intensity days. Portland, OR is indicated by the red dot.

Figure 1. 4 12-node SOM for the 1569 days of the high intensity days showing (a) SLP [hPa] (contours at $5 \mathrm{hPa}$ spacing), (b) Z500 [m](contours at $50 \mathrm{~m}$ spacing), and (c) V250 [ms1](contours at $5 \mathrm{~m} \mathrm{~s}-1$ spacing) concurrent with high intensity days. Portland, OR is indicated by the red dot.

Figure 1. 5 Histogram showing number of days assigned to each month for each node for high intensity days. The fraction of total input days assigned to each node is indicated in red above respective histogram.

Figure 1. 6 Composites of daily maximum temperature anomaly $\left[{ }^{\circ} \mathrm{C}\right]$ for all days assigned to

each node. Portland, OR is indicated by the red dot.

Figure 1. 7 Same as in Fig. 1.6, but for daily precipitation anomaly as percent of climatology $[\%]$. Portland, OR is indicated by the red dot...

Figure 1. 8 Same as in Fig. 1.6, but for daily precipitation amount [mm/day]. Portland, OR is indicated by the red dot.

Figure 1. 9 Same as in Fig. 1.6, but for IVT [kg m-1 s-1; contours at $50 \mathrm{~kg} \mathrm{~m}-1 \mathrm{~s}-1 \mathrm{spacing}$ ]. Bold dashed white contour indicates the $250 \mathrm{~kg} \mathrm{~m}-1 \mathrm{~s}-1$ threshold for AR classification. Red numbers are the percent of days in each node that are concurrent with an AR over the study area and shading visualizes AR strength and orientation.

Figure 1.10 When two high intensity days occur back-to-back, this heatmap shows the where in the SOMs space the second day occurs. The $\mathrm{x}$-axis shows the starting node assignment and the y-axis shows the node assignment of the consecutive day. Heatmap values indicate the percentage of consecutive days assigned to each next-day-node for each given starting node. For example, $94 \%$ of high intensity days that were initially assigned to node 12, were still assigned to node 12 on the second day...........................................................34 Figure 1. 11 LSPMs for December 6, 2015 - December 10, 2015 (top). Synoptic structure of winter CSO following shading and contours of Figure 1.4 (SLP (a), Z500 geopotential heights (b), and Z250 winds (c)) and Figure 1.6 (IVT (d)). Spatial distribution of precipitation across all HYDRA stations with dots proportional to precipitation magnitude (bottom). ....35

Figure 1.12 As in Fig. 1.11, but for June 17, 2014. 
Figure 2. 1 Workflow of mapping CMIP5 models to the reference MERRA-2 SOM using Metric T. Metric T defined in the grey box.

Figure 2. 2 Wet season (November-April) climatology of SLP [hPa] (contours at $5 \mathrm{hPa}$ spacing), Z500 [m](contours at $50 \mathrm{~m}$ spacing), and V250 [ms-1](contours at $5 \mathrm{~m} \mathrm{~s}-1$ spacing) in (a) MERRA-2, and (b) the CMIP5 multi-model ensemble mean. (c) The CMIP5 bias computed bias computed by subtracting (a) from (b). SLP [hPa] (contours ar $2 \mathrm{hPa}$ spacing), Z500 [m] (contours at 5m spacing), and V250 [ $\left.\mathrm{ms}^{-1}\right]$ (contours at $2 \mathrm{~ms}^{-1}$ spacing).

Figure 2. 3 Taylor diagrams of SLP (a), Z500 (b), and V250 (c) climatology fields relative to the MERRA-2 reference dataset. Standard deviation and centered RMSD fields normalized by reference spatial standard deviation. Grey dashed lines indicate the centered RMSE. CMIP5 model indicated in (d).

Figure 2. 4 12-node wet season refSOM showing (a) SLP [hPa] (contours at $5 \mathrm{hPa}$ spacing), (b) Z500 [m] (contours at $50 \mathrm{~m}$ spacing), and (c) V250 [ms-1] (contours at $5 \mathrm{~m} \mathrm{~s}-1$ spacing) in MERRA-2. 66

Figure 2. 5 12-node wet season pSOM color shaded as in Fig. 2.4, but showing composite patterns for all days mapped to each node for the respective field SLP (a), Z500 (b), and V250 (c) across the suite of 24 CMIP5 models.

Figure 2. 6 Portrait diagrams summarizing the Metric T skill score for each CMIP5 models at each node. Heatmap (a) show the skill score when considering all three fields simultaneously, as is done to assign each model day to a node. Heatmap (b-d) show the skill scores only considering the SLP, H500, and V250 fields respectively.

Figure 2. 7 Portrait diagram showing the node occurrence bias in node assignment calculated as the percent of days assigned to each node in models - the percent of days assigned to each node in MERRA-2.

Figure 2. 8 Composites for MIROC5 color shaded as in Fig. 2.4. Red numbers above each node indicate the Metric T skill score, and the percent of total days assigned to the respective

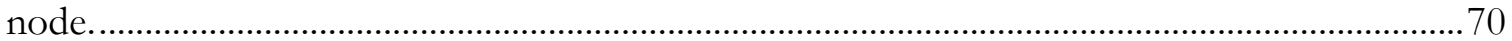

Figure 2. 9 As in Fig. 2.8, but for IPSL CM5B LR..................................................................

Figure 2.10 Composites of daily average precipitation [ $\mathrm{mm} / \mathrm{day}]$ for all days assigned to each node in MERRA-2 (a) and in the CMIP5 ensemble (b) .....................................................72

Figure 2.11 As in Fig. 2.10 but for all days assigned to each node in MIROC5.....................73

Figure 2.12 As in Figure 2.10, but for the IPSL CM5B LR model. ........................................74

Figure 2. 13 PDFs of precipitation at Portland International Airport (PDX) and at the North Fork SNOTEL station in Bull Run. Station precipitation observations, MERRA-2 precipitation at the coinciding pixel, the CMIP5 ensemble average precipitation at the coinciding pixel are shown for each node. Black numbers indicate the node number, and blue numbers indicate the percent of $99^{\text {th }}$ percentile precipitation events that were mapped to a given node. 


\section{Chapter 1: Characterization of LSMPs associated with extreme precipitation over Portland, OR}

\subsection{Introduction}

Precipitation extremes are associated with a multitude of societal and environmental impacts across a spectrum of spatial and temporal scales. Anthropogenic climate warming is projected to alter precipitation extremes, with an overall increase projected at the global scale (Hartmann et al. 2013). However, there is considerable uncertainty in the magnitude and even sign of change in precipitation extremes at regional to local scales. Further exacerbating this uncertainty is the fact that most state-of-the-art climate models do not readily resolve the scales that precipitation extremes typically occur on. This limitation is particularly acute in regions of meteorologically-influential complex topography like Portland, Oregon. One way to address this scale mismatch is to focus on the large-scale meteorological patterns (LSMPs) associated with the local scale extremes (Grotjahn et al. 2016). Study of LSMPs provides both a useful diagnosis of the meteorological mechanisms that drive the high-impact events by relying on large synoptic scale patterns that are resolvable by climate models. As a first step towards addressing the above mentioned challenges, here we present a climatology of the LSMPs associated with precipitation extremes over Portland in the current climate.

Portland, the most populous city in Oregon, is within a region of complex topography with elevations in the city spanning 0 to over 300 meters above sea level, with higher mountain ranges in close proximity. The city lies within the rain shadow of the Coastal Mountain Ranges,

typically shielding it from the heaviest precipitation associated with Pacific extratropical cyclones. Precipitation climatology in Portland and the greater PNW is characterized by a distinct seasonal cycle of wet winters and dry summers (Hoerling et al. 2016; Parker and 
Abatzoglou 2015), with annual rainfall totals as high as $1188 \mathrm{~mm}$ in the foothills of the Cascades and as low as $916 \mathrm{~mm}$ near the Columbia River. Wind flow relative to topography has also been shown to influence precipitation climatology. For example, analysis of WSR$88 \mathrm{D}$ radar shows lower tropospheric wind speed and direction relative to the orographic gradient plays an essential role in the spatial precipitation distribution in the nearby Cascades, with orography approximately perpendicular to winds receiving the most frequent and intense precipitation (Yuter et al. 2011).

Meteorologically, precipitation extremes in the PNW are commonly associated with distinct LSMPs (e.g. Loikith et al. 2017; DeAngelis et al. 2013; Warner et al. 2012) with nearly all moisture sourced directly from the Pacific Ocean (Bracken et al. 2015). West of the Cascades (where Portland is located), extratropical cyclones and associated atmospheric rivers (ARs), are the predominant mechanisms behind synoptic scale extreme precipitation (Kunkel et al. 2012b; Warner et al. 2012; Parker and Abatzoglou 2015; Rutz et al. 2013; Waliser and Guan 2017). Bands of high values of integrated water vapor in the warm sector of an extratropical cyclone narrow as the associated cold front progresses cyclonically towards the warm front, lifting water vapor as it travels creating an AR (Dacre et al. 2015). When the low level moisture within an AR is lifted by local topography, the result can be copious amounts of rain and mountain snow (Rutz et al. 2013; Bin et al. 2016). Along the US west coast as a whole, ARs contribute $30-50 \%$ of annual precipitation, and are associated with $60-100 \%$ of extreme storms in the top $2 \%$ of the precipitation distribution (Lamjiri et al. 2017; Waliser and Guan 2017). Closed lows have been linked to extreme precipitation in the warm season, typically producing more localized extreme precipitation than ARs and are an important component of the interannual variability of summer precipitation (Parker and Abatzoglou 2015; Abatzoglou 2016). 
Hourly-to-daily precipitation extremes can lead to varied local-scale impacts that warrant distinct planning strategies. In urban areas, such as Portland, spatially limited impacts can have consequences for large numbers of people. At the urban catchment scale, drainage systems are vulnerable to overflow and flooding from inundation caused by extreme precipitation events (Willems et al. 2012). Combined sewer overflows (CSOs) are a recognized urban impact in many cities including Portland that result when heavy rainfall overwhelms sewage treatment facility storage capacity in combined systems, ultimately resulting in discharge of untreated sewage into receiving waters (Mailhot et al. 2015; Riechel et al. 2016). As heavy precipitation events may change under climate warming, it is vital for managers and decision makers to have reliable data for infrastructure and resiliency planning.

Specific to the Portland and the greater PNW, existing assessments of observed change in extreme precipitation to date at annual and seasonal scales generally show a low signal relative to the dominant interannual-to-decadal scale variability (Abatzoglou et al. 2014). Despite this, previous work has found that hourly (Prein et al. 2017) and daily (Kunkel et al. 2012a) precipitation extremes have increased over the observational past. Looking forward, considerable uncertainty exists around projections of future changes in extreme precipitation over the region with some studies showing increases in the frequency and severity of extremes (Singh et al. 2013; Huang and Ullrich 2017) and others showing little or no change (Wehner 2013; Janssen et al. 2014). Some of this uncertainty can likely be attributed to disparate methodological definitions of extremes, and to differences in model skill at reproducing precipitation climatology (Rupp et al. 2017). This uncertainty makes it challenging for stakeholders to plan for future climate impacts as they relate to extreme precipitation.

This work, conducted in partnership with the Portland Bureau of Environmental Services (BES), is motivated by a desire to better understand the synoptic meteorology behind 
urban-scale heavy precipitation days and associated CSOs. Towards this goal, this paper presents a novel methodology for linking local-scale heavy precipitation to large-scale circulation in Portland, through (1) building a climatology of the range of LSMPs associated with local-scale hourly and daily heavy precipitation, (2) characterizing meteorologically important variables associated with the different LSMPs, (3) providing context for the LSMP climatology through case study analysis, and (4) connecting the LSMPs to local impacts.

\subsection{Data}

The City of Portland Hydrologic Data Retrieval and Alarm (HYDRA) Rainfall Network is a high-density precipitation gauge network within the Portland Metropolitan Region (Fig. 1). HYDRA is managed by BES and has a total of 42 stations with nine stations dating back to 1977. Precipitation data is provided every 15 seconds, but here we aggregate to hourly temporal resolution.

The Modern-Era Retrospective analysis for Research and Applications, Version 2 (MERRA-2) is used for SLP, 500-hPa geopotential heights (Z500), 250-hPa wind speed, and integrated vapor transport (Gelaro et al. 2017). MERRA-2 is a product of the National Aeronautics and Space Administration available from 1979 to present. MERRA-2 data are provided on a $0.5^{\circ} \times 0.625^{\circ}$ latitude/longitude grid mesh at hourly temporal resolution. The Rutz AR Catalog, which is freely available on the web and based on MERRA-2 input data was used to identify days with ARs (Rutz et al. 2014). This study maintains the Rutz et al. (2014) definition of ARs: narrow corridors of water vapor transport $\geq 2000 \mathrm{~km}$ in length with integrated vapor transport (IVT) $\geq 250 \mathrm{~kg} \mathrm{~m}^{-1} \mathrm{~s}^{-1}$. For each grid point within the box bounded by 45 and 46 north latitude, and -123 and -122 east longitude, the AR catalogue indicates if an AR was present at three-hour time intervals. 
GRIDMET data were used for surface temperature and regional precipitation figures. GRIDMET is a University of Idaho product available from 1979 to present. GRIDMET data are on a $1 / 24^{\circ} \times 1 / 24^{\circ}$ latitude/longitude grid mesh, at daily temporal resolution, and are freely available via the web (Abatzoglou 2013). GRIDMET combines high temporal resolution data from the North American Land Data Assimilation System Phase 2 with high spatial resolution data from the Parameter-elevation Regressions on Independent Slopes Model (PRISM).

National Weather Service (NWS) Level II Next Generation Weather Radar (NEXRAD) Weather Surveillance Radar-1988 Doppler (WSR-88D) radar reflectivity observations for the KRTX radar were obtained from the National Climate Data Center (NCDC). Reflectivity data from two days (December 7, 2015, and June 17, 2014) were used to verify the spatial precipitation distribution over Portland in our storm case studies. Reflectivity images were made using the NOAA Weather and Climate Toolkit. United States Geological Survey (USGS) discharge observations for Johnson Creek (Gauge 14211550), an urban stream in Portland, were obtained through the National Water Information System Web Interface. These observations are available in 15-minute intervals and were used to frame the hydrological impacts of our storm case studies.

\subsection{Methodology}

\subsubsection{Heavy precipitation event definition}

The nine long-term HYDRA stations (records starting prior to 1980) were used to define heavy precipitation days (Fig. 1.1). Heavy precipitation days are defined based on 1-day accumulated rainfall total (heavy total events herein) and daily maximum 1-hour precipitation intensity (high intensity events herein), where days are defined as starting at 00 UTC. This 
approach is designed to capture longer-duration heavy events as well as shorter duration high intensity events, both of which are associated with urban scale impacts in Portland, such as CSOs. Events are defined using the $90^{\text {th }}$ percentile of the frequency distribution of daily rainfall totals and daily maximum 1-hour rainfall rate computed over the 37-year period of 1980-2016. The $90^{\text {th }}$ percentile threshold was chosen as a compromise between capturing a large enough sample of days for robust statistics while still being considered rare in frequency. More stringent thresholds were explored, but did not capture as many CSOs which was a detriment to the applications aspect of this work. Only days that had measurable precipitation are included to define the $90^{\text {th }}$ percentile. In order for a day to be considered in our analysis, at least one of the nine HYDRA stations had to surpass its $90^{\text {th }}$ percentile threshold. The definition results in 1045 heavy total days and 1569 high intensity days. Analysis is performed separately for heavy total days and high intensity events, however results are generally similar in that the LSMPs associated with high intensity days largely resemble those associated with heavy total days, with some exceptions. This results from a large proportion of heavy total days coinciding with high intensity days. Because results are similar between the two types of extremes and because high intensity days were found to be associated with a slightly higher number of CSO events in Portland, we primarily focus on high intensity days in this paper. Analogous results for heavy total days are provided in the Appendix and referenced in the results section where noteworthy differences exist. Appendix figures are labeled A1-A13.

An Empirical Orthogonal Function (EOF) analysis was conducted on the HYDRA stations for precipitation accumulation and separately for maximum intensity, to confirm that all nine stations usually covary enough to consider them together in the definition of a heavy total or high intensity event. Results yielded a dominant EOF 1 pattern showing covariability 
in heavy total and high intensity precipitation across all stations with all subsequent individual EOFs contributing little to the overall explained variability.

\subsubsection{Self-organizing maps}

We employ the self-organizing maps (SOMs) approach to cluster the LSMPs associated with heavy precipitation days in Portland into "nodes" such that events with similar LSMPS are assigned to the same node. SOMs are a class of unsupervised neural networks that organize input data (LSMPs for extreme precipitation days here) into a user-defined matrix of output nodes (Sheridan and Lee 2011). The SOMs approach has been demonstrated as a useful synoptic climatology analysis tool across an increasingly wide range of applications (e.g. Hewitson and Crane 2002; Lennard and Hegerl 2015; Johnson et al. 2008; Johnson and Feldstein 2010; Glisan et al. 2016; Kennedy et al. 2016; Mechem et al. 2018) and has been employed to elucidate, characterize, and describe LSMPs and for connecting LSMPs with other meteorological impacts such as temperature and precipitation extremes (Gibson et al. 2017; Loikith et al. 2017; Loikith and Broccoli 2014; Cassano et al. 2015; Ford and Schoof 2017; Liu and Weisberg 2011). SOMs have also been applied to characterize variability in patterns of other meteorological phenomena such as ARs (Radić et al. 2015) and sea ice (Chen et al. 2016).

In this study, SOMs are used as a clustering approach to group LSMPs associated with heavy precipitation days in Portland into nodes, with each heavy day assignment based on which node comprises the most similar LSMPs. We use the MATLAB SOMs Toolbox for this analysis. In the SOMs routine, the first step is to seed a user-defined number of nodes with daily total field SLP, Z500, and $250 \mathrm{hPa}$ wind, Loikith et al. (2017). Note that here we only provide input data for heavy days. The input data is first normalized by the spatial standard deviation computed for all input days of the field, so the training is not 
disproportionately influenced by the inherent magnitude differences of the three variables, and weighted by area by multiplying each grid point by the square root of the cosine of its latitude. By providing SLP, Z500, and $250 \mathrm{hPa}$ wind simultaneously as input to the SOM we capture circulation near the surface and in the mid and upper troposphere, respectively. This trains the SOM over a more meteorologically complete set of information than if only one variable were provided, but also increase the number of variables to be interpreted. As in Loikith et al. (2017), total field is provided as input, as opposed to anomalies, because it increased the physical interpretability of the patterns and in our case provides a more intuitive view of heavy rainfall weather patterns for use in applications. Next, the first input data, which here is the tri-variate LSMP for the first heavy day in the record, is assigned to the node with the shortest Euclidean distance between the data in the seeded node and the input data. This "winning" node and the surrounding nodes are adjusted towards the input data. This procedure is repeated for each input data point until a stable SOM is achieved. A matrix, spanning the range of LSMPs associated with heavy precipitation days in Portland results, with each heavy day assigned to one of the nodes. The SOMs approach shares commonalities with other clustering methodologies, such as k-means, however it has the advantage of being able to capture a continuum of patterns via the adjustment of neighboring nodes to the winning node, which is advantageous when studying synoptic climatology as it can capture patterns that may fall in between clusters.

There are several user provided decisions that must be made when performing the SOMs approach. First, the number of nodes must be chosen. This is often made with some level of subjectivity, with efforts to balance the desire for to capture a sufficient level of detail in the range of LSMPs while not having so many nodes as to reduce physical interpretability. In other words, a larger SOM would give more detail with fewer days assigned to each node, 
while a smaller SOM would be a more generalized depiction of the range of patterns. An optimal SOM configuration will capture the full range of LSMPs with the node pattern in one corner of the SOM most different from the pattern at the opposite corner of the SOM. After testing a wide range of node configurations and numbers (as in Agel et al. 2018), we found that a 12 -node SOM organized in a 4x3 node configuration worked optimally for capturing the range of LSMPs associated with extreme precipitation in a physically interpretable way. Additionally, a single-dimensional lattice with rectangular topology was chosen for the output SOM architecture, and a sheet was selected for the global map shape to optimize interpretability. The neighborhood radius determines the number of surrounding nodes that are adjusted towards the winning node. We use a large initial neighborhood radius $(r=4)$ and a small final neighborhood radius $(r=1)$ to ensure that the map topology initially moves to the data distribution, but eventually stabilizes to converge on a solution. Additional information on the MATLAB SOM Toolbox 2.0 can be found at http://www.cis.hut.fi/somtoolbox/.

It is important to note that our implementation of SOMs to address our research objectives is somewhat novel compared with more commonly used approaches. Often, studies construct a SOM using all days in the data record as input and then identify which patterns out of the range of possible patterns are most commonly associated with a feature, such as heavy precipitation. These studies also often seasonally stratify the analysis so that the influence of the seasonal cycle is reduced on the training of the SOM. This is the approach used by Loikith et al. (2017) over the PNW as well as numerous other studies over different geographies (e.g. Mechem et al. 2018; Lennard and Hegerl 2015). Here we only provide LSMPs from heavy precipitation days defined in Portland across the entire seasonal cycle as a way to display a highly detailed view of the full range of LSMPs that are associated with high impact precipitation. These two approaches address somewhat different research goals. In our case, 
the SOMs approach provides a concise and detailed view of the full range of storm types (described using LSMPs) that are associated with heavy precipitation days in Portland. This provides a high level of utility for applications such as identifying particularly problematic storm types for impacts such as CSOs across the annual cycle. The other approach as in Loikith et al. (2017) addresses a more fundamental characterization of synoptic climatology and informs on where in the continuum of possible patterns heavy precipitation days are most likely. This is powerful for understanding synoptic climatology, but would provide a much coarser level of detail on the specific storm types associated with heavy precipitation. Moreover, nodes identified as being most likely to be associated with heavy precipitation days would likely also have non-heavy days assigned to that node. By isolating only heavy days and using SOMs to cluster the patterns, we are able to see a more complete picture of the full range of LSMPs associated with heavy precipitation.

\subsection{Results}

\subsubsection{Climatology}

Fig. 1.2a displays the precipitation climatology across Portland, while Fig. 1.2b,c show the heavy total and high intensity climatology, respectively. The frequency of heavy total days peaks in December at about five days/month and decreases in frequency each month until July (Fig. 1.2b). The highest average daily total magnitude tends to occur between September and February (Fig. 1.2b). A different seasonality pattern emerges for high intensity days. High intensity days peak in November with about six days/month, comprise about $13 \%$ of days per month from June to May, and are lowest in July and August (Fig. 1.2c). The fraction of wet

days that are high intensity events in the warm season between May and September is noteworthy in that there are a lower proportion of wet days but a higher proportion of these 
wet days are high intensity events (Fig. 1.2c). The magnitude of these high intensity events is highest between June and September, suggesting precipitation is convective in nature in these low frequency, high intensity events.

\subsubsection{LSMPs and associated meteorology}

To achieve a general picture of the LSMPs associated with heavy and intense precipitation days over Portland, Fig. 1.3 shows composites of SLP, Z500, and $250 \mathrm{hPa}$ wind speed concurrent with all high intensity days. The composites are characterized by an area of low SLP to the north and west and an area of relatively high SLP to the south and southwest. This results in a pressure gradient implying onshore winds near the surface in the Portland region. For Z500, a trough is centered slightly offshore with an apparent negative tilt to the trough axis, indicative of upward vertical motion over the Portland area and consistent with expectations for heavy precipitation. At $250 \mathrm{hPa}$, a prominent jet streak is nosing into the Oregon coast, putting Portland within the vicinity of the poleward front quadrant of the jet streak and therefore a favorable location for upward vertical motion and precipitation. Composite patterns are very similar for heavy total days (Fig. A1). Note that while strong baroclinic systems often exhibit a vertical tilt to the pressure patterns with height, these composites are largely vertically stacked. This is indicative of the fact that landfalling extratropical cyclones in the PNW are often more vertically stacked than in other mid-latitude locations (e.g. Warner et al. 2012, DeAngelis et al. 2012, Loikith et al. 2017) but may also be an artifact of compositing a diverse variety of storm types. Therefore, while these patterns provide a broad view of the LSMPs associated with heavy precipitation over Portland, make broad meteorological sense, and are physically consistent with synoptic expectations, the composite averaging of all heavy days masks the variety of synoptic setups that can lead to high intensity precipitation in Portland. Therefore, additional analysis to expose intra- 
ensemble pattern variability is necessary to best characterize the range of key LSMPs that drive heavy rainfall events over Portland.

Fig. 1.4 shows the SOMs results to elucidate the range of LSMPs associated with high intensity precipitation days in Portland. Panel (a) shows the 12-node SOMs results for SLP, panel (b) for Z500, and panel (c) for $250 \mathrm{hPa}$ wind. Corresponding nodes between variables are assigned to node one through 12. Each high intensity day is assigned to the node with the most similar LSMPs. So, for example, days that are assigned to N1 (we use the notation of "N1" to indicate node number herein) are characterized by a strong surface low to the northwest of Portland, a sharp Z500 trough, and a strong jet stream just to the south of Portland. As is inherent to the SOMs algorithm, similar patterns are closer together in the SOMs space while opposite corners of the SOMs space are dissimilar, as illustrated by the differences between $\mathrm{N} 1$ and N12. The upper SOMs nodes (N1, N2, N3, and N4) are all characterized by relatively deep low-pressure patterns and strong jet streams, the left central nodes (N5, N6, N7, and N9) have more moderate low-pressure patterns with jet streams that are weaker than the top row, and the lower right corner of the SOMs $(\mathrm{N} 8, \mathrm{~N} 10, \mathrm{~N} 11$, and N12) are higher-pressure patterns with weaker jet streams. The deep low-pressure nodes are indicative of westerly or southwesterly surface winds with advection of warm, moist air from the Pacific, combined with Z500 troughs and strong jet streams. The deeper low pressure patterns here are similar to Node 5 in the DJF SOM in Loikith et al. (2017), which they show to be associated with extreme precipitation in Portland. However, results here show more nuance to the pattern configurations than is possible in the all days SOM in Loikith et al. (2017). High-pressure at the surface (N8, N10, N11 and N12) along with trough at Z500 suggest that upper level disturbances associated with cool air aloft drive precipitation, likely 
convective in nature. SOMs for heavy total days show a similar range of patterns with some differences in the middle of the SOM (Fig. A3).

Fig. 1.5 provides insight as to the seasonality and frequency of daily assignments to the 12 SOM nodes. Note that while most nodes have a seasonal maxima in frequency, all nodes span more than one season, and N6 and N12 are found in all seasons. N6 and N12 are the most common high intensity patterns (10-11\% of days) while N1 and N5 are the least common (5-6\% of days). Also, N6 and N12 are nearly opposite in synoptic structure and seasonality. N6 is a fall-winter low-pressure pattern with a surface low off the coast of Alaska and a prominent upper level trough, whereas N12 shows a high-pressure summer pattern with a weak jet stream. The least frequent intensity patterns are N1, a deep low-pressure pattern, and N5 a moderate low-pressure pattern with a closed low off the coast of British Columbia propagating into the middle and upper troposphere. The SOMs show three warm season patterns - two predominantly in summer (N7 and N12), and one predominantly in spring (N11), while the rest are fall-winter patterns. Most high intensity days occur during the fall and winter when the strongest dynamics are present, driven by baroclinicity to facilitate extratropical cyclone development, as is seen in the deep SLP low near or upstream of Portland. Warm season patterns (N11 and N12) are associated with upper level disturbances indicated by a deep Z500 trough associated with cool air aloft promoting instability and convective precipitation. The heavy total SOM patterns are largely similar to the high intensity SOM patterns, but the heavy total days don't capture as many warm season days. This suggests that the warm season days that are only captured in the high intensity SOM are likely high intensity convective events that don't meet the heavy total accumulation threshold. We note that the seasonal cycle is pronounced for Z500 where warm season nodes have higher Z500 values due to the hypsometric relationship between temperature and Z, however N11 and 
N12, for example, are not simply warmer versions of predominantly winter patterns and that the flow patterns in the Z500 fields are a better diagnostic of the meteorology associated with high intensity precipitation.

\subsubsection{Composites}

To get a more complete synoptic view of the meteorology associated with each node, Fig. 1.6 shows composites of daily maximum temperature anomalies for all days assigned to each node. N2 and N3 stand out as having widespread warm temperature anomalies. These predominantly fall and winter nodes show a strong SLP gradient in Fig. 1.4, directing warm air north towards the region. This is in conjunction with an upstream Z500 trough and downstream ridge, consistent with warm air advection in the mid-troposphere. N1 and N4 are characterized by weak anomalies in the Portland area and warm anomalies inland. Western cool and eastern warm anomalies are also present in N5 and N6, with inland warm anomalies possibly due to a combination of warm air advection and clear skies. The rest of the nodes are all associated with widespread cool anomalies, with the warm season nodes of N7, N10, N11, and N12 showing large negative temperature anomalies. In these cases, cool anomalies are likely the result of the cloud cover during an otherwise relatively sunny time of year and/or unseasonably cool air associated with Pacific storms.

Fig. 1.7 shows composites of daily precipitation anomalies for days assigned to each node while Fig. 1.8 shows composites of daily total accumulated precipitation, to put local heavy precipitation in Portland into perspective with the larger synoptic environment. Widespread, heavy regional precipitation is seen with the deep low-pressure nodes. While the heaviest precipitation falls in the higher elevations (Fig. 1.8), precipitation anomalies show that high intensity days in Portland tend to be more anomalous in the lower elevations in N1, N2, and N5. The more zonal low level flow associated with N4 results in more anomalous 
precipitation in the north-south oriented mountains surrounding Portland than in lower elevations, suggesting that the low level moisture transport intercepting the topography at a near right angle is enhancing rainfall rates in the mountains relative to other patterns. Summer and spring nodes show considerably lower precipitation totals that are spatially limited compared to the winter precipitation patterns. However, the most anomalous precipitation ( $600 \%$ of daily normal) is associated with summer nodes N7 and N12. This suggests smallerscale mechanisms as the driver behind heavy summer precipitation events.

\subsubsection{Association with atmospheric rivers}

To better understand the role that ARs have on high intensity precipitation in Portland, Fig. 1.9 shows composite averages of the IVT for days assigned to each node. Note that there are a higher proportion of AR days (75\%; Figure A8) associated with heavy total patterns compared to high intensity patterns (58\%), suggesting ARs are more associated with prolonged heavy rainfall than short duration high intensity rainfall in Portland. The highest proportion of AR days coincide with the strongest low-pressure patterns while the lowest AR incidence occurs in conjunction with higher pressure patterns. AR orientation appears to be key to spatial precipitation patterns with peak precipitation amounts coinciding with peak IVT levels over land (Fig. 1.8). AR-related precipitation patterns tend to show the highest totals in the mountains to the east and west of Portland where orographic enhancement is prominent. More zonal AR trajectories tend to show Portland at the southern end of heavy precipitation, whereas southwesterly to northeasterly oriented ARs (N1, N2, N3) show Portland in the center of heavy precipitation and are associated with the most high intensity days. This is likely because as ARs cross the north-south oriented Coastal Mountains at an angle, resulting in a weaker rain shadow effect than if the AR were perpendicular to the mountains (N4). This supports previous findings that ARs are a key mechanism for heavy precipitation in the Pacific 
Northwest (Warner et al. 2012; Kunkel et al. 2012b); however not all high intensity days are associated with an AR.

\subsubsection{Consecutive high intensity days}

The impacts of high intensity precipitation, such as flooding and loss of life, can be exacerbated when multiple high intensity precipitation days occur consecutively (Lorente et al. 2008; Mahoney et al. 2014; Trigo et al. 2016). To better document under what conditions consecutive high intensity days occur, Table 1 shows the fraction of days in each node that were part of a string of two or more consecutive high intensity days. More than $40 \%$ of days in N1, N2, N3, and N7 are part of a string of consecutive high intensity days. N1, N2, and N3 are all deep low-pressure cool-season patterns with regionally widespread precipitation with a high incidence of ARs, indicating that these types of storm events are more likely to be associated with impacts resulting from the compounding effect of prolonged periods of heavy rainfall. N7 is also a low-pressure pattern with a high incidence of ARs but occurs predominantly in spring and fall and has more spatially limited precipitation. N8, N10, N11, and N12 have the smallest fraction of assignments that are part of a string of consecutive high intensity days. These are all high pressure patterns with the lowest incidence of ARs that tend to occur in summer or the transition seasons. This indicates that high intensity days associated with these LSMPs are generally brief and are therefore less likely to be associated with impacts such as CSOs.

Fig. 1.10 shows the node assignment for the subsequent day when a high intensity day is followed by another. In such cases, the second day is most often assigned to the same node as the previous day. In other words, when high intensity days occur back-to-back, it is most common for both days to be assigned to the same node. This is especially true for N8, N11, and N12. These nodes are among the least likely to be part of a string of two or more 
consecutive high intensity days (Table 1), however when they do occur as part of such a streak, it is rare that one high intensity day is followed by another that is assigned to a different node. This suggests that these warm season patterns don't often transition to other rainy patterns. In other nodes, consecutive high intensity days also tend to be within the same node most often, but transition to other nodes is also common. For example, when N1-N4 high intensity days are followed by another consecutive high intensity day, N9 is the most common pattern. This is dynamically consistent if N1 and N2 are weakening, and if N3 and N4 have low pressure centers that are progressing southward. Similarly, N6 preferentially transitions to N10 while other transition probabilities for consecutive days show less of a preferred consecutive high intensity day node.

\subsection{Individual Case Studies}

To further examine the accuracy of the SOMs approach for capturing the range of storm types associated with heavy rainfall, specifically those that have historically been associated with CSOs, we investigate two notable case studies. Each case study was associated with a CSO in Portland and met the criteria for a high intensity day (Note that 93\% of CSOs between 2011 and 2016 were concurrent with a high intensity day). The two case studies are also chosen to explore very different storm types: an early winter series of AR landfalls and a summer event.

\subsubsection{Winter case study}

December 2015 was the wettest December on record in Portland with numerous high intensity and heavy total days. The recurrent heavy precipitation events were associated with numerous impacts on the urban and natural landscape including landslides, urban and small stream flooding, and CSOs. A particularly wet stretch spanned December $5^{\text {th }}$ through 
December $13^{\text {th }}$ with December $7^{\text {th }}$ setting the one-day precipitation accumulation record at Portland Airport. At Johnson Creek, there is a clear concurrent peak in the hydrograph on December $7^{\text {th }}$, when peak flows increase 10 -fold compared to the previous two days (Fig. A12). December $7-10^{\text {th }}$ all surpassed the threshold for being considered a high intensity day (note that December $6^{\text {th }}-10^{\text {th }}$ all surpassed the threshold for being considered a heavy total day) and were assigned to N3, N3, N2, and N1 respectively. LSMPs for the individual high intensity days are shown in Fig. 1.11 along with the total daily accumulation and maximum one-hour rainfall intensity at each of the HYDRA stations.

All days were associated with deep low-pressures upstream of Portland with the lowpressure center approaching Portland on December $10^{\text {th }}$ (Fig. 1.11, column a). All days also show a deep upstream Z500 trough, approaching the coast with a negative tilt on December $10^{\text {th }}$ (column b). A strong $250 \mathrm{hPa}$ jet stream is evident on all days (column c), with a southward propagation of the core of the jet from December $8^{\text {th }}$ to the $10^{\text {th }}$ as the surface low pressure moves towards the coast. Comparing with the node patterns that these days are assigned to (Fig. 1.4) shows that the SOMs patterns capture these features well and that these individual high impact days fit well into their associated nodes. This supports the efficacy of the SOMs approach as employed here for highlighting the range of key storm types associated with high intensity precipitation over Portland.

The IVT maps (Fig. 1.11, column d) show that these days were associated with elevated moisture flux and strong ARs on some of the days. The strongest and most prominent AR is present on the $7^{\text {th }}$ and $8^{\text {th }}$. Between December $9^{\text {th }}$ and $10^{\text {th }}$, it appears that a secondary cyclone forms along the AR and develops rapidly as it moves towards the coast on the $10^{\text {th }}$ (Pinto et al. 2014). Specific to December $7^{\text {th }}$, precipitation accumulation associated with this event was the greatest in the southeast quadrant of the study area where upwards of $100 \mathrm{~mm}$ of rain fell 
over the 24-hour period, while precipitation intensity was highest in the southern half of the study area where the maximum one-hour rainfall rate exceeded $14 \mathrm{~mm} / \mathrm{hr}$. Precipitation totals were lowest over the city center and southwest hills even though these areas generally recorded high intensity, suggesting the heaviest precipitation was more prolonged throughout the day in the eastern portion of the region (Fig. 1.11, right panel). NEXRAD WRS-88D radar reflectivity data provides additional perspective on the spatial characteristics of the precipitation intensity (Fig. A10). There is notable, spatially-contiguous high intensity precipitation throughout the day, as one might expect with a cool-season AR event. The radar frames also show evidence of the widespread high intensity with this event, along with the more prolonged rainfall leading to higher totals in the eastern half of the Portland region.

\subsubsection{Summer case study}

Hourly intensity thresholds capture more heavy precipitation days in the summer compared to daily accumulation thresholds. This means that the summer days that are captured by the intensity threshold are very intense in nature, but are likely short in duration, not producing enough precipitation in a day to exceed the heavy accumulation threshold. Although short in duration, these high intensity events can bring impacts. All summer CSO events that were captured by the intensity threshold, but not the accumulation threshold, are short-duration, high intensity events, suggesting rainfall was convective in nature and likely spatially limited in extent.

One such warm season event occurred on June 17, 2014 (Fig. 1.12). There is a steep ascending arm in the hydrograph leading to the daily peak flow at Johnson Creek around 12am Z-time (Fig. A13). This is approximately a 4-fold increase in peak flows compared to previous days. This day surpassed the high intensity threshold, resulted in a CSO, and was assigned to N12 but did not qualify as a heavy total day. The LSMP for the event was characterized by 
high pressure near the surface to the southwest of Portland, a closed Z500 low overhead and to the east, and a notable jet streak to the west and south. It is evident that most of the precipitation causing dynamics were aloft, as there is not a discernible surface cyclone present. However, the Z500 closed low is indicative of cooler air aloft, which combined with mid-June insolation likely resulted in instability and convection. This is combined with some upward vertical motion promoted by the nearby jet streak. No AR is present (column d) in Fig. 1.12. This synoptic setup matches N12 well and helps confirm that this warm season pattern is associated with more subtle synoptic-scale features and smaller scale high intensity convection. This is further supported by the isolated nature of the high intensity rainfall across the HYDRA Network in Fig. 1.12, bottom panel. Three stations received relatively high precipitation totals and only two stations observed relatively high maximum one-hour rainfall intensity. Other stations did receive measurable rainfall, however, and the isolated nature of the rainfall makes it possible that even the high density HYDRA Network does not capture all significant rainfall on days with this meteorology. NWS NEXRAD WRS-88D radar reflectivity data for this day confirms this as it shows the highest intensity precipitation around $12 \mathrm{Z}$ and a second bout of lower intensity precipitation around 16Z (Fig. A11). This reflectivity illuminates the spatially and temporally limited nature of this event.

\subsection{Summary}

In this study we comprehensively identify and examine the key LSMPs associated with heavy precipitation across seasons over Portland, OR. This study employs SOMs in a novel manner, whereby the array of synoptic patterns associated with heavy precipitation days are revealed. Analysis is performed for both heavy total and high maximum hourly intensity days using a high-density gauge network (Fig. 1.1). This work is motivated in part by a desire by the City of Portland's BES to better understand the meteorological 
conditions that are associated with CSOs and therefore favors study of high intensity over heavy accumulation days as they were more commonly associated with this impact. The LSMPs associated with high intensity days are defined as synoptic scale fields of SLP, Z500, and $250 \mathrm{hPa}$ wind speed. Composites of these fields for all high intensity days reveal relatively low SLP to the northwest of Portland concurrent with a Z500 trough, and a prominent 250 $\mathrm{hPa}$ jet streak with Portland located in the poleward exit region (Fig. 1.3).

To further highlight the range of LSMPs associated with high intensity days, a 12-node Self Organizing Map is employed (Fig. 1.4). SOM node patterns can generally be classified as high-pressure or low-pressure patterns, and Fig. 1.5 reveals the seasonality and frequency of occurrence for each SOM node. Most heavy precipitation days occur in the cool season and are associated with strong low-pressure systems at the surface, while most high-pressure LSMPs occur in the spring or summer. Composites of temperature anomalies (Fig. 1.6), precipitation anomalies (Fig. 1.7), precipitation totals (Fig. 1.8), and IVT (Fig. 1.9) show that low-pressure nodes are generally associated with near zero to positive temperature anomalies, anomalously high and regionally widespread precipitation, and a strong association with ARs. This contrasts the high-pressure dominated nodes that are linked to positive temperature anomalies, more spatially-limited heavy precipitation, and a lower percentage of days coinciding with ARs. Subsequent heavy precipitation days can exacerbate impacts and upon examination, the deep low-pressure patterns associated with widespread regional precipitation and ARs, tend to be the most likely to fall on successive days (Table 1). Examination of two case-studies (one winter and one summer) shows that the detailed dynamics of individual highimpact events are well-captured by the 12-node SOM, supporting the methodology as efficacious in studying the range of LSMPs that can lead to high intensity precipitation in Portland (Figs. $1.11 \& 1.12)$ 
Towards supporting the work of resiliency planners, urban-scale impacts can be mapped onto SOM nodes so that impactful storm patterns can be identified. This study uses CSOs as a reference urban-scale impact and it is evident that there are preferred nodes that result in CSOs (Fig. A1). 86\% and 93\% of CSO events between 2011-2016 were captured by the heavy total and high intensity thresholds respectively. Winter CSO events in Portland are mostly associated with low pressure LSMPs and ARs. Several spring and summer CSO events are captured only using the intensity storm criteria and not the heavy storm total criteria, suggesting that intensity may be a better tool for linking CSOs to circulation patterns. While CSOs are the urban impact motivating this study, the same methodology could be used to explore numerous meteorologically driven local-scale impacts.

The approach demonstrated here can be extensible to other locations and other meteorologically driven phenomena. Furthermore, the approach carries potential for studying how climate change may be influencing the frequency of occurrence of extreme events, in this case high intensity precipitation, at local, impact-relevant scales. One of the key challenges in studying extreme events at local scales in the context of climate change is the scale mismatch between what most state-of-the-art climate models can resolve and the resolution necessary to capture the extremes. This challenge is particularly acute in places like Portland, where complex topography, that cannot be resolved by most climate models, is influential on precipitation. The approach demonstrated here is therefore not only useful in aiding in our understanding of the large-scale meteorology that is key to a high impact local extreme, but carries potential for being used as a way to study local extreme precipitation events in climate models without the constraint of needing to resolve small-scale features. Because climate models can readily resolve the LSMP scale, these patterns can be used as a proxy for local scale extreme precipitation and be applied as a model evaluation target and a way to assess simulated 
projections of future change in the LSMPs. Extending this methodology into the climate model space in this way is the subject of ongoing research. 


\begin{tabular}{cc}
1.7 Tables & \\
\hline Node & Fraction \\
\hline 1 & 0.457 \\
2 & 0.510 \\
3 & 0.545 \\
4 & 0.267 \\
5 & 0.287 \\
6 & 0.291 \\
7 & 0.415 \\
8 & 0.128 \\
9 & 0.258 \\
10 & 0.200 \\
11 & 0.209 \\
12 & 0.207 \\
\hline
\end{tabular}

Table 1. 1 Fraction of heavy intensity days for nodes that are part of a consecutive string of two or more heavy intensity days. 


\subsection{Figures}

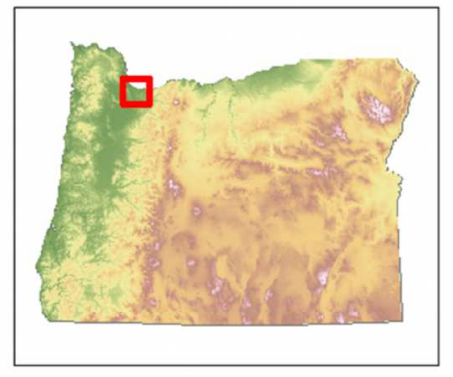

Legend

- Long Term HYDRA Gages

- HYDRA Gages

Major Roads

Rivers

\section{Elevation}

[m]

High : 2500

Low : -20

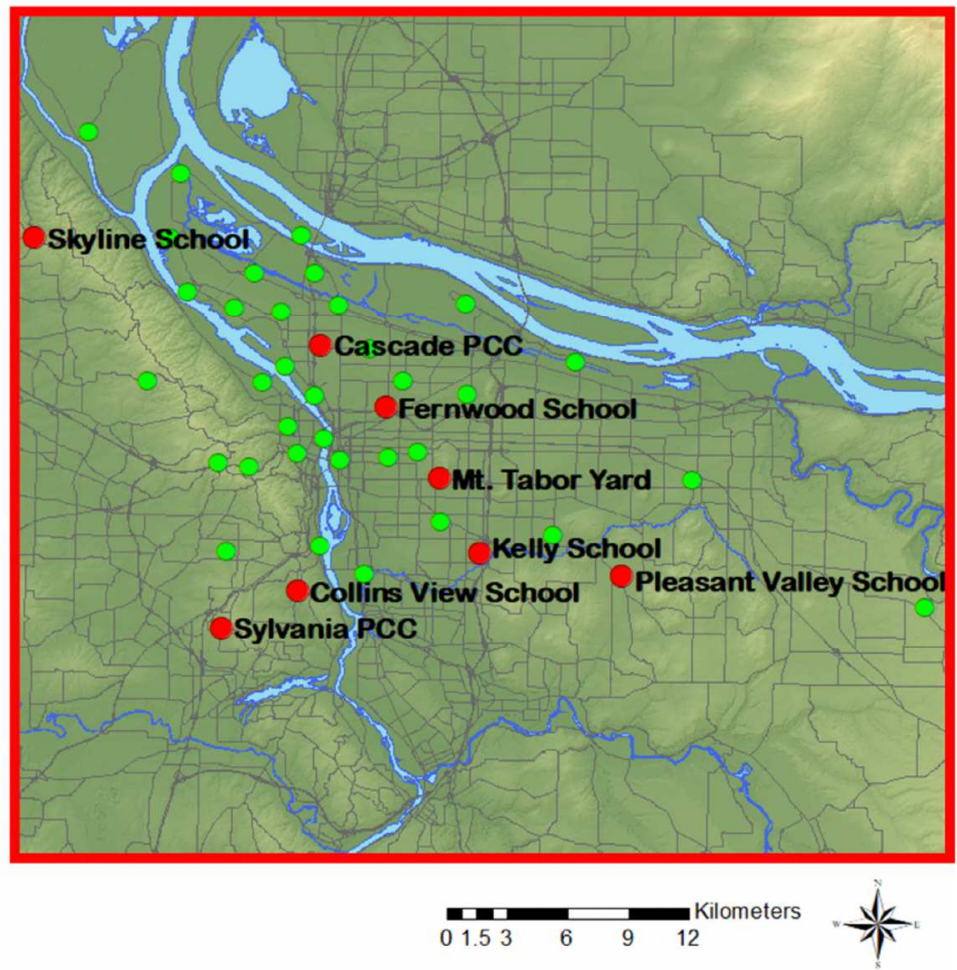

Figure 1. 1 (Upper left panel) Map of the state of Oregon with elevation shaded and study area outlined in red. (Right Panel) Detailed map of study area showing long-term (red) and shorter-term (green) HYDRA Network precipitation gauges. 

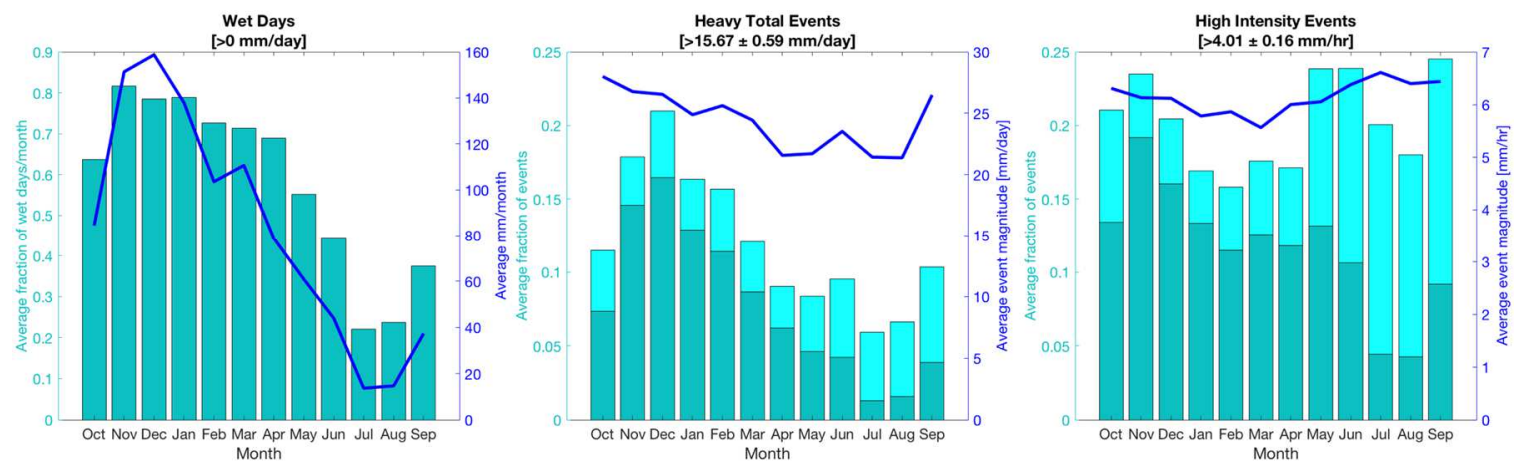

Figure 1. 2 (a) Climatology of wet day precipitation $(>0 \mathrm{~mm}$ ) with left y-axis corresponding to the bar chart indicating the average fraction of wet days per month, and the right $y$-axis indicating the average wet day precipitation accumulation amount per month corresponding to line chart. (b) Climatology of heavy total days with the left y-axis corresponding to the bar chart indicating the average fraction of heavy total days per month, and the right $y$-axis indicating the average heavy total daily precipitation accumulation corresponding to line chart. Turquoise bars indicate the fraction of days per month that are heavy total days and cyan bars indicate the fraction of wet days per month that are heavy total days. (c) Same as center, but for high intensity days. 

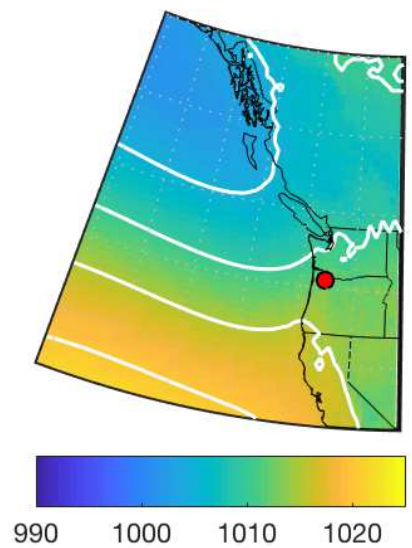
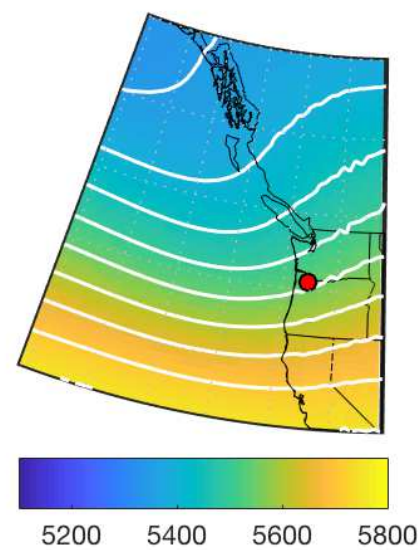
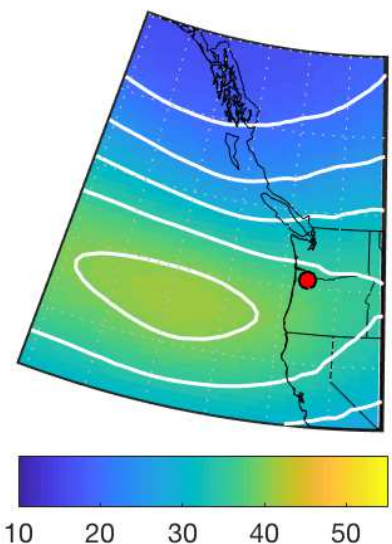

Figure 1. 3 Composite averages of (left) SLP [hPa] (contours at $5 \mathrm{hPa}$ spacing), (center) Z500 [m](contours at $50 \mathrm{~m}$ spacing), and (right) V250 [ms-1](contours at $5 \mathrm{~m} \mathrm{~s}-1$ spacing) concurrent with high intensity days. Portland, OR is indicated by the red dot. 


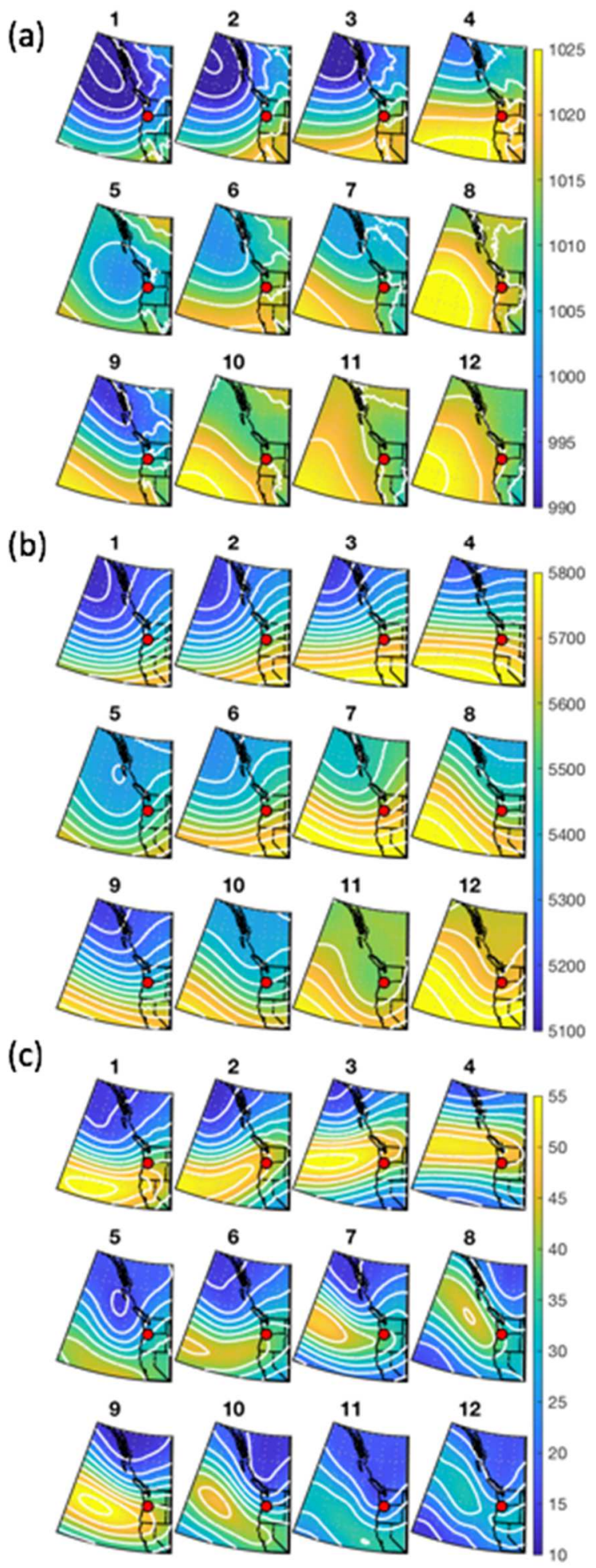

Figure 1. 4 12-node SOM for the 1569 days of the high intensity days showing (a) SLP [hPa] (contours at $5 \mathrm{hPa}$ spacing), (b) Z500 [m] (contours at $50 \mathrm{~m}$ spacing), and (c) V250 [ms1](contours at $5 \mathrm{~m} \mathrm{~s}-1$ spacing) concurrent with high intensity days. Portland, OR is indicated by the red dot. 

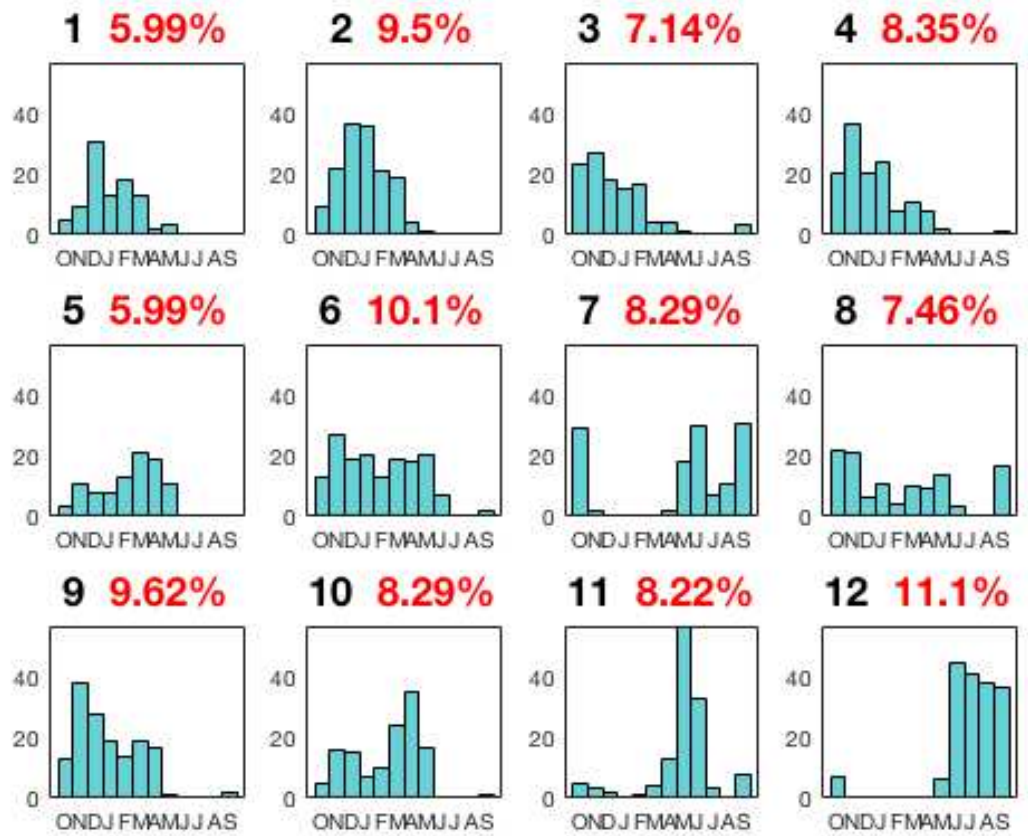

Figure 1. 5 Histogram showing number of days assigned to each month for each node for high intensity days. The fraction of total input days assigned to each node is indicated in red above respective histogram. 

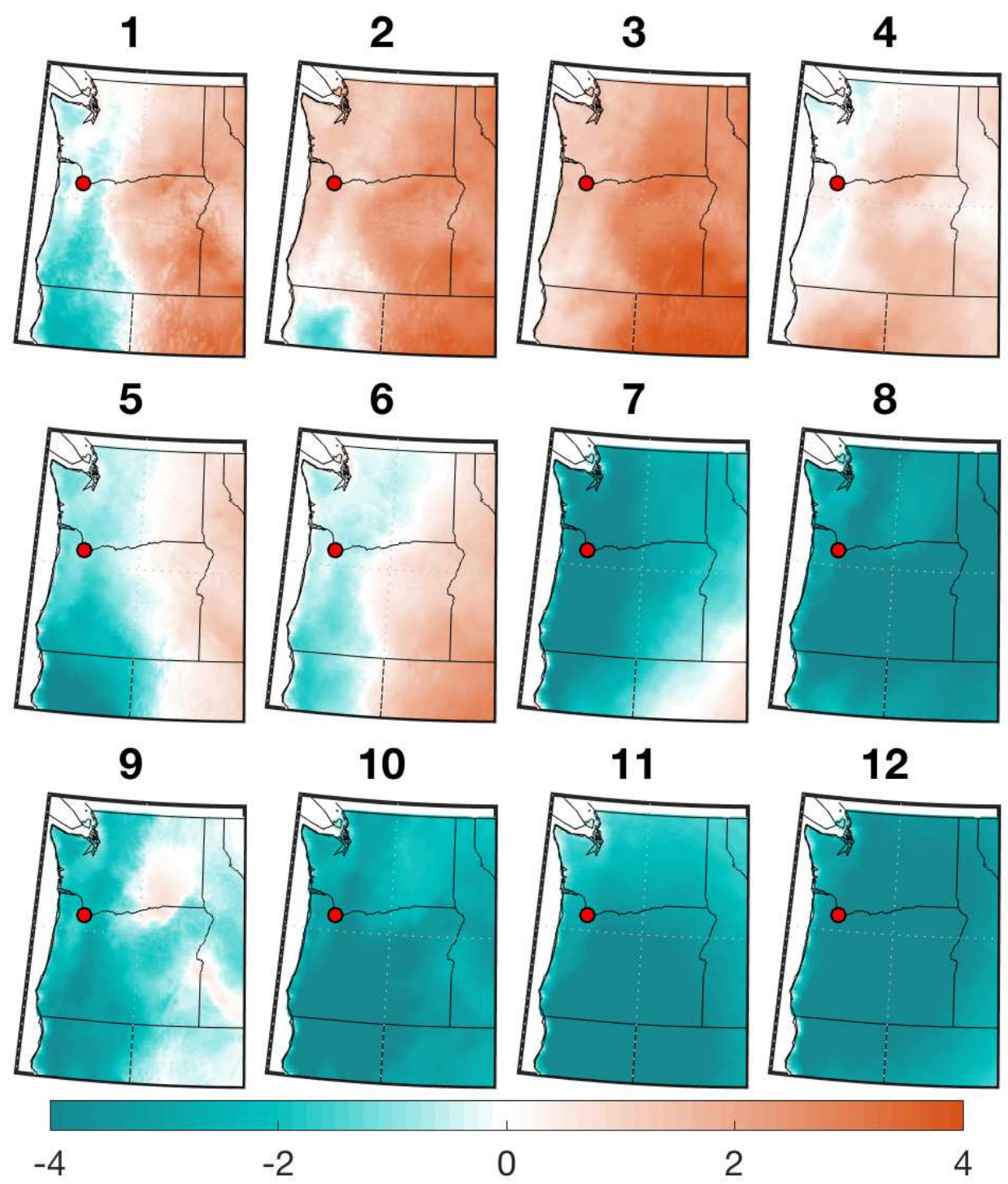

Figure 1. 6 Composites of daily maximum temperature anomaly $\left[{ }^{\circ} \mathrm{C}\right]$ for all days assigned to each node. Portland, OR is indicated by the red dot. 

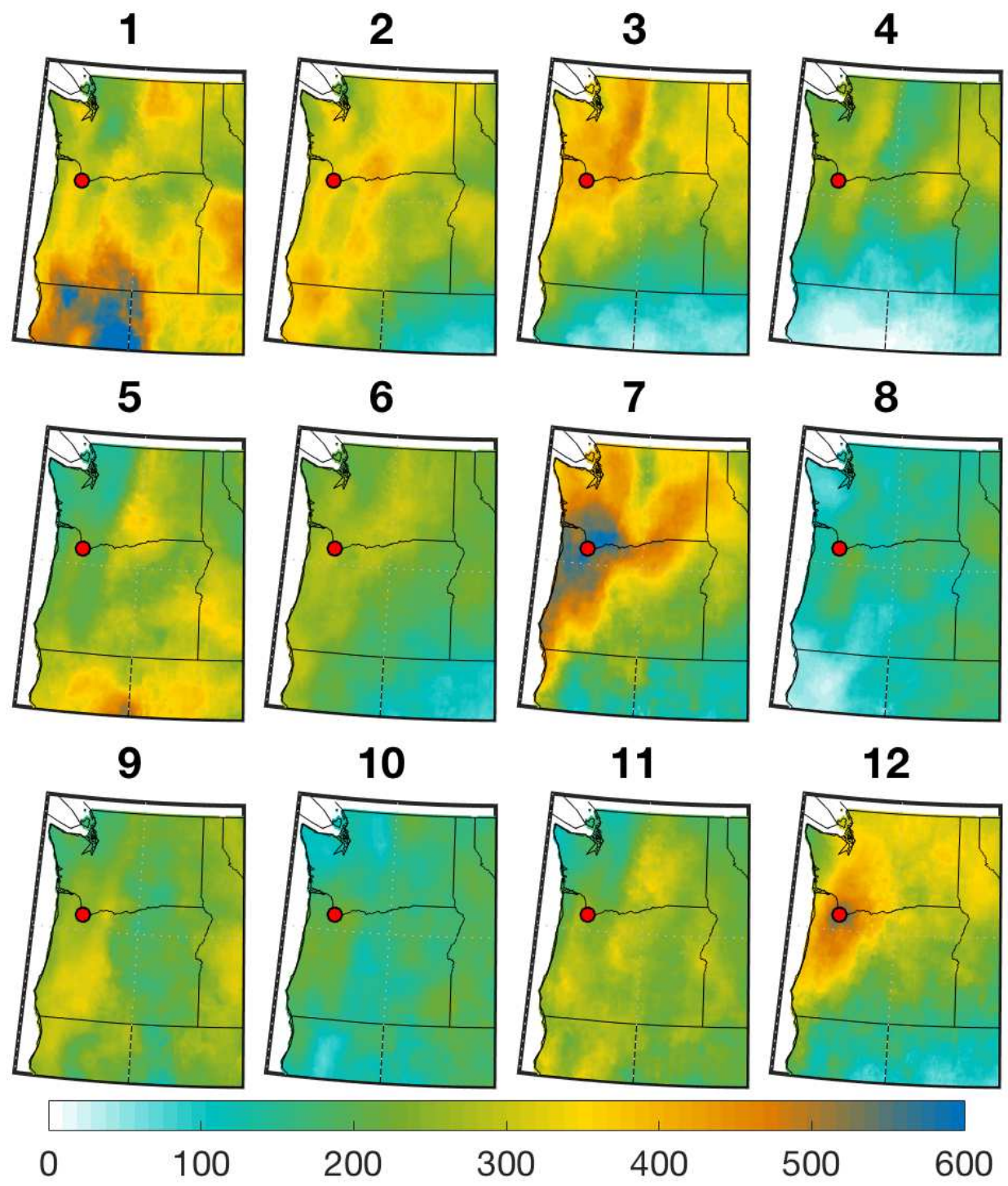

Figure 1. 7 Same as in Fig. 1.6, but for daily precipitation anomaly as percent of climatology $[\%]$. Portland, OR is indicated by the red dot. 

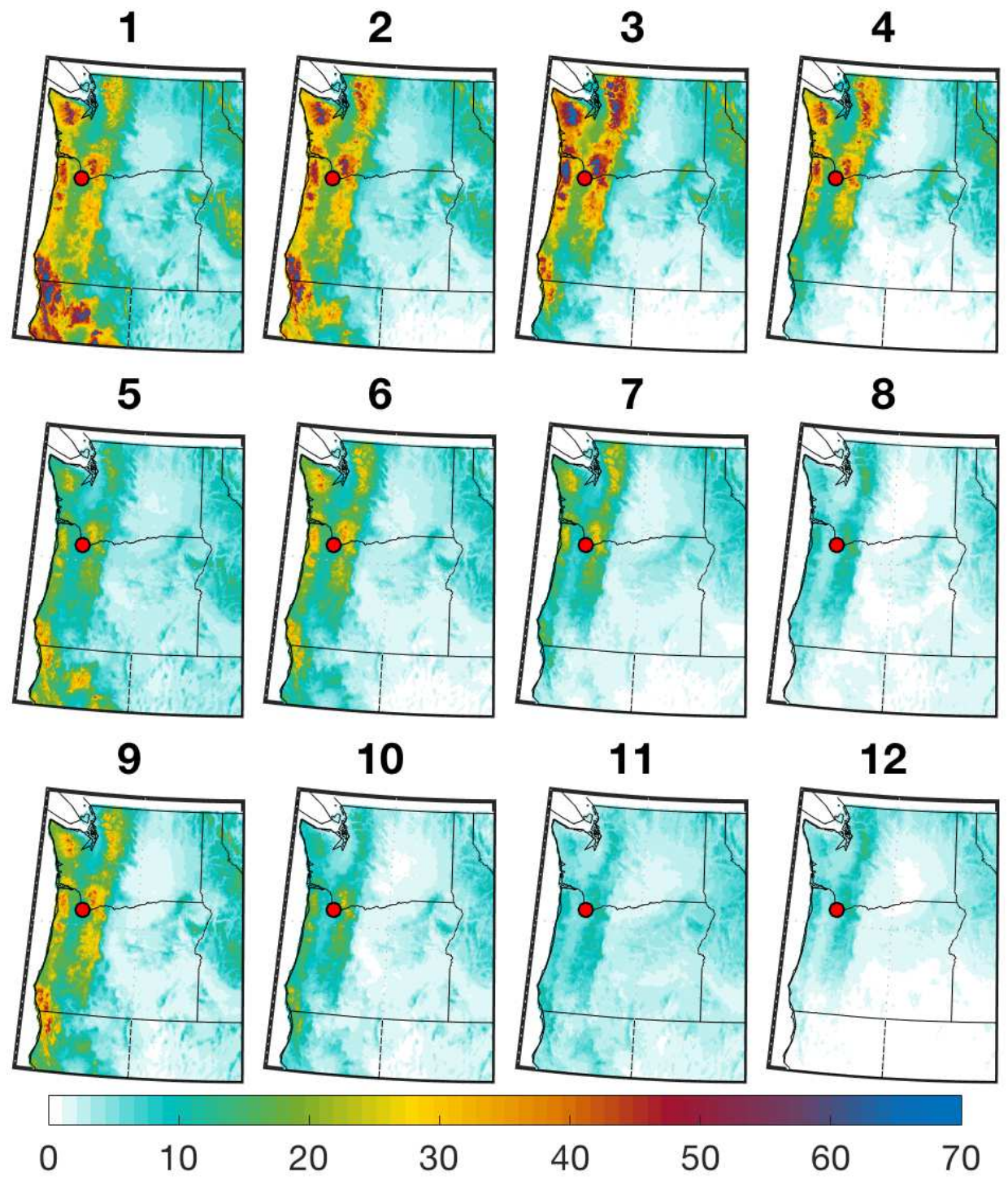

Figure 1. 8 Same as in Fig. 1.6, but for daily precipitation amount [mm/day]. Portland, OR is indicated by the red dot. 

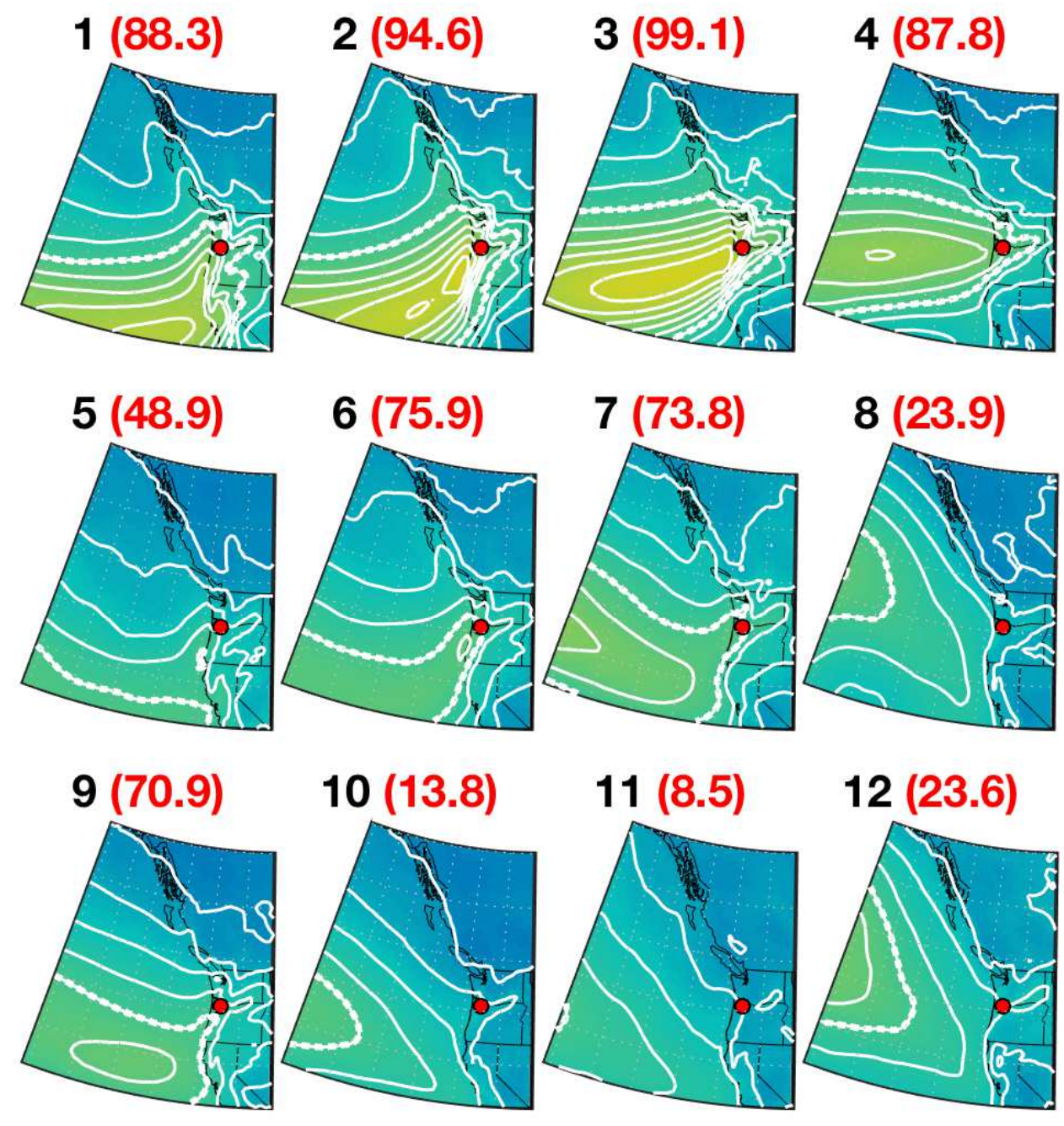

$12(23.6)$ 0 100
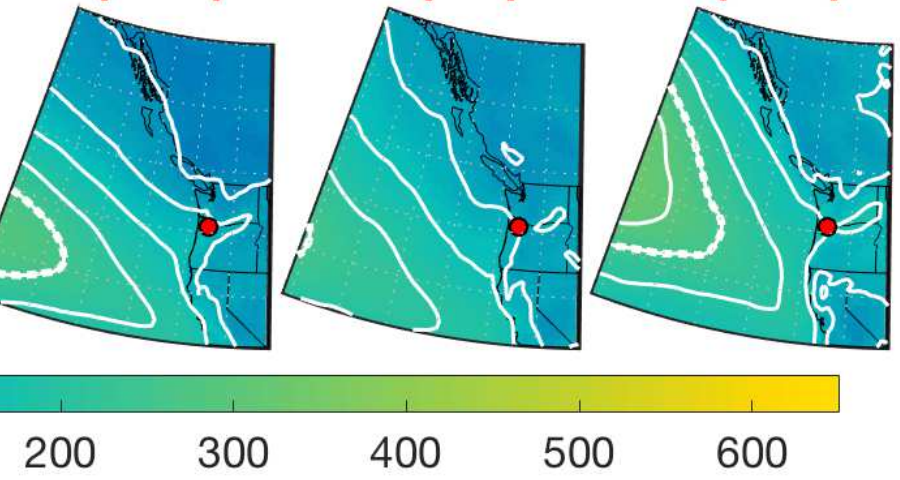

Figure 1. 9 Same as in Fig. 1.6, but for IVT [kg m-1 s-1; contours at $50 \mathrm{~kg} \mathrm{~m}-1 \mathrm{~s}-1 \mathrm{spacing}]$. Bold dashed white contour indicates the $250 \mathrm{~kg} \mathrm{~m}-1 \mathrm{~s}-1$ threshold for AR classification. Red numbers are the percent of days in each node that are concurrent with an AR over the study area and shading visualizes AR strength and orientation. 


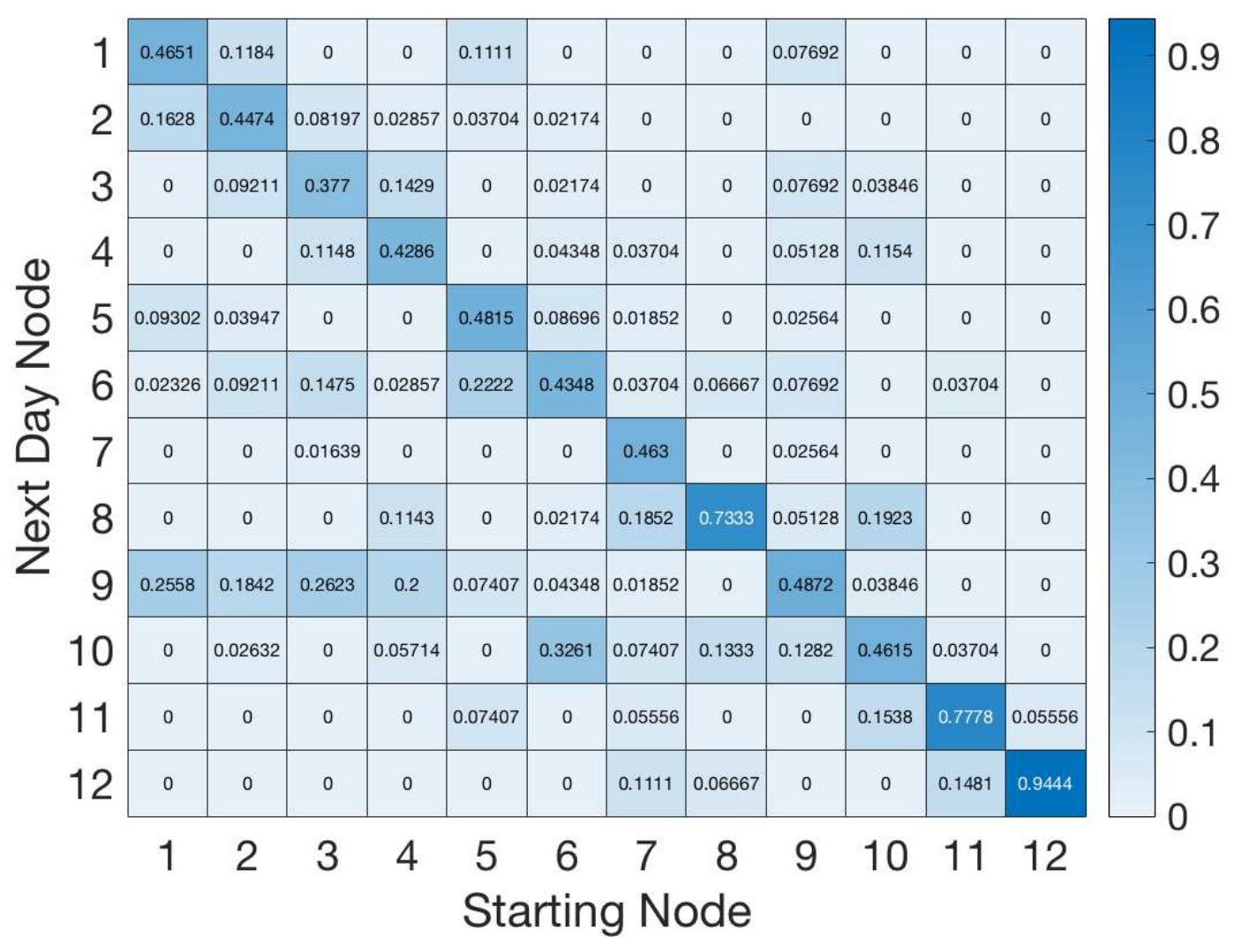

Figure 1.10 When two high intensity days occur back-to-back, this heatmap shows the where in the SOMs space the second day occurs. The $\mathrm{x}$-axis shows the starting node assignment and the $y$-axis shows the node assignment of the consecutive day. Heatmap values indicate the percentage of consecutive days assigned to each next-day-node for each given starting node. For example, $94 \%$ of high intensity days that were initially assigned to node 12 , were still assigned to node 12 on the second day. 


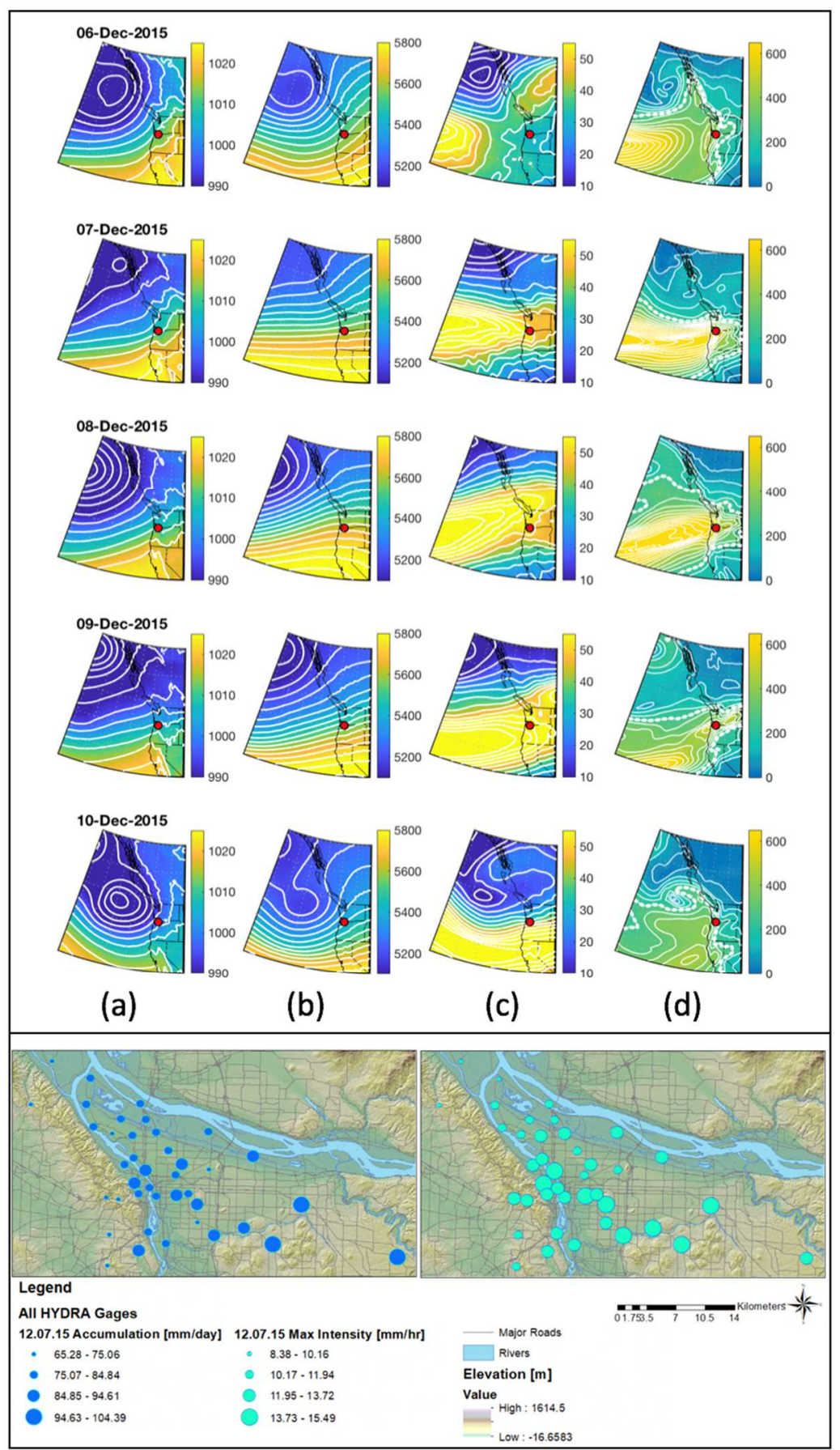

Figure 1. 11 LSPMs for December 6, 2015 - December 10, 2015 (top). Synoptic structure of winter CSO following shading and contours of Figure 1.4 (SLP (a), Z500 geopotential heights (b), and Z250 winds (c)) and Figure 1.6 (IVT (d)). Spatial distribution of precipitation across all HYDRA stations with dots proportional to precipitation magnitude (bottom). 


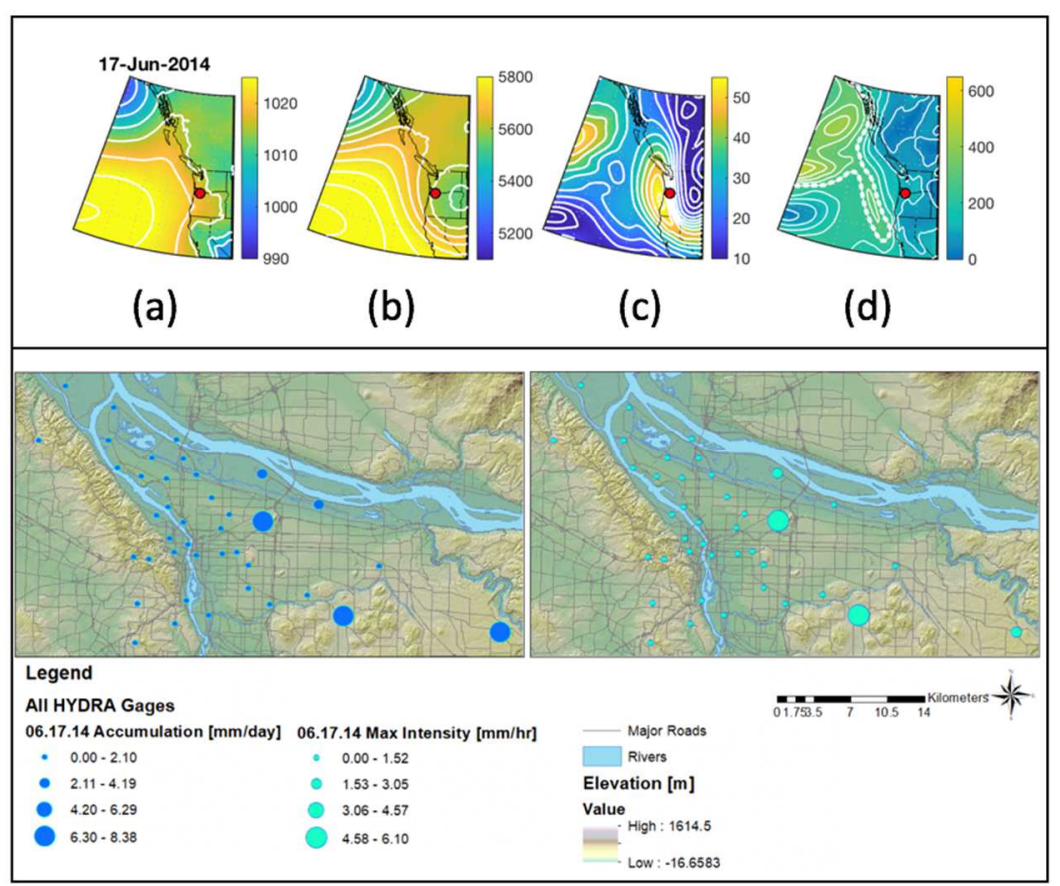

Figure 1.12 As in Fig. 1.11, but for June 17, 2014. 


\subsection{References}

Abatzoglou, J. T., 2013: Development of gridded surface meteorological data for ecological applications and modelling. International Journal of Climatology, 33, 121-131, doi:10.1002/joc.3413.

_ 2016: Contribution of Cutoff Lows to Precipitation across the United States. J. Appl. Meteor. Climatol., 55, 893-899, doi:10.1175/JAMC-D-15-0255.1.

- D. E. Rupp, and P. W. Mote, 2014: Seasonal Climate Variability and Change in the Pacific Northwest of the United States. Journal of Climate, 27, 2125-2142, doi:10.1175/JCLI-D-13-00218.1.

Bin, G., D. E. Waliser, F. M. Ralph, E. J. Fetzer, and P. J. Neiman, 2016: Hydrometeorological characteristics of rain-on-snow events associated with atmospheric rivers. Geophysical Research Letters, 2964-2973, doi:10.1002/2016GL067978@10.1002/(ISSN)1944-8007.ATMOS_RIVERS1.

Bracken, C., B. Rajagopalan, M. Alexander, and S. Gangopadhyay, 2015: Spatial variability of seasonal extreme precipitation in the western United States. Journal of Geophysical Research: Atmospheres, 120, 4522-4533, doi:10.1002/2015JD023205.

Cassano, E., J. Glisan, J. Cassano, W. Gutowski, and M. Seefeldt, 2015: Self-organizing map analysis of widespread temperature extremes in Alaska and Canada. Climate Research, 62, 199-218, doi:10.3354/cr01274.

Chen, H. W., F. Zhang, and R. B. Alley, 2016: The Robustness of Midlatitude Weather Pattern Changes due to Arctic Sea Ice Loss. Journal of Climate; Boston, 29, 78317849, doi:http://dx.doi.org.ezproxy.library.ubc.ca/10.1175/JCLI-D-16-0167.1.

Dacre, H. F., P. A. Clark, O. Martinez-Alvarado, M. A. Stringer, and D. A. Lavers, 2015: How Do Atmospheric Rivers Form? Bulletin of the American Meteorological Society, 96, 1243-1255, doi:10.1175/BAMS-D-14-00031.1.

DeAngelis, A. M., A. J. Broccoli, and S. G. Decker, 2013: A Comparison of CMIP3 Simulations of Precipitation over North America with Observations: Daily Statistics and Circulation Features Accompanying Extreme Events. Journal of Climate, 26, 3209-3230, doi:10.1175/JCLI-D-12-00374.1.

Ford, T. W., and J. T. Schoof, 2017: Characterizing extreme and oppressive heat waves in Illinois. Journal of Geophysical Research: Atmospheres, 122, 682-698, doi:10.1002/2016JD025721.

Gelaro, R., and Coauthors, 2017: The Modern-Era Retrospective Analysis for Research and Applications, Version 2 (MERRA-2). J. Climate, 30, 5419-5454, doi:10.1175/JCLID-16-0758.1. 
Gibson, P. B., A. J. Pitman, R. Lorenz, and S. E. Perkins-Kirkpatrick, 2017: The Role of Circulation and Land Surface Conditions in Current and Future Australian Heat Waves. J. Climate, 30, 9933-9948, doi:10.1175/JCLI-D-17-0265.1.

Glisan, J. M., W. J. Gutowski, J. J. Cassano, E. N. Cassano, and M. W. Seefeldt, 2016: Analysis of WRF extreme daily precipitation over Alaska using self-organizing maps. Journal of Geophysical Research: Atmospheres, 121, 7746-7761, doi:10.1002/2016JD024822.

Grotjahn, R., and Coauthors, 2016: North American extreme temperature events and related large scale meteorological patterns: a review of statistical methods, dynamics, modeling, and trends. Climate Dynamics; Heidelberg, 46, 1151-1184, doi:http://dx.doi.org.ezproxy.library.ubc.ca/10.1007/s00382-015-2638-6.

Hartmann, D. L., and Coauthors, 2013: Chapter 2: Observations: Atmosphere and Surface. Climate Change 2013: The Physical Science Basis. Contribution of Working Group I to the Fifth Assessment Report of the Intergovernmental Panel on Climate Change, Cambridge University Press, Cambridge, United Kingdom and New York, NY, USA.

Hewitson, B. C., and R. G. Crane, 2002: Self-organizing maps: applications to synoptic climatology. Climate Research, 22, 13-26, doi:10.3354/cr022013.

Hoerling, M., J. Eischeid, J. Perlwitz, X.-W. Quan, K. Wolter, and L. Cheng, 2016: Characterizing Recent Trends in U.S. Heavy Precipitation. J. Climate, 29, 2313-2332, doi:10.1175/JCLI-D-15-0441.1.

Huang, X., and P. A. Ullrich, 2017: The Changing Character of Twenty-First-Century Precipitation over the Western United States in the Variable-Resolution CESM. J. Climate, 30, 7555-7575, doi:10.1175/JCLI-D-16-0673.1.

Janssen, E., D. J. Wuebbles, K. E. Kunkel, S. C. Olsen, and A. Goodman, 2014: Observational- and model-based trends and projections of extreme precipitation over the contiguous United States. Earth's Future, 2, 99-113, doi:10.1002/2013EF000185.

Johnson, N. C., and S. B. Feldstein, 2010: The Continuum of North Pacific Sea Level Pressure Patterns: Intraseasonal, Interannual, and Interdecadal Variability. Journal of Climate; Boston, 23, 851-858,860-864,866-867.

,-- , and B. Tremblay, 2008: The Continuum of Northern Hemisphere Teleconnection Patterns and a Description of the NAO Shift with the Use of SelfOrganizing Maps. J. Climate, 21, 6354-6371, doi:10.1175/2008JCLI2380.1.

Kennedy, A., X. Dong, and B. Xi, 2016: Cloud fraction at the ARM SGP site: reducing uncertainty with self-organizing maps. Theoretical \& Applied Climatology, 124, 43 54, doi:10.1007/s00704-015-1384-3. 
Kunkel, K. E., and Coauthors, 2012a: Monitoring and Understanding Trends in Extreme Storms: State of Knowledge. Bull. Amer. Meteor. Soc., 94, 499-514, doi:10.1175/BAMS-D-11-00262.1.

—, D. R. Easterling, D. A. R. Kristovich, B. Gleason, L. Stoecker, and R. Smith, 2012b: Meteorological Causes of the Secular Variations in Observed Extreme Precipitation Events for the Conterminous United States. J. Hydrometeor., 13, 1131-1141, doi:10.1175/JHM-D-11-0108.1.

Lamjiri, M. A., M. D. Dettinger, F. M. Ralph, and B. Guan, 2017: Hourly storm characteristics along the U.S. West Coast: Role of atmospheric rivers in extreme precipitation. Geophysical Research Letters, 44, 7020-7028, doi:10.1002/2017GL074193.

Lennard, C., and G. Hegerl, 2015: Relating changes in synoptic circulation to the surface rainfall response using self-organising maps. Climate Dynamics, 44, 861-879, doi:10.1007/s00382-014-2169-6.

Liu, Y., and R. H. Weisberg, 2011: A Review of Self-Organizing Map Applications in Meteorology and Oceanography. Self Organizing Maps - Applications and Novel Algorithm Design,.

Loikith, P. C., and A. J. Broccoli, 2014: Comparison between Observed and ModelSimulated Atmospheric Circulation Patterns Associated with Extreme Temperature Days over North America Using CMIP5 Historical Simulations. J. Climate, 28, 20632079, doi:10.1175/JCLI-D-13-00544.1.

Loikith, P. C., B. R. Lintner, and A. Sweeny, 2017: Characterizing Large-Scale Meteorological Patterns and Associated Temperature and Precipitation Extremes over the Northwestern United States Using Self-Organizing Maps. J. Climate, 30, 2829-2847, doi:10.1175/JCLI-D-16-0670.1.

Lorente, P., E. Hernández, S. Queralt, and P. Ribera, 2008: The flood event that affected Badajoz in November 1997. Advances in Geosciences, 16, 73-80, doi:10.5194/adgeo-16-73-2008.

Mahoney, K., F. M. Ralph, K. Wolter, N. Doesken, M. Dettinger, D. Gottas, T. Coleman, and A. White, 2014: Climatology of Extreme Daily Precipitation in Colorado and Its Diverse Spatial and Seasonal Variability. J. Hydrometeor., 16, 781-792, doi:10.1175/JHM-D-14-0112.1.

Mailhot, A., G. Talbot, and B. Lavallée, 2015: Relationships between rainfall and Combined Sewer Overflow (CSO) occurrences. Journal of Hydrology, 523, 602-609, doi:10.1016/j.jhydrol.2015.01.063.

Mechem, D. B., C. S. Wittman, M. A. Miller, S. E. Yuter, and S. P. de Szoeke, 2018: Joint Synoptic and Cloud Variability over the Northeast Atlantic near the Azores. J. Appl. Meteor. Climatol., 57, 1273-1290, doi:10.1175/JAMC-D-17-0211.1. 
Parker, L. E., and J. T. Abatzoglou, 2015: Spatial coherence of extreme precipitation events in the Northwestern United States. International Journal of Climatology, 36, 24512460, doi:10.1002/joc.4504.

Prein, A. F., R. M. Rasmussen, K. Ikeda, C. Liu, M. P. Clark, and G. J. Holland, 2017: The future intensification of hourly precipitation extremes. Nature Climate Change, 7 , 48-52, doi:10.1038/nclimate3168.

Radić, V., A. J. Cannon, B. Menounos, and N. Gi, 2015: Future changes in autumn atmospheric river events in British Columbia, Canada, as projected by CMIP5 global climate models. Journal of Geophysical Research: Atmospheres, 120, 9279-9302, doi:10.1002/2015JD023279.

Riechel, M., and Coauthors, 2016: Impacts of combined sewer overflows on a large urban river - Understanding the effect of different management strategies. Water Research, 105, 264-273, doi:10.1016/j.watres.2016.08.017.

Rupp, D. E., J. T. Abatzoglou, and P. W. Mote, 2017: Projections of 21st century climate of the Columbia River Basin. Clim Dyn, 49, 1783-1799, doi:10.1007/s00382-016-34187.

Rutz, J. J., W. J. Steenburgh, and F. M. Ralph, 2013: Climatological Characteristics of Atmospheric Rivers and Their Inland Penetration over the Western United States. Mon. Wea. Rev., 142, 905-921, doi:10.1175/MWR-D-13-00168.1.

Sheridan, S. C., and C. C. Lee, 2011: The self-organizing map in synoptic climatological research. Progress in Physical Geography; London, 35, 109-119, doi:http://dx.doi.org.ezproxy.library.ubc.ca/10.1177/0309133310397582.

Singh, D., M. Tsiang, B. Rajaratnam, and N. S. Diffenbaugh, 2013: Precipitation extremes over the continental United States in a transient, high-resolution, ensemble climate model experiment. Journal of Geophysical Research: Atmospheres, 118, 7063-7086, doi:10.1002/jgrd.50543.

Trigo, R. M., C. Ramos, S. S. Pereira, A. M. Ramos, J. L. Zêzere, and M. L. R. Liberato, 2016: The deadliest storm of the 20th century striking Portugal: Flood impacts and atmospheric circulation. Journal of Hydrology, 541, 597-610, doi:10.1016/j.jhydrol.2015.10.036.

Waliser, D., and B. Guan, 2017: Extreme winds and precipitation during landfall of atmospheric rivers. Nature Geoscience, 10, 179-183, doi:10.1038/ngeo2894.

Warner, M. D., C. F. Mass, and E. P. Salathé, 2012: Wintertime Extreme Precipitation Events along the Pacific Northwest Coast: Climatology and Synoptic Evolution. Mon. Wea. Rev., 140, 2021-2043, doi:10.1175/MWR-D-11-00197.1.

Wehner, M. F., 2013: Very extreme seasonal precipitation in the NARCCAP ensemble: model performance and projections. Climate Dynamics, 40, 59-80, doi:10.1007/s00382-012-1393-1. 
Willems, P., K. Arnbjerg-Nielsen, J. Olsson, and V. T. V. Nguyen, 2012: Climate change impact assessment on urban rainfall extremes and urban drainage: Methods and shortcomings. Atmospheric Research, 103, 106-118, doi:10.1016/j.atmosres.2011.04.003.

Yuter, S. E., D. A. Stark, J. A. Crouch, M. J. Payne, and B. A. Colle, 2011: The Impact of Varying Environmental Conditions on the Spatial and Temporal Patterns of Orographic Precipitation over the Pacific Northwest near Portland, Oregon. J. Hydrometeor., 12, 329-351, doi:10.1175/2010JHM1239.1. 


\section{Chapter 2: Evaluation of CMIP5 fidelity at simulating wet season large-scale meteorological patterns and associated precipitation over the Pacific Northwest}

\subsection{Introduction}

Precipitation is an essential part of the water cycle that links atmospheric water vapor to terrestrial water resources. In the Pacific Northwest (PNW) region of North America, the timing, magnitude, and phase of precipitation is vital for addressing questions of municipal, agricultural, and ecological water resources and impacts. Despite the importance of precipitation to human and ecological systems, characterization of the timing and magnitude of precipitation can be challenging due its inherent temporal variability and uneven spatial distribution (Oki and Kanae 2006). Furthermore, the spatial and temporal character of future precipitation is expected to change globally under climate warming due to a combination of dynamic and thermodynamic mechanisms (Seager et al. 2010; Emori and Brown 2005; Dalton et al. 2017). However, projections of future change are associated with considerable uncertainty over the Pacific Northwest. For example, Mote and Salathe (2010) used projections of change in climate models contributing to the third phase of the Couple Model Intercomparison Project (CMIP3) and found a near zero change in annual average precipitation in the multi-model ensemble mean by the 2080s, though individual models range from a projected $10 \%$ decrease to a $20 \%$ increase. Similarly, Rupp et all (2017) found that while models generally agree on projected increases in winter and spring precipitation, and decreases in summer precipitation, some models predicted increases and decreases in all seasons. According to the Fourth National Climate Assessment (2014), there is a general consensus of a small change relative to interannual variability (May et al. 2018). This range of projections motivates further research on understanding model projections of precipitation and assessing model fidelity at capturing key climatological features of precipitation. 
Synoptic-scale dynamical conditions can be linked to local-scale phenomena, such as precipitation and precipitation extremes, to bridge the scale-gap (Gao et al. 2014; Collow et al. 2016). This scale bridge can be important when considering extremes, which tend to be rare and often localized as well as other impacts such as flooding. Several studies suggest that analysis of synoptic-scale circulation patterns may better capture mean and heavy precipitation frequency and change than model simulated precipitation (Hewitson and Crane 2006; Gao et al. 2014; DeAngelis et al. 2013). Hewitson and Crane (2006) used synopticscale circulation patterns to optimize precipitation downscaling in climate models. Gao et al. (2014) used synoptic-scale circulation patterns to identify heavy precipitation events without relying on modeled precipitation. DeAngelis et al. (2013) evaluated daily precipitation statistics, extreme precipitation and their associated large-scale physical drivers in CMIP3 models. Warner et al. (2012) linked extreme precipitation events along the PNW Coast to LSMPs and found that these events were associated with negative anomalies in sea level pressure and upper-level heights in the central Pacific coinciding with high pressure anomalies over the southwestern United States. Widespread precipitation and precipitation extremes in the PNW are often associated atmospheric rivers (Warner et al. 2012; Loikith et al. 2017), while more localized precipitation have been linked to cutoff lows (Abatzoglou 2016). Loikith et al. (2017) used self-organizing-maps (SOMs) to elucidate the array of LSMPs in each season over the observational record and linked these LSMPs to precipitation anomalies and extremes.

Previous studies have evaluated precipitation in climate models over the PNW and western United States (Rupp David E. et al. 2013; Rupp et al. 2017; Abatzoglou et al. 2014; Rana and Moradkhani 2016; Huang and Ullrich 2017). Rupp et al. (2013) evaluated monthly precipitation data from 41 GCMs and found considerable spread in performance metrics 
between CMIP5 models. The findings of Rupp et al. (2017) showed that annual precipitation in the PNW is expected to increase overall, with seasonal increases in winter precipitation, and decreases in summer, although this signal was low relative to projected increases in interannual variability. It is of note that the CMIP5 GCMs that better captured the historical climate, project greater increases in precipitation (Rupp et al. 2017). Abatzoglou et al. (2014) evaluated temperature and precipitation in CMIP5 models and found that while there was high skill in producing consistent temperature estimates across models, the same models produced inconsistent precipitation estimates and projections. Other studies that used downscaling techniques to consider changes in PNW precipitation also found high levels of uncertainty related to the character of precipitation change (Rana and Moradkhani 2016; Huang and Ullrich 2017). This suggests an incomplete mechanistic understanding of precipitation drivers.

This research evaluates the ability of the models contributing to CMIP5 to simulate wet season large-scale meteorological patterns (LSMPs) over the PNW. LSMPs are identified using the SOMs approach and defined with sea level pressure, $500 \mathrm{hPa}$ geopotential height, and $250 \mathrm{hPa}$ wind speed. SOMs have been shown to be an effective tool for characterizing the range of synoptic-scale circulation patterns (Loikith et al. 2017; Lennard and Hegerl 2015; Hewitson and Crane 2002; Aragon et al. TBD), and are also useful for climate model evaluation (Gibson et al. 2016; Cassano et al. 2006; Loikith and Broccoli 2014). This work is complimentary to previous studies in two primary ways. First, this study considers the largescale circulation mechanisms that drive precipitation rather than just the precipitation itself. Second, in places such as the PNW, precipitation often results from the interaction of synoptic-scale features and local terrain, but most climate models have too coarse of a resolution to resolve synoptically relevant topography. Thus, using LSMPs, which are not 
scale-limited, as a proxy for precipitation, may help to increase confidence in model evaluation and projections. This work has three primary objectives: (1) use SOMs to delineate the array of wet season (NDJFMA) synoptic-scale meteorological patterns across the PNW, (2) evaluate the ability of CMIP5 models to capture this array of wet season patterns, and (3) link these patterns to local to regional precipitation climatology. Results provide a mechanistic perspective on model fidelity in capturing synoptic climatology and associated precipitation characteristics across the PNW.

\subsection{Data}

Daily mean gridded reference data, specifically for sea level pressure (SLP), 500-hPa geopotential heights (Z500), 250-hPa wind speed (V250), and precipitation (PRCP), are from the Modern-Era Retrospective analysis for Research and Applications, Version 2 ( MERRA2; Gelaro et al. 2017; Reichle et al. 2016). MERRA-2 is a reanalysis product of the National Aeronautics and Space Administration (NASA) available from 1979 to present and freely available via the web.

Climate model data are from 24 historical simulations (Table 1) contributing to the fifth phase of the Coupled Model Intercomparison Project (CMIP5; Taylor et al. 2012). We include all models that provide data for all fields required for our analysis. In the case that there are multiple ensemble members contributed by a model, we evaluated the first ensemble member. CMIP5 historical simulations end in 2005, while MERRA-2 is available through the present. In order to maximize the sample size of days, we utilize a 38-year period for both datasets, however this period covers 1980-2018 in MERRA2 and 1967-2005 in CMIP5. Results were assessed using a shorter period that had complete overlap between the two datasets with no apparent sensitivity suggesting that this temporal offset is unlikely to introduce any bias to our 
results. All gridded data, MERRA-2 and CMIP5, are regridded to a common $2^{\circ}$ longitude by $2^{\circ}$ latitude grid mesh. Only data for the wet season, defined as October through April is analyzed.

In-situ precipitation observations are from the North Fork Snow Telemetry (SNOTEL) station in this study and the Portland International Airport Global Historical Climatology Network Daily (GHCN-D) station. The Natural Resources Conservation Service (NRCS) manages SNOTEL stations across the western United States. The North Fork station is located at an elevation of $932 \mathrm{~m}$ and daily precipitation observations are available starting in 1979. National Centers for Environmental Information (NCEI) quality controls data and provides access to GHCN-D data. The Portland International Airport station is located at an elevation of $5.8 \mathrm{~m}$ and daily precipitation observations start in 1936.

\subsection{Methodology}

\subsubsection{Self-organizing maps}

We use SOMs to illustrate the array of PNW wet season LSMPs following the SOMs methodology described in chapter 2. The SLP, Z500, and V250 from MERRA-2 for all wet season (November - April) days over our 38-year climatology are used as the input to the SOMs algorithm. The resulting SOM serves to delineate the array of key wet season LSMPs upon which the CMIP5 models will be evaluated. This MERRA-2 SOM will be referred to as refSOM for the remainder of this paper.

\subsubsection{CMIP5 model evaluation}

MERRA-2 defined node patterns in the refSOM are used as the reference patterns for evaluation of CMIP5 models. In order to evaluate the climate models, each day in each CMIP5 
model is mapped to one of the 12 refSOM nodes according to the following procedure as outlined in Fig. 2.1. First, the twelve MERRA-2 node patterns are converted into standardized anomalies by subtracting the daily climatological mean from each day and then dividing by the daily climatological standard deviation, performed separately for each variable. Next, the SLP, Z500, and V250 fields for each day are converted to standardized anomalies following the same process, except using the standard deviation and climatology of each model. This results in 12 standardized anomaly node patterns for three variables from MERRA-2, and a standardized anomaly pattern for each day in each model for each of the three variables. This puts all data into common units of standard deviation, preventing variables with larger values (e.g. geopotential height) from disproportionately influencing the comparison metric calculation.

Next, we employ metric T (MetT) to find the node pattern that each CMIP5 tri-variate day is most similar to (Tian et al. 2017). Met'T combines both pattern correlation and MSE as shown in the equation box in Figure 2.1 and a value of one indicates perfect agreement between the two fields being compared. The node with the highest MetT is considered the "winning node" and that model day is assigned to that node. This is repeated for all days and all models resulting in each CMIP5 day being assigned to one of the 12 MERRA-2 nodes. Finally, composites of all days assigned to each node are computed, resulting a "pseudo SOM" (or pSOM herein) for the model. The term pseudo is used to distinguish the CMIP5 LSMPs which are not constructed using the SOM algorithm, from the MERRA-2 reference SOM (i.e refSOM) which is. If a model perfectly reproduced the MERRA-2 synoptic climatology as defined by the 12-node SOM, its 12 composites for each of the three variables would be nearly identical to the 12-node patterns for each of the three variables in MERRA-2. 


\subsection{Evaluation of LSMPs}

\subsubsection{Evaluation of CMIP5 synoptic climatology}

Before evaluating the climatology of LSMPs in the CMIP5 models, we first evaluate overall ensemble bias in the three meteorological fields. Figures $2.2 \mathrm{a}$ and $2.2 \mathrm{~b}$ show the wet season climatology for SLP, Z500, and V250 in MERRA-2 and the CMIP5 multi-model ensemble mean, respectively. The MERRA-2 climatology depicts lower SLP to the northwest with higher pressure to the south, a slight ridge inland of the coast of North America, and a $250 \mathrm{hPa}$ jet centered on northern Oregon. Figure 2,2c shows the bias in the CMIP5 multi-model ensemble relative to MERRA-2. The CMIP5 ensemble captures the offshore low pressure to the northwest and the slight inland ridge at Z500, but there is a domain-wide negative bias in Z500 that increases in magnitude from north to south. SLP values exhibit positive bias inland while values over the ocean are very similar to MERRA-2. To ensure that the Z500 negative bias is not an artifact of the temporal offset in the climatololgies being compared (with CMIP5 comprising earlier years and, under a warming climate, potentially cooler years), the bias was computed using only overlapping years and revealed a very similar negative bias. The average climatology associated with V250 in CMIP5 is markedly different than the reference dataset with the CMIP5 ensemble showing a positive bias to the south and a negative bias to the north, revealing a jet stream that is located to the south compared to reference.

The mean wet season climatologies of SLP, Z500, and V250 from the individual CMIP5 models are compared to the mean wet season climatologies of the respective fields in the MERRA-2 reference dataset using Taylor diagrams (Fig. 2.3). The ensemble mean climatology has the highest metT scores for Z500, followed by SLP, and V250. While the spread in model 
similarity compared with MERRA-2 is considerable for all variables, it is least for Z500 and most for V250 with the multi-model ensemble average showing the closest resemblance to MERRA-2 for Z500.

Figure 2.4 illustrates the 12-node refSOMs results for the (a) SLP, (b) Z500, and (c) V250 fields in MERRA-2. Each of the 12 node maps in a given field shows the resulting LSMP from all days assigned to a given node. More similar LSMPs are found in adjacent nodes and highly different patterns are found at diagonal corners across the SOMs space. In general, high SLP patterns are located in the top left corner of the SOMs space, while low SLP patterns are in the bottom right corner. For example, N1 (node 1) illustrates a pattern of high pressure offshore and over southern Canada, along with an offshore ridge axis at Z500, and a relatively weak jet along the northern extent of the region. This is in contrast to N12, which is characterized by a deep low pressure to the northwest of the PNW at the surface, an offshore trough at Z500, and a strong zonal jet directed at northern California. The LSMPs depicted in this SOM are reflective of the LSMPs for the 12-node DJF SOM found in Loikith et al. (2017). For example, nearly identical LSMPs as N1 and N12 from the refSOM were also found in the Loikith et al. (2017) for DJF except that the patterns occupied opposite corners of the SOM space. Similarly, N3 and N6 in the reference SOM reflect N6 and N9 in the Loikith et al. SOM. Other patterns (e.g. N8) in the refSOM capture LSMPs at the surface and mid-troposphere, but have different upper tropospheric wind patterns. The LSMPs in N8 and N12 mirror the LSMPs of Loikith et al. (2017) that were associated with positive temperature anomalies and widespread extreme precipitation days over Washington/Oregon and northern California/southern Oregon respectively. N9 in the reference SOM is a distinctly unique pattern to the refSOM. Relative to the low SLP features in N12 and N8, N9 shows a moderate 
low SLP center off the coast of Oregon, an offshore Z500 trough, and a relatively weak jet at the southernmost edge of the study domain. Since we are including the whole wet season in our input data, it is likely that this is a springtime pattern not captured in the DJF SOM in Loikith et al. (2017).

Figure 2.5 depicts the pSOM multi-model ensemble composite patterns of SLP (a), Z500 (b), and V250 (c) for all models in the CMIP5 ensemble. These composites are constructed by first producing a pSOM for each of the 24 models and then averaging the 24 individual node patterns. The CMIP5 ensemble pSOM largely captures the refSOM patterns qualitatively, although some node patterns are better represented than others. In general, the bottom right of the of the refSOM $(\mathrm{N} 6, \mathrm{~N} 7, \mathrm{~N} 8, \mathrm{~N} 9, \mathrm{~N} 10, \mathrm{~N} 11, \mathrm{~N} 12)$ is better represented by the model composites than the upper left corner $(\mathrm{N} 1, \mathrm{~N} 2, \mathrm{~N} 3, \mathrm{~N} 4, \mathrm{~N} 5)$. The patterns in the bottom right corner are largely low SLP patterns, while the patterns in the upper left are predominately Z500 ridging patterns. This could have important implications when evaluating for future change. Furthermore, the Z500 field patterns appear to best resemble MERRA-2, followed by SLP, and the V250 field patterns have the most deviation from the reference patterns overall. For example, N3 in the MERRA-2 SOM composites (Fig. 2.5a-c) shows a high pressure ridge over the Western US, and a weak southwesterly jet. The CMIP5 ensemble (2.5a-c) captures these patterns well at the surface and at Z500, but has a different jet pattern, showing jet streaks in the southwest and northeast corner of the node spatial domain, although the jet stream orientation is similar to that in MERRA-2. N2 in the MERRA-2 SOM composites has a high pressure ridge over the southern node domain and a strong jet over southern British Columbia. N2 is better captured by the CMIP5 ensemble than N3, though the curvature of the jet is underestimated by the model figures. 


\subsubsection{Overview of individual models}

Figure 2.6 shows portrait diagrams summarizing the met'T skill scores for each CMIP5 models at each node. Figure 2.6a shows the relative skill of each model in capturing each node in the refSOM considering SLP, Z500, and V250 simultaneously. The high metTs in Figure 2.6a illustrate that the CMIP5 models generally capture the refSOM node patterns with reasonable skill. In general, all models perform well over the 12 nodes with mean met $T$ scores ranging from 0.91 to 0.95 . Despite this, the spread of met'T scores suggests that there is a hierarchy in model ability to capture archetypal LSMPs. The mean metT scores for individual nodes range from $0.92(\mathrm{~N} 1)$ to $0.96(\mathrm{~N} 10)$. The lower node mean met'T scores are associated with PNW ridging patterns and the higher node mean metT scores are associated with low SLP patterns, providing confidence in the qualitative comparison of the refSOM to the ensemble mean pSOM.

The metTs in panel $6 \mathrm{a}$ are reflective of how well the pSOM nodes for each model resemble the corresponding refSOM nodes from MERRA-2. However, it does not provide information on whether some variables are better reproduced by the CMIP5 models than others. Panels 6b-6d show the metT values computed by comparing the node patterns for each variable individually, using the same node assignments as in panel 6a. This reveals some considerable differences across the variables with the highest met'T scores associated with Z500, followed by SLP, and the lowest scores associated with V250. It is of note that when considering the SLP, Z500, and V250 fields independently, the variability in model performance appears predominately between nodes, as opposed to between models. This suggests that the model ensemble systematically performs better and worse at capturing certain node LSMPs. 
Figure 2.6b shows the metT skill scores for each model at each node for the SLP field. The SLP LSMPs of N1, N11, and N12 are not captured as well as other SLP nodes, and the SLP of N9 and N10 are captured the best. N1 and N12 are described in the previous section. N10 shows high SLP across the southwest corner of the study domain, a trough along the North American coast at Z500, and northwest to southeast oriented jet off the coast of California in the refSOM. There is an additional high SLP area in the northeast corner of the study domain in N10 of the ensemble mean pSOM's SLP field. Figure 2.6c gives the metT scores for Z500. Overall the metT scores are higher for each model at each node than the SLP metT scores. Similar to the SLP field, the node mean metT scores are the lowest for N1, and N12. Figure 2.6d provides the V250 metT skill scores for each model at each node. N4 and N5 have the lowest skill scores for the V250 field. Low wind speeds span from the northwest to the southeast corner of the N4 V250 field the refSOM. N4 in the CMIP5 pSOM shows much lower wind speeds spanning from the northwest to the east of the study domain and hints at a jet along the south boundary of the study domain. The wind field in the refSOM N5 shows a weak northerly jet along the pacific coast whereas the CMIP5 pSOM shows the highest wind speed in the south east corner of the study domain.

The portrait diagram in Figure 2.7 shows the occurrence bias of each node in each model relative to the number of days assigned to each node in the refSOM. The patterns in occurrence bias are largely consistent across models and vary by node. There is an overall overrepresentation of N1 (2.3\%), N2 (0.6\%), N5 (2.3\%), N7 (0.6\%), N11 (1.6), and N12 (2.8\%), while N3(-1.7\%), N4(-1.7\%), N6(-2.8\%), N8(-0.7\%), N9(-0.2\%), and N10(-3.1\%) are underrepresented.

\subsubsection{Individual model examples}


While all models show generally reasonable skill scores in Figures 2.6 and 2.7, intraensemble variability is still apparent across the CMIP5 suite. Here we provide two examples of individual model results from a model with relatively good evaluation scores and a model with relatively poor evaluation scores. The MIROC5 model had one of the highest overall metT skill scores of the CMIP5 models (Fig 2.6a). Figure 2.8 shows the MIROC5 pSOM with the composite LSMPs for all days mapped to each node. The red numbers following the node number indicate met $\mathrm{T}$ followed by the percent of total days assigned to the respective node. The SLP LSMPs from MIROC5 have Tmet scores ranging from 0.77 at N12 - a deep offshore closed low pressure to the west of southern British Columbia, to 0.99 at N9 - a closed low pressure to the west of Oregon. The pSOM N12 LSMP has a shallower, smaller low pressure than the MERRA-2 N12 LSMP. The MIROC5 Z500 field has Tmets that range from 0.91 (N1) to 1.0 (N9). The V250 field has Tmets as low as 0.66 (N5), and as high as 0.96 (N12). N5 had the highest frequency of occurrence in this model, which overestimated the pattern occurrence compared to our reference, and N3 had the lowest, which underrepresented the node assignment in the MERRA-2 SOM (Fig. 2.7).

The majority of the MIROC5 node LSMPs resemble the corresponding MERRA-2 node LSMPs and create a picture that is dynamically consistent across the three atmospheric levels. For example, in N7, the lower pressure to the northwest coupled with an offshore Z500 trough and a strong southwest to northeast oriented jet streak are all consistent based on synoptic dynamics. A few exceptions exist in the V250 field where the composite patterns in N1, N3, and N5 differ in dynamically important ways. For example, N5 in the V250 field shows higher wind speeds in the northwest and southeast corners, and lower wind speeds in the northeast and southwest corners, whereas the V250 field in MERRA-2 shows a weak northerly jet along the coast of North America (Fig 2.4c). 
The IPSL CM5B LR model has the lowest overall metT (0.92) of the CMIP5 models, mean met'T for SLP, Z500, and V250 are 0.9, 0.96, and 0.77 respectively (Fig. 2.6). The pSOM for IPSL CM5B LR is found in Figure 2.11. Unlike MIROC5, there are several model nodes that result in LSMPs that are dynamically different than the MERRA-2 LSMPs. The $250 \mathrm{hPa}$ wind field shows poor agreement with MERRA-2. For example, the wind field in the refSOM N5 shows a weak northerly jet along the pacific coast whereas the IPSL CM5B LR N5 shows a westerly jet at the very south of the node domain. This suggest a poor representation of the modeled wind field relative to the SLP and Z500 fields in the model. This is again apparent in N1 of the pSOM. The IPSL CM5B LR N1 shows an inland high pressure at the surface, an amplified ridge in the mid-troposphere, and a jet that curves southward along the node domain.

\subsection{Evaluation of Associated Precipitation}

Here we evaluate the ability of the models to capture broad precipitation patterns associated with each node as a way to further evaluate model skill by asking the question: Do models produce reasonable precipitation with the right meteorological mechanisms?

\subsubsection{SOM precipitation composites}

In order to link the key circulation patterns indicated in the refSOM to precipitation in the PNW, the composites of daily averaged precipitation for all days assigned to each node in MERRA-2. Composite figures of daily precipitation for all days assigned to each of the 12 nodes in the refSOM can be found in Figure 2.5a. N1-N3 receive nearly no average daily precipitation while N4, N5, N6, N9, and N10 receive low average daily precipitation, and N7, N8, N11, and N12 have the highest average daily precipitation in the PNW. N1 is the driest node over the PNW, characterized by a pronounced ridge centered just off the coast of 
western North America and only showing precipitation from central to northern British Columbia. The ridging patterns N2, and N3 show relatively high precipitation over $\mathrm{BC}$, but zero to minimal precipitation over the northwest US. N4 and N5 show minimal precipitation along the west coast of North America. Relatively high daily precipitation is located in the northeast corner of Washington in N7, with considerable precipitation to the north along the coast of $\mathrm{BC}$ and to the south to northern California. Spatially, the precipitation in N8 is similar to N7, but of a lower magnitude. Moderate daily precipitation is centered over northern California in N9, and N10 shows light precipitation along the extent of the west coast. N11 shows high precipitation from southern BC to norther California. The highest average spatially contiguous daily precipitation is visible in N12, spanning from the Canadian border to northern California. Considering the precipitation patterns in the context of associated refSOM LSMPs, N3, N7, N8, N11, and N12 appear to have dynamics that would be conducive to landfalling atmospheric rivers. In each of these nodes, there is a high SLP gradient that would likely advect warm, moist air from the Pacific, and a strong jet that helps to point the storm track to the region showing precipitation.

Analogous precipitation composites for the CMIP5 ensemble are illustrated in Figure 2.5b. There is reasonable qualitative agreement in average daily precipitation with wet nodes in MERRA-2 generally being wet in CMIP5, and dry nodes in MERRA-2 also generally being dry in CMIP5 suggesting the CMIP5 models are producing precipitation for plausible dynamic reasons. Though subtle, the magnitude of average daily precipitation in the CMIP5 composites is slightly lower than their MERRA-2 counterparts, and the precipitation extent is shifted somewhat south. It is of note that while the MERRA2 composites show no precipitation under the ridge in $\mathrm{N} 1, \mathrm{~N} 2$, and $\mathrm{N} 3$, the model composites show light average daily precipitation. 
Figure 2.12 shows the precipitation composites for the aforementioned MIROC5 model. As MIROC5 largely captures the LSMPs of the refSOM, it also largely captures the location and magnitude of precipitation relative to MERRA-2, though there are a few differences. N2, N6 and N7 show moderate coastal precipitation extending further to the north than in MERRA-2, while N8, N11, and N12 have lower average precipitation magnitude.

The precipitation composites in Fig. 2.12 help to illuminate how the differing LSMPs in IPSL CM5B LR result in distinctive precipitation climatologies for each node compared to MERRA-2. Generally, modeled precipitation is shifted to the south and is of greater magnitude than the reference precipitation (Fig. 2.5). N8 depicts moderate-high average daily precipitation predominately in northern California. This is very different than N8 in MERRA2 that shows moderate average daily precipitation climatology along the coast of BC and northern Washington.

\subsubsection{Station data}

In order to emphasize the value of using synoptic-scale patterns to understand precipitation, this work will consider two nearby observing stations in Oregon. Figure 2.13 shows precipitation density plots for each of the 12 nodes at Portland, the largest urban center in Oregon, and in Bull Run, the watershed supplying Portland's water. Each plot shows station precipitation observations, MERRA-2 precipitation at the coinciding pixel, the CMIP5 ensemble average precipitation at the coinciding pixel, and the spread of CMIP5 models at the coinciding pixel. The black numbers above each plot indicate the node number, and the blue numbers indicate the percent of $99^{\text {th }}$ percentile precipitation events that were mapped to a given node. While we do not expect reanalysis or models to fully 
capture the pdfs of precipitation at a given station since they are constructed using very different scales, this analysis serves as an assessment of the models' ability to capture the fundamental shape of the precipitation distribution at each node. There is additional utility in this analysis to understand how resolution may influence the qualitative character of mean and extreme precipitation.

The pdfs of station precipitation in Portland are captured reasonably well in N1, and N4, but less well in other nodes. Between N7, N9, N11, and N12, about $88 \%$ of $99^{\text {th }}$ percentile extreme precipitation extremes are captured. On average, the occurrence of N7, N11, and N12 are over-estimated while N9 is slightly overestimated. N7 has the highest occurrence $(32 \%)$ of extreme precipitation events in Portland. While the ensemble mean precipitation pdf in N7 is close to the station pdf, there is a large amount of model spread in these nodes.

The Portland metro region and Bull Run are close enough in space that they fall into the same pixel on the 2 degree grid. Despite this, Bull Run has a very different precipitation climatology than Portland based on station observations. The Bull Run watershed is located approximately 42 kilometers from the city center of Portland and precipitation climatology is not well captured by the models or MERRA-2. Fig. 2.13 indicates that the average daily precipitation pdfs are far too low in all of the 12 nodes. This is likely because Bull Run is located in complex topography on the windward side of the Cascades where orographic precipitation enhancement is known to occur (Luce et al. 2013).

While the coarse model resolution may be inadequate for capturing topographically influenced precipitation, the models do a good job of capturing the synoptic-scale circulation that results in precipitation. Because of this, we explore the utility of using LSMPs as analogs 
for extreme precipitation. $82 \%$ of $99^{\text {th }}$ percentile precipitation extremes in Bull Run are mapped to N6, N7, and N11, with N7 accounting for 47\% of events. The occurrence of N6 is under represented in the models, but N7 and N11 are overrepresented in models.

Subsequent work will need to consider node occurrence bias when evaluating how these patterns may change in the future since some nodes are systematically overrepresented in models, while others are underrepresented. Furthermore, it is clear that different nodes are important for extreme precipitation at a given geographic location. The LSMP approach to extremes could allow us to evaluate patterns that are impactful over a specific location, while minimizing concerns of resolution limitations.

\subsection{Summary}

This study provides a multi-model evaluation of fidelity of CMIP5 models (Table 1) in capturing the array of archetypal LSMPs that exist in the wet season over the PNW. LSMPs defined as SLP, Z500, and V250 are used to capture circulation at the surface, the midtroposphere, and the upper-troposphere. A comparison of mean climatology of these fields in the CMIP5 ensemble to the reference dataset (MERRA-2), reveals a clear negative bias in the models' Z500 field, and a jet stream that that is south of the reference jet stream (Fig. 2.2). Taylor diagrams showed that individual models varied in their ability to capture the mean climatology of SLP, Z500, and V250 (Fig. 2.3).

A 12-node reference SOM (refSOM) is used to reveal the array of LSMPs that occur over the PNW during the wet season (Fig. 2.4). Following the methodology outlined in Figure 1, the daily LSMPs of all 24 CMIP5 models are assigned to one of the 12 refSOM nodes using a metric T skill score. Composite SLP, Z500, and V250 LSMPs are made based on this assignment resulting in a pseudo SOM (pSOM) (Fig. 2.5). A qualitative analysis of LSMPs 
shows that the low pressure patterns in the bottom right corner of the refSOM are better represented than the ridging patterns in upper right corner. Portrait diagrams are used to evaluate to performance of each CMIP5 model at each node considering SLP, H500 and V250 fields simultaneously (Fig. 2.6a) and independently (Fig. 2.6b-d). In general, the CMIP5 models capture node patterns with reasonable fidelity, but some models perform better than others. In considering CMIP5 model fidelity at capturing fields independently, the Z500 field is best captured, followed by SLP, and then V250. In each of these fields, the variability in model performance appears predominately between nodes, as opposed to between models. This suggests that the model ensemble systematically performs better and worse at capturing certain node LSMPs. Similarly, certain nodes are systematically overrepresented in the models, while other nodes are under represented (Fig. 2.7).

In order to understand if models produce wet and dry conditions for the right underlying circulation, composites of precipitation in are analyzed. In general, we find that the CMIP5 models do generally produce precipitation in the right locations for the right reasons (Fig 2.10). The LSMPs associated with the driest and wettest conditions in the PNW are the most overrepresented pSOM nodes, while the LSMPs that are most underrepresented in the CMIP5 models are associated with light average daily precipitation across the pacific northwest (Fig. 2.7). Finally, this study compares the precipitation pdfs of two stations in Oregon to the spatially analogous precipitation in the CMIP5 models and MERRA-2 to link local-scale precipitation to LSMPs (Fig. 2.13). An analysis of the precipitation pdfs at these two stations, which are located in the same 2-degree pixel, suggests there may be utility in exploring the use of LSMPs as an analogue for extreme precipitation when considering projections of future climates. These results provide a 
mechanistic perspective on model fidelity in capturing synoptic climatology and associated precipitation characteristics across the PNW.

Several considerations should be taken into account when interpreting these results. First, this methodology assumes all input fields (SLP, Z500, and V250) are of equal importance. While all three field are useful in producing a complete picture of LSMPs through the thickness of the troposphere, it is clear from our results that depending on day, lower level disturbance or upper level disturbance may be more important to contributing to precipitation and precipitation extremes. It is possible that LSMPs are influenced by lower modes of climate variability (e.g. ENSO, PDO) and therefore the ability to realistically simulate the climatology of LSMPs would be partially contingent on the models' ability to simulate these teleconnections realistically.

This work demonstrates a novel methodology for climate model evaluation that uses SOMs to identify key LSMPs and metT to evaluate the ability of CMIP5 models to capture these key LSMPs. Since most climate model evaluation considers seasonal or longer climatologies, this approach is unique in that it evaluates circulation patterns at daily time steps to evaluate key patterns. This allows us to evaluate if precipitation is being produced in the right regions and for the right reasons. This work supports previous work by Rupp et al. (2017) that indicate a hierarchy amongst models to capture climatological trends in the PNW, but is unique in that it ranks models in ability to capture the circulation dynamics as opposed to precipitation statistics alone. To these authors' knowledge, this is the first study to evaluate climate models in their ability to capture synoptic circulation patterns over the PNW. In answering questions of future changes to precipitation, it is vital that the models that capture accurate precipitation dynamics are considered. 
This study creates many opportunities for further research. The methodology outlined in this study can be applied to similar analysis for any spatial domain, or multiple spatial domains to compare results. Future studies could also delve deeper into understanding the link between precipitation extremes and LSMPs over the PNW. This work lays a foundation for the evaluation of future LSMPs under multiple warming scenarios. 


\subsection{Tables}

\begin{tabular}{lc}
\hline & \\
\hline Model & Native Resolution lat x lon ['] \\
\hline ACCESS 1.0 & $1.25 \times 1.875$ \\
ACCESS1.3 & $1.25 \times 1.875$ \\
CanESM2 & $2.7906 \times 2.8125$ \\
CMCC_CESM & $3.4431 \times 3.75$ \\
CMCC_CM & $0.7484 \times 0.75$ \\
CMCC_CMS & $3.7111 \times 3.75$ \\
CNRM_CM5 & $1.4008 \times 1.40625$ \\
GFDL_CM3 & $2 \times 2.5$ \\
GFDL_ESM2G & $2.0225 \times 2$ \\
GFDL_ESM2M & $2.0225 \times 2.5$ \\
HadCM3 & $2.5 \times 3.75$ \\
HadGEM2_CC & $1.25 \times 1.875$ \\
IPSL_CM5A_LR & $1.8947 \times 3.75$ \\
IPSL_CM5A_MR & $1.2676 \times 2.5$ \\
IPSL_CM5B_LR & $1.8947 \times 3.75$ \\
MIROC_ESM & $2.7906 \times 2.8125$ \\
MIROC_ESM_CHEM & $2.7906 \times 2.8125$ \\
MIROC5 & $1.4008 \times 1.40625$ \\
MPI_ESM_LR & $1.8653 \times 1.875$ \\
MPI_ESM_MR & $1.8653 \times 1.875$ \\
MPI_ESM_P & $1.8653 \times 1.875$ \\
MRI_CGCM3 & $1.12148 \times 1.125$ \\
MRI_ESM1 & $1.12148 \times 1.125$ \\
NorESM1_M & $1.8947 \times 2.5$ \\
Reference: MERRA-2 & $0.5 \times 5 / 8$ \\
\hline
\end{tabular}

Table 2. 1 CMIP5 models used in this study (left) and the associated native resolution (right). 


\subsection{Figures}

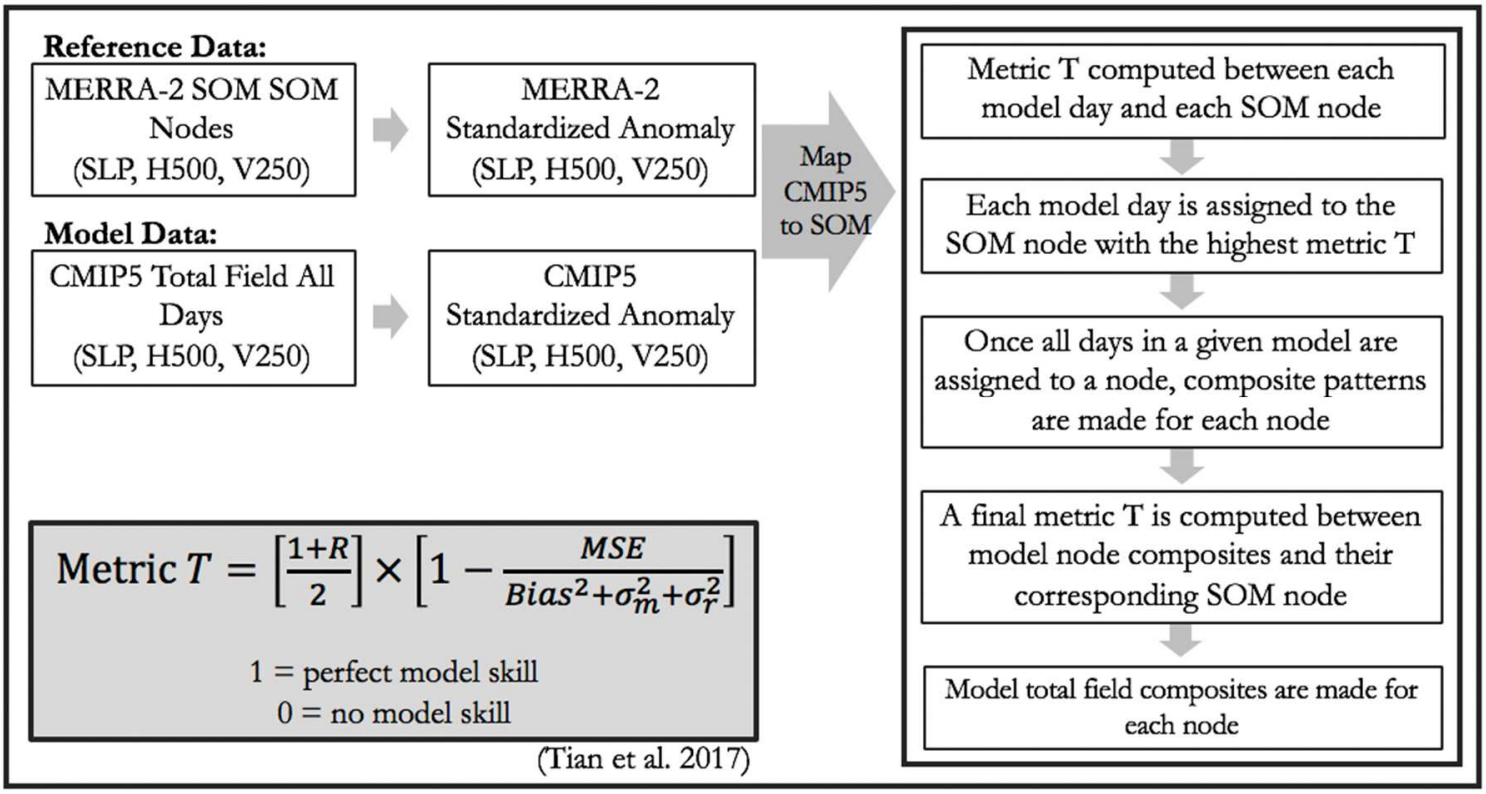

Figure 2. 1 Workflow of mapping CMIP5 models to the reference MERRA-2 SOM using Metric T. Metric T defined in the grey box. 
(a)
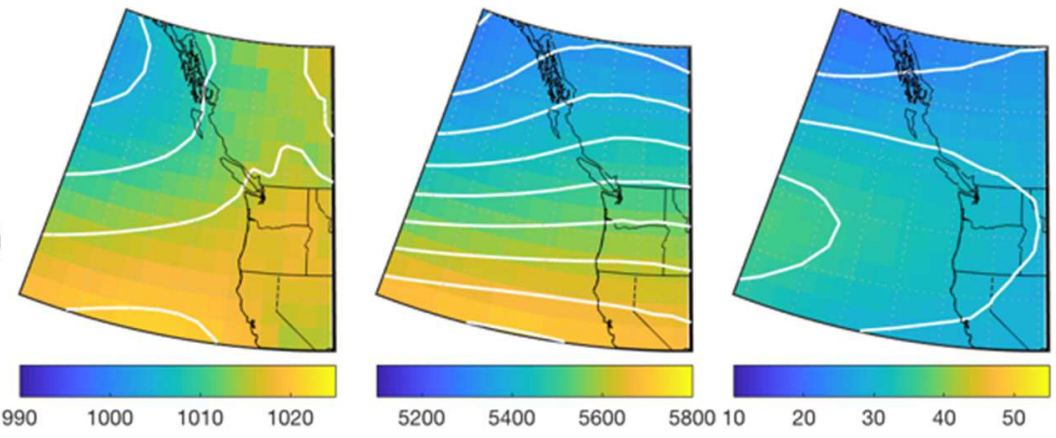

(b)
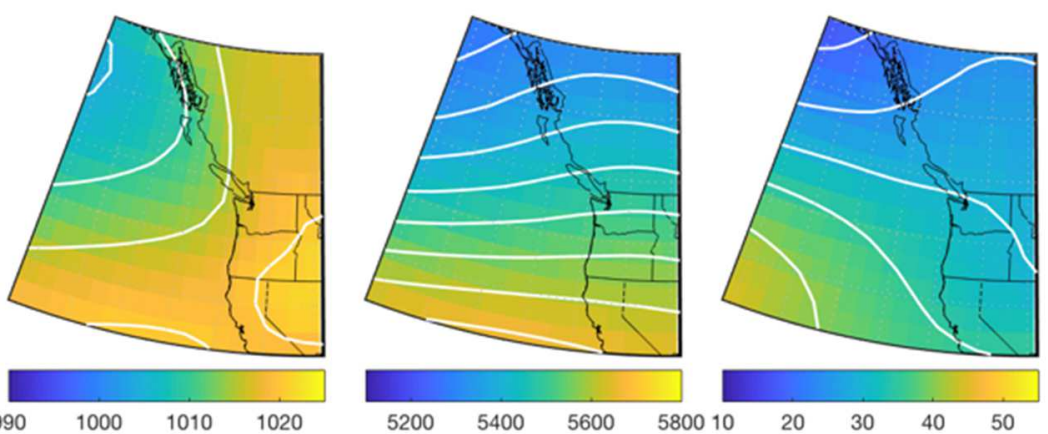

(c)
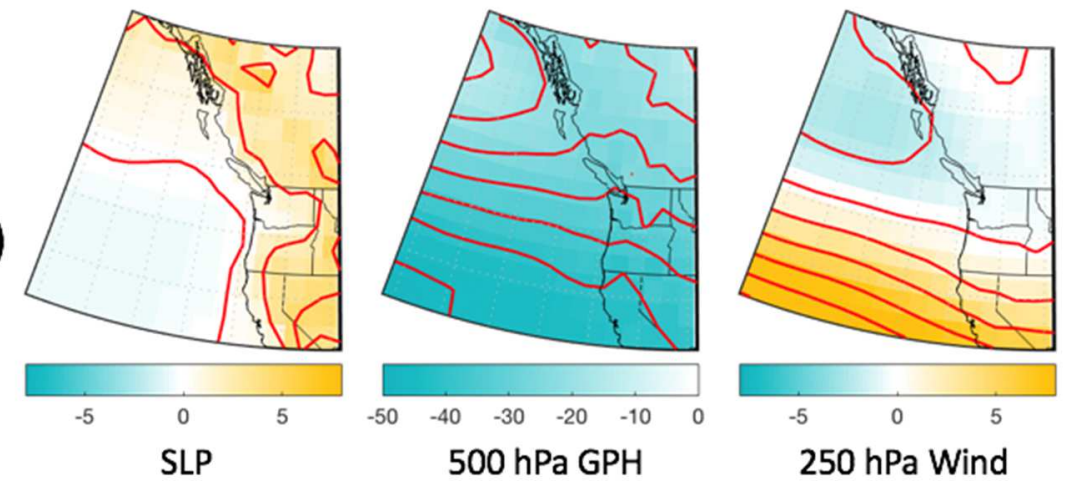

Figure 2. 2 Wet season (November-April) climatology of SLP [hPa] (contours at $5 \mathrm{hPa}$ spacing), Z500 [m](contours at $50 \mathrm{~m}$ spacing), and V250 [ms-1](contours at $5 \mathrm{~m} \mathrm{~s}-1$ spacing) in (a) MERRA-2, and (b) the CMIP5 multi-model ensemble mean. (c) The CMIP5 bias computed bias computed by subtracting (a) from (b). SLP [hPa] (contours ar $2 \mathrm{hPa}$ spacing), $\mathrm{Z} 500[\mathrm{~m}]$ (contours at $5 \mathrm{~m}$ spacing), and V250 $\left[\mathrm{ms}^{-1}\right]$ (contours at $2 \mathrm{~ms}^{-1}$ spacing). 


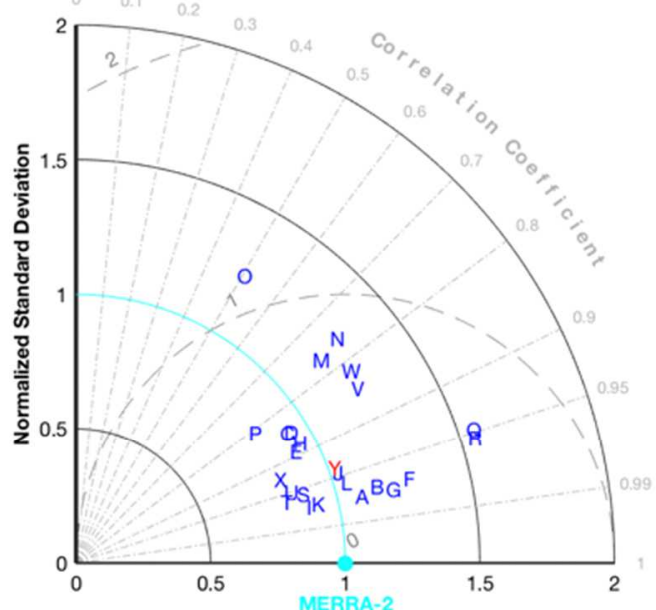

(a)

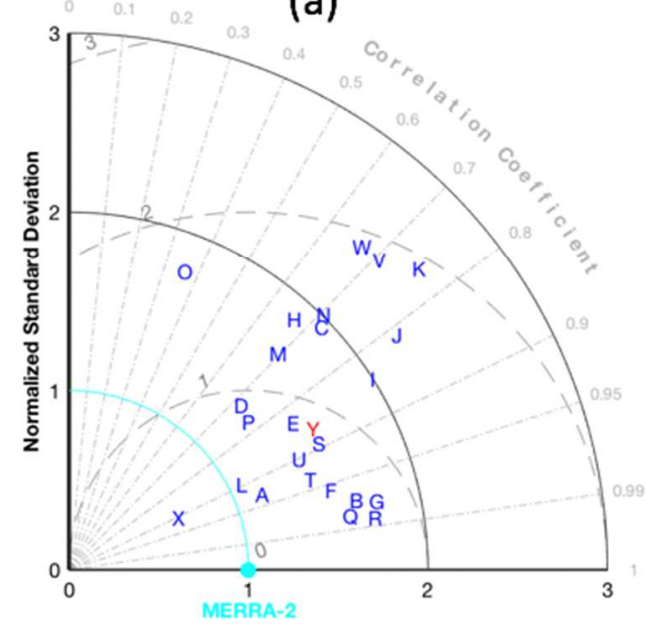

(c)

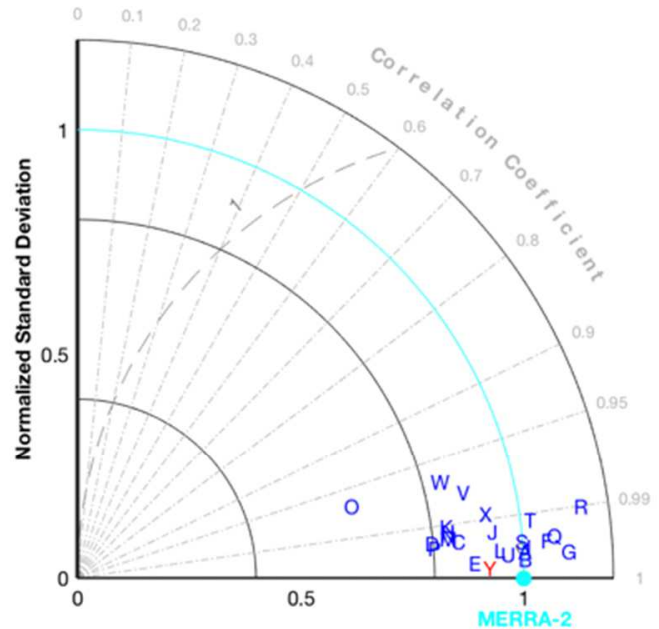

(b)

\begin{tabular}{|ll|}
\hline A - ACCESS1.0 & N-IPSL_CM5A_MR \\
B-ACCESS1.3 & O-IPSL_CM5B_LR \\
C-CMCC_CESM & P-MIROC5 \\
D-CMCC_CM & Q-MIROC_ESM \\
E-CMCC_CMS & R-MIROC_ESM_CHEM \\
F-CNRM_CM5 & S-MPI_ESM_LR \\
G - CanESM2 & T-MPI_ESM_MR \\
H-GFDL_CM3 & U-MPI_ESM_P \\
I-GFDL_ESM2G & V-MRI_CGCM3 \\
J-GFDL_ESM2M & W-MRI_ESM1 \\
K-HadCM3 & X-NorESM1_M \\
L-HadGEM2_CC & Y-Ensemble Mean \\
M-IPSL_CM5A_LR & \\
\hline
\end{tabular}

(d)

Figure 2. 3 Taylor diagrams of SLP (a), Z500 (b), and V250 (c) climatology fields relative to the MERRA-2 reference dataset. Standard deviation and centered RMSD fields normalized by reference spatial standard deviation. Grey dashed lines indicate the centered RMSE. CMIP5 model indicated in (d). 


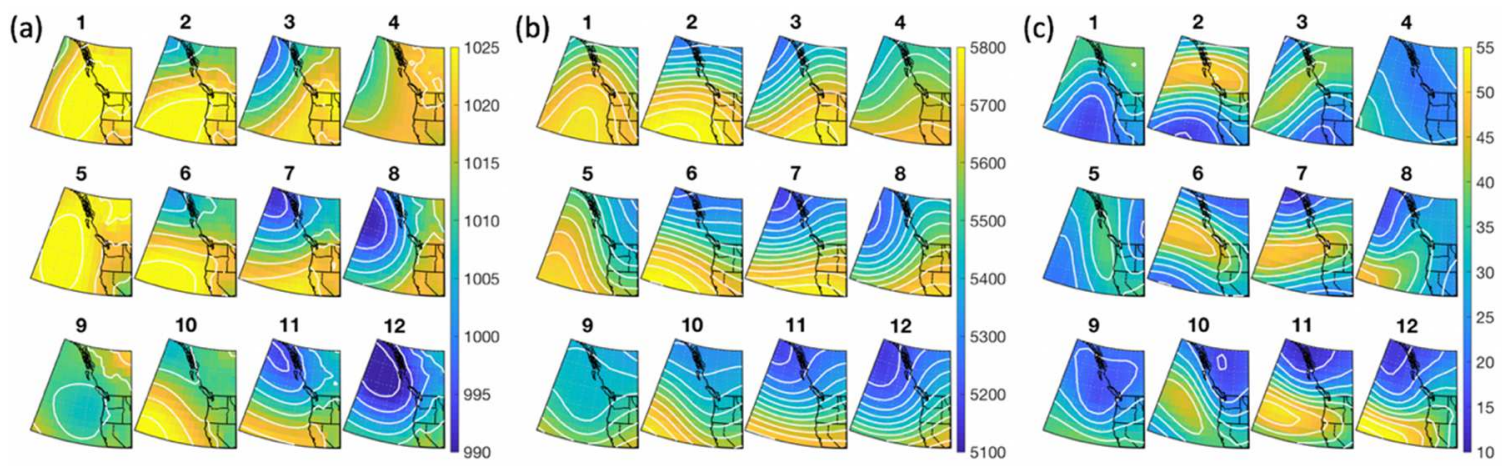

Figure 2. 4 12-node wet season refSOM showing (a) SLP [hPa] (contours at $5 \mathrm{hPa}$ spacing), (b) Z500 [m] (contours at $50 \mathrm{~m}$ spacing), and (c) V250 [ms-1](contours at $5 \mathrm{~m} \mathrm{~s}-1$ spacing) in MERRA-2. 

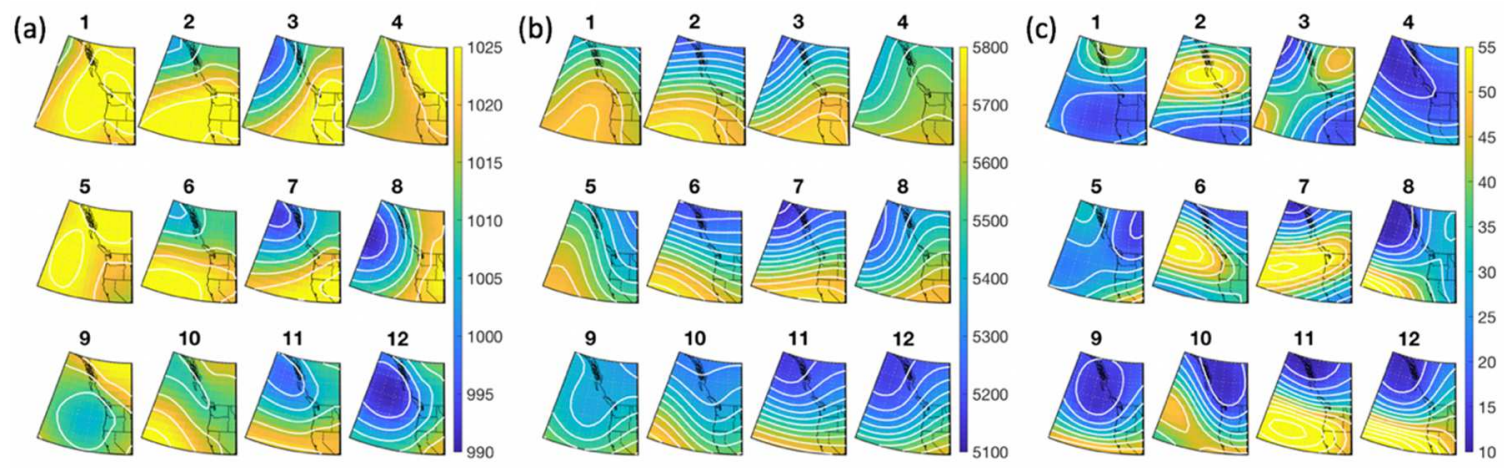

Figure 2. 5 12-node wet season pSOM color shaded as in Fig. 2.4, but showing composite patterns for all days mapped to each node for the respective field SLP (a), Z500 (b), and V250 (c) across the suite of 24 CMIP5 models. 

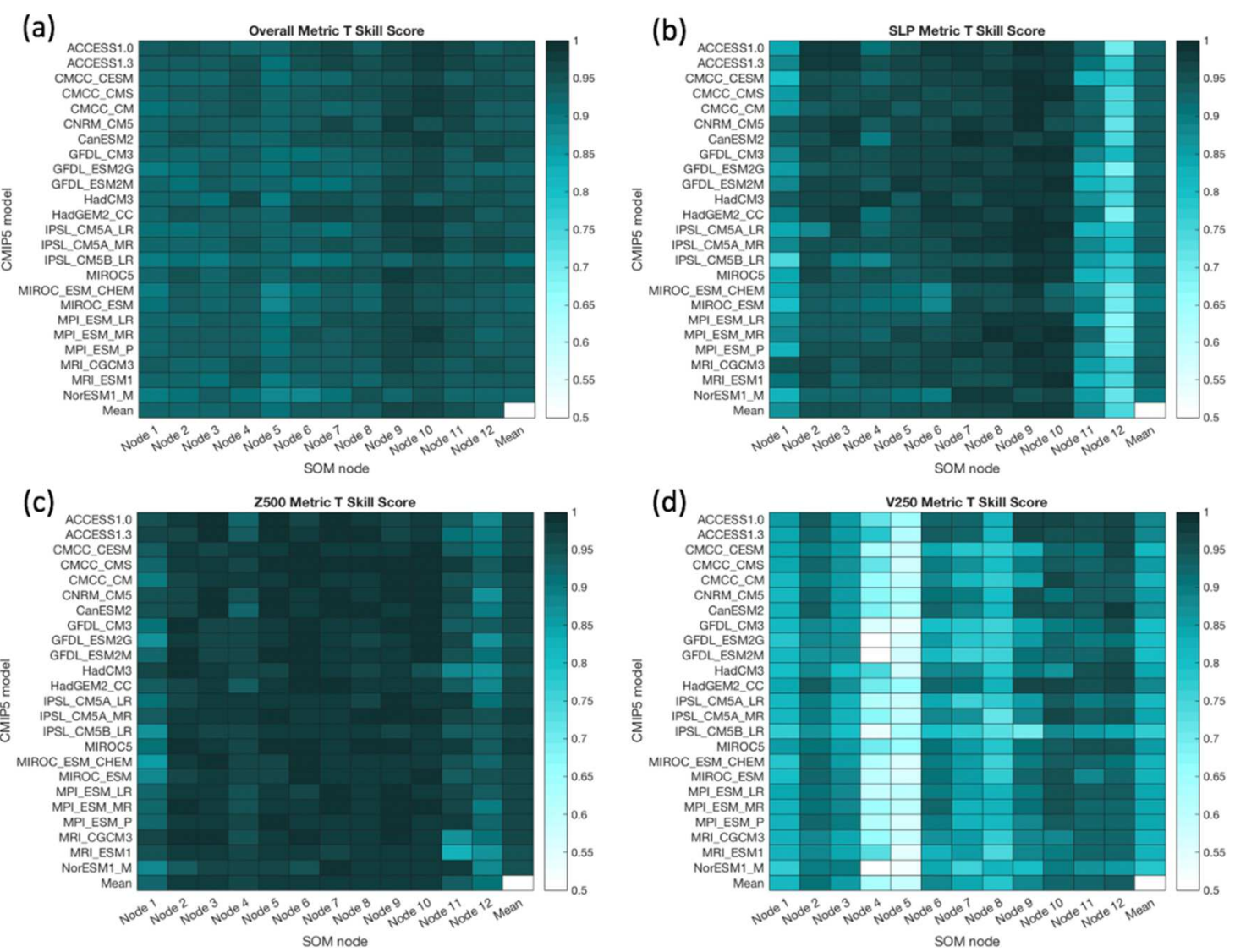

Figure 2. 6 Portrait diagrams summarizing the Metric T skill score for each CMIP5 models at each node. Heatmap (a) show the skill score when considering all three fields simultaneously, as is done to assign each model day to a node. Heatmap (b-d) show the skill scores only considering the SLP, H500, and V250 fields respectively. 


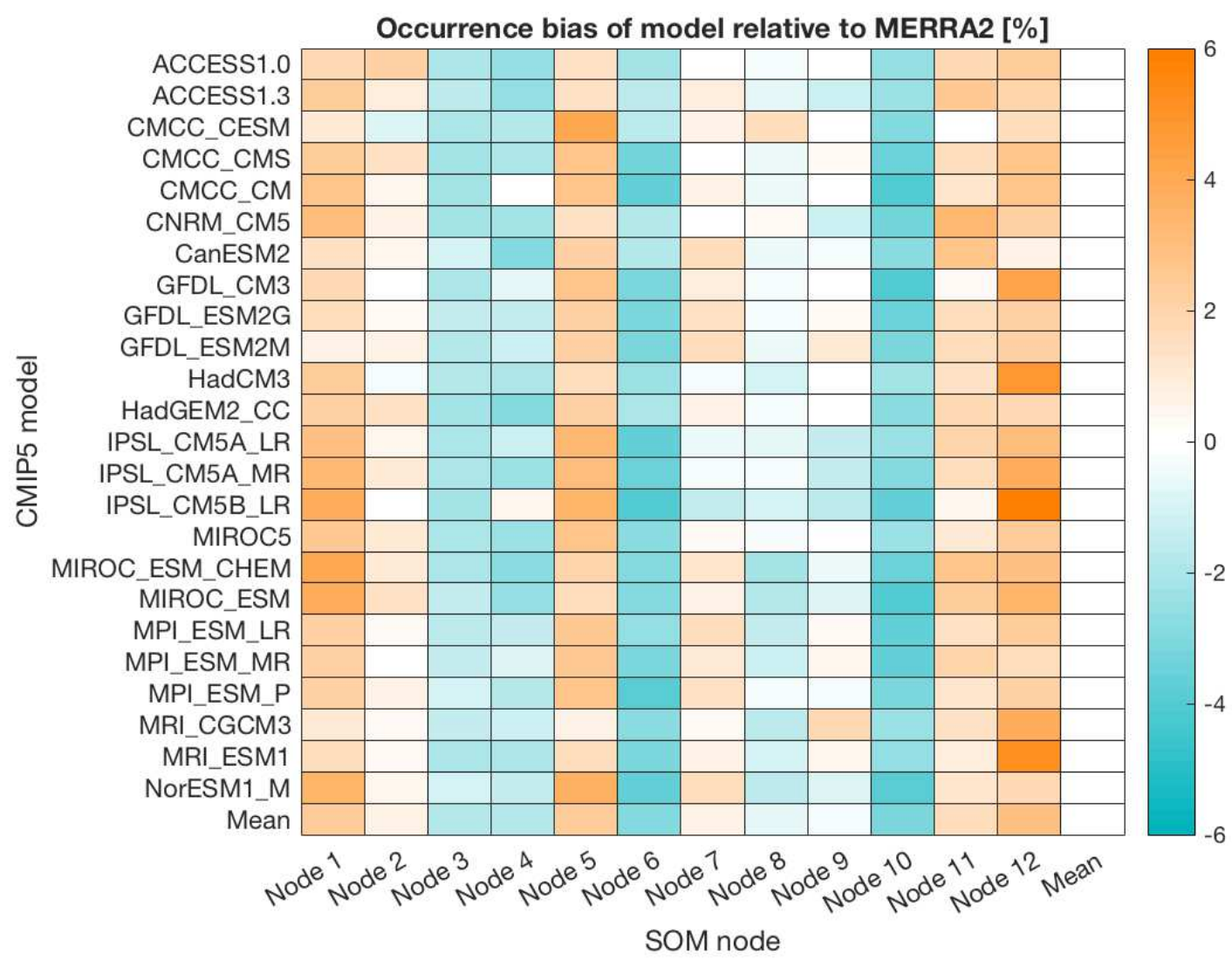

Figure 2. 7 Portrait diagram showing the node occurrence bias in node assignment calculated as the percent of days assigned to each node in models - the percent of days assigned to each node in MERRA-2. 


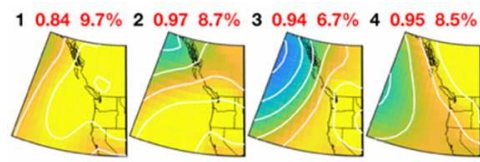

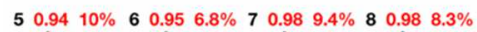

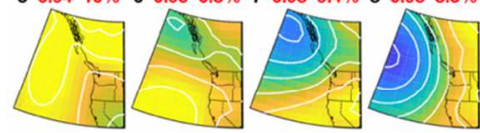

$90.997 .6 \% 100.986 .9 \% 110.830 .1 \% 120.770 .2 \%$

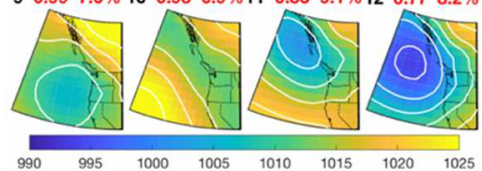

(a)

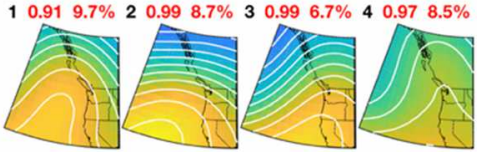

$5 \quad 0.9910 \% \quad 6 \quad 0.996 .8 \% \quad 7 \quad 0.98 \quad 9.4 \% 8 \quad 0.998 .3 \%$

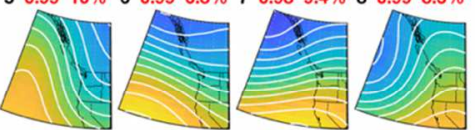

$917.6 \% \quad 10 \quad 0.98 \quad 6.9 \% 11 \quad 0.98 \quad 9.1 \% 12 \quad 0.938 .2 \%$

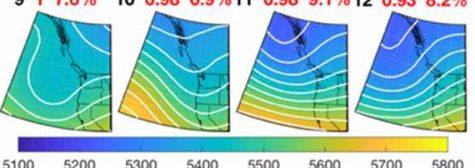

(b)

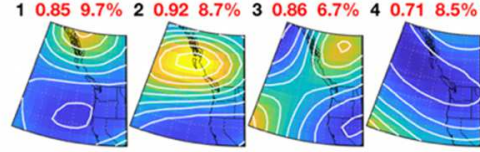

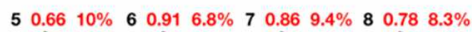

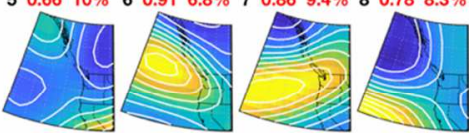

$90.917 .6 \% 10 \quad 0.94 \quad 6.9 \% 11 \quad 0.959 .1 \% 12 \quad 0.968 .2 \%$

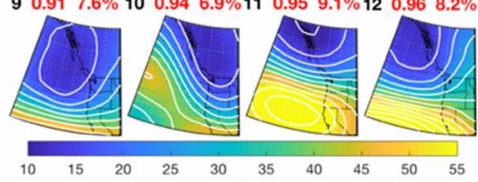

(c)

Figure 2. 8 Composites for MIROC5 color shaded as in Fig. 2.4. Red numbers above each node indicate the Metric T skill score, and the percent of total days assigned to the respective node. 

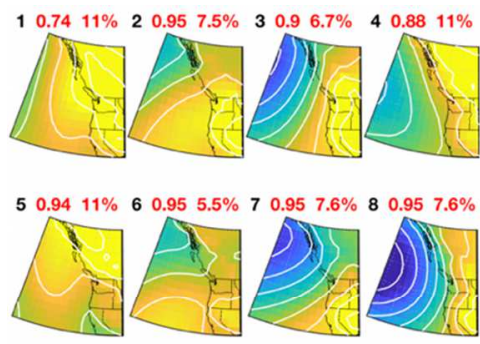

$90.986 .2 \% 10 \quad 0.97 \quad 5.6 \% 110.85 \quad 8.6 \% 120.77 \quad 12 \%$

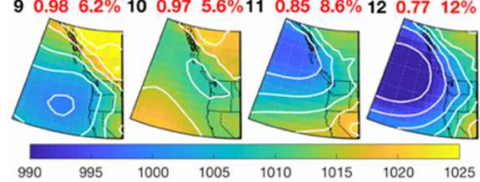

(a)
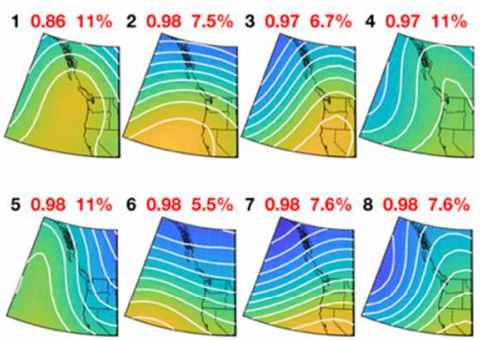

$90.976 .2 \% 10 \quad 0.98 \quad 5.6 \% 110.948 .6 \% 120.93 \quad 12 \%$

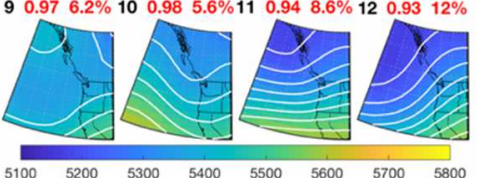

(b)
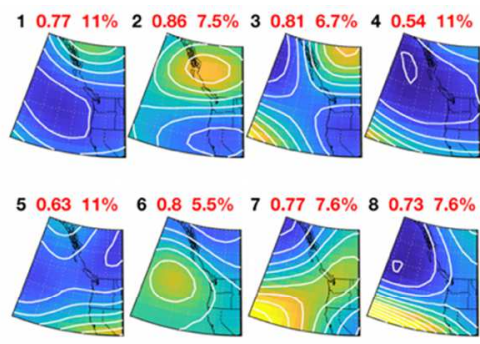

$90.69 \quad 6.2 \% 10 \quad 0.895 .6 \% 11 \quad 0.86 \quad 8.6 \% 12 \quad 0.84 \quad 12 \%$

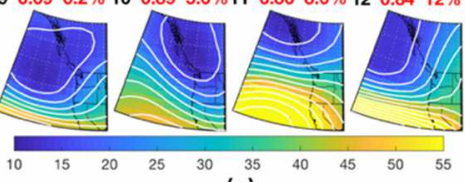

(c)

Figure 2. 9 As in Fig. 2.8, but for IPSL CM5B LR. 

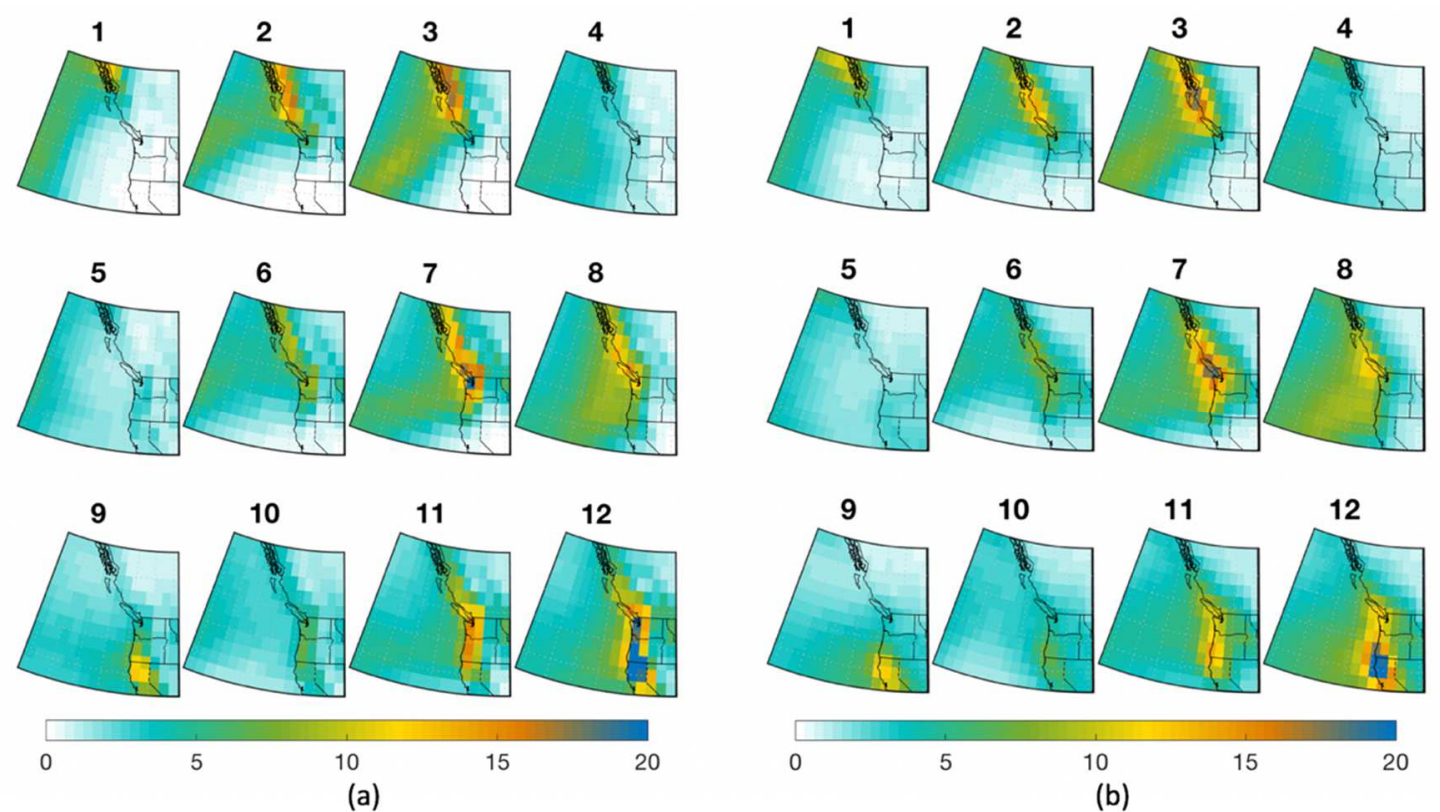

Figure 2.10 Composites of daily average precipitation [mm/day] for all days assigned to each node in MERRA-2 (a) and in the CMIP5 ensemble (b). 

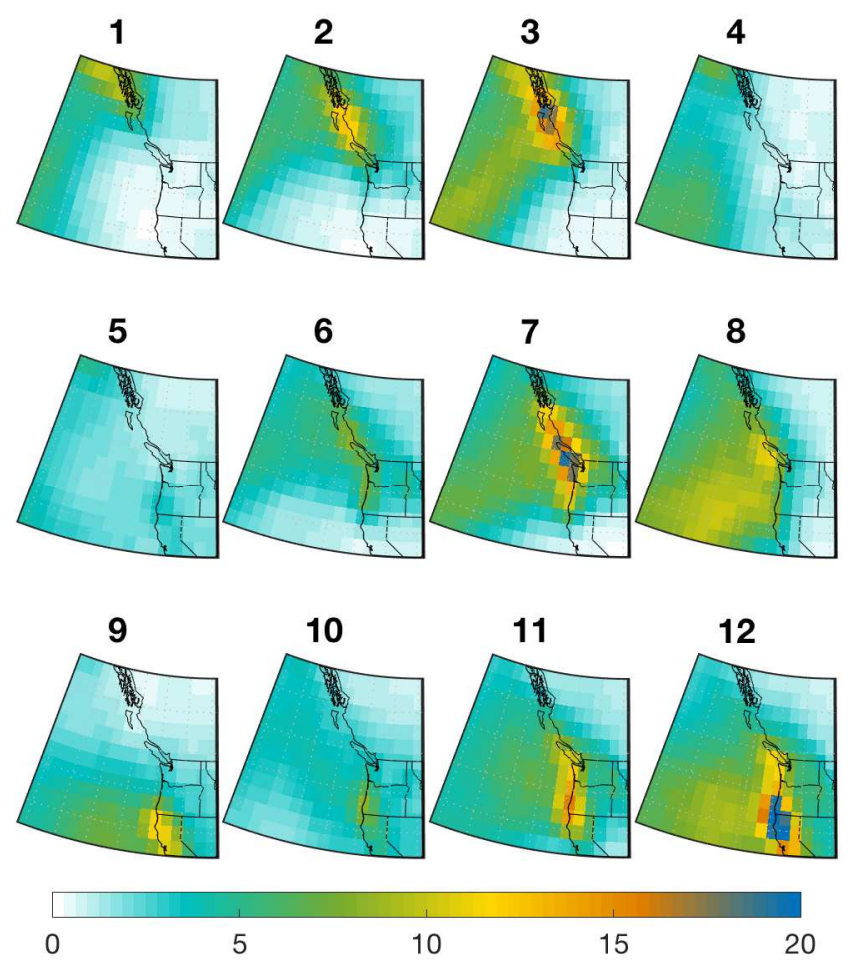

Figure 2.11 As in Fig. 2.10 but for all days assigned to each node in MIROC5. 

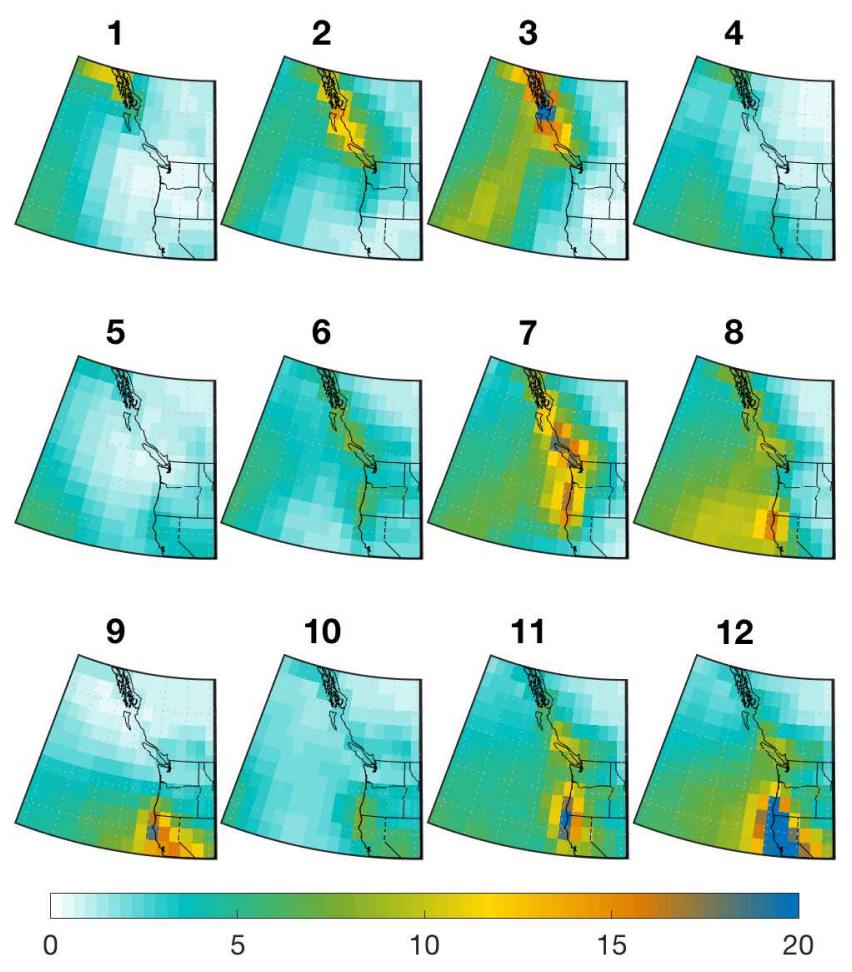

Figure 2.12 As in Figure 2.10, but for the IPSL CM5B LR model. 

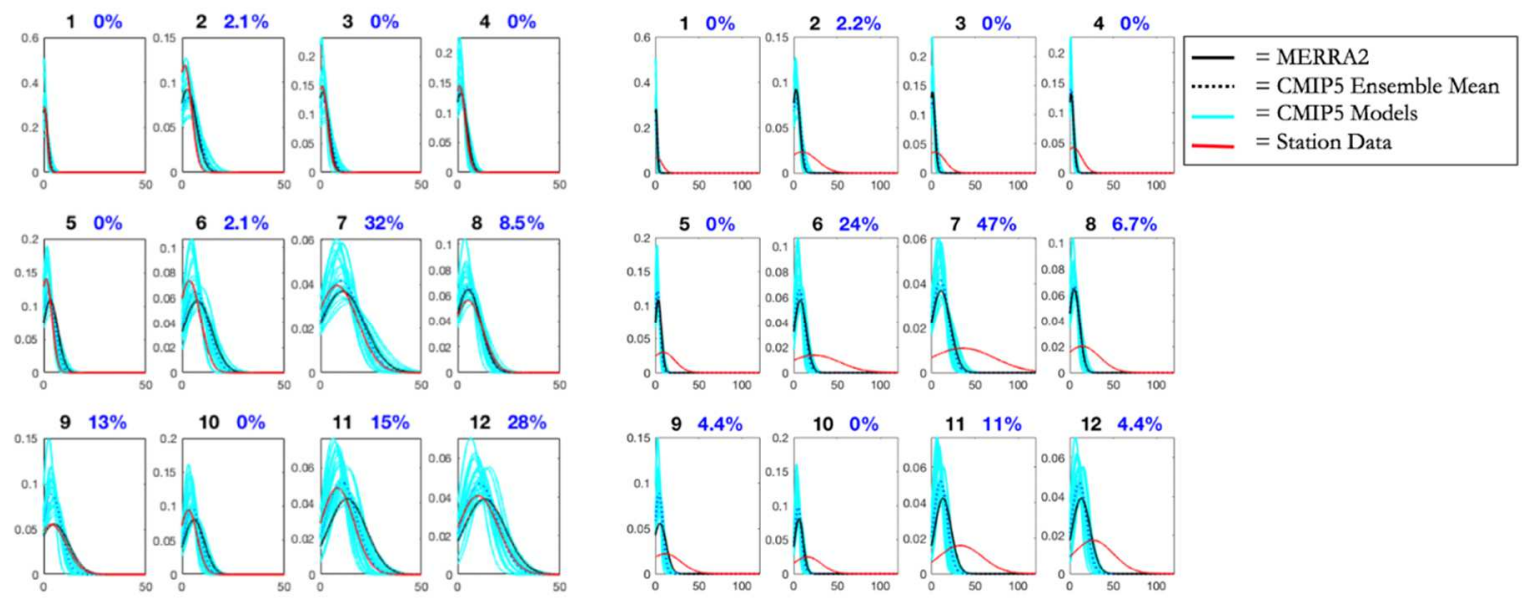

Portland
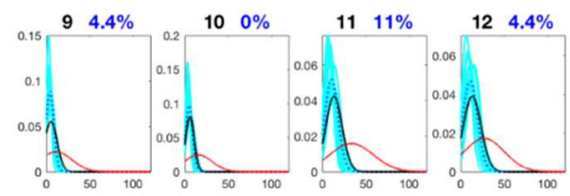

Bull Run

Figure 2. 13 PDFs of precipitation at Portland International Airport (PDX) and at the North Fork SNOTEL station in Bull Run. Station precipitation observations, MERRA-2 precipitation at the coinciding pixel, the CMIP5 ensemble average precipitation at the coinciding pixel are shown for each node. Black numbers indicate the node number, and blue numbers indicate the percent of $99^{\text {th }}$ percentile precipitation events that were mapped to a given node. 


\subsection{References}

Abatzoglou, J. T., 2016: Contribution of Cutoff Lows to Precipitation across the United States. J. Appl. Meteor. Climatol., 55, 893-899, https://doi.org/10.1175/JAMC-D15-0255.1.

- D. E. Rupp, and P. W. Mote, 2014: Seasonal Climate Variability and Change in the Pacific Northwest of the United States. Journal of Climate, 27, 2125-2142, https://doi.org/10.1175/JCLI-D-13-00218.1.

Cassano, E., J. Glisan, J. Cassano, W. Gutowski, and M. Seefeldt, 2015: Self-organizing map analysis of widespread temperature extremes in Alaska and Canada. Climate Research, 62, 199-218, https://doi.org/10.3354/cr01274.

Cassano, J. J., P. Uotila, and A. Lynch, 2006: Changes in synoptic weather patterns in the polar regions in the twentieth and twenty-first centuries, part 1: Arctic. International Journal of Climatology, 26, 1027-1049, https://doi.org/10.1002/joc.1306.

Chen, H. W., F. Zhang, and R. B. Alley, 2016: The Robustness of Midlatitude Weather Pattern Changes due to Arctic Sea Ice Loss. Journal of Climate; Boston, 29, 7831 7849, http://dx.doi.org.ezproxy.library.ubc.ca/10.1175/JCLI-D-16-0167.1.

Collow, A. B. M., M. G. Bosilovich, and R. D. Koster, 2016: Large-Scale Influences on Summertime Extreme Precipitation in the Northeastern United States. Journal of Hydrometeorology, 17, 3045-3061, https://doi.org/10.1175/JHM-D-16-0091.1.

Dalton, M. M., K. D. Dello, L. Hawkins, P. W. Mote, and D. E. Rupp, 2017: The Third Oregon Climate Assessment Report. Oregon Climate Change Research Institute, College of EArth, Ocean, and Atmospheric Sciences, Oregon State University, http://www.occri.net/media/1055/ocar3_final_all_01-30-2017_compressed.pdf (Accessed May 31, 2019).

DeAngelis, A. M., A. J. Broccoli, and S. G. Decker, 2013: A Comparison of CMIP3 Simulations of Precipitation over North America with Observations: Daily Statistics and Circulation Features Accompanying Extreme Events. Journal of Climate, 26, 3209-3230, https://doi.org/10.1175/JCLI-D-12-00374.1.

Emori, S., and S. J. Brown, 2005: Dynamic and thermodynamic changes in mean and extreme precipitation under changed climate. Geophysical Research Letters, 32, https://doi.org/10.1029/2005GL023272. http://agupubs.onlinelibrary.wiley.com/doi/abs/10.1029/2005GL023272 (Accessed May 16, 2019).

Ford, T. W., and J. T. Schoof, 2017: Characterizing extreme and oppressive heat waves in Illinois. Journal of Geophysical Research: Atmospheres, 122, 682-698, https://doi.org/10.1002/2016JD025721.

Gao, X., C. A. Schlosser, P. Xie, E. Monier, and D. Entekhabi, 2014: An Analogue Approach to Identify Heavy Precipitation Events: Evaluation and Application to 
CMIP5 Climate Models in the United States. J. Climate, 27, 5941-5963, https://doi.org/10.1175/JCLI-D-13-00598.1.

Gelaro, R., and Coauthors, 2017: The Modern-Era Retrospective Analysis for Research and Applications, Version 2 (MERRA-2). J. Climate, 30, 5419-5454, https://doi.org/10.1175/JCLI-D-16-0758.1.

Gibson, P. B., S. E. Perkins-Kirkpatrick, and J. A. Renwick, 2016: Projected changes in synoptic weather patterns over New Zealand examined through self-organizing maps. International Journal of Climatology, 36, 3934-3948, https://doi.org/10.1002/joc.4604.

- A. J. Pitman, R. Lorenz, and S. E. Perkins-Kirkpatrick, 2017: The Role of Circulation and Land Surface Conditions in Current and Future Australian Heat Waves. J. Climate, 30, 9933-9948, https://doi.org/10.1175/JCLI-D-17-0265.1.

Glisan, J. M., W. J. Gutowski, J. J. Cassano, E. N. Cassano, and M. W. Seefeldt, 2016: Analysis of WRF extreme daily precipitation over Alaska using self-organizing maps. Journal of Geophysical Research: Atmospheres, 121, 7746-7761, https://doi.org/10.1002/2016JD024822.

Hewitson, B. C., and R. G. Crane, 2002: Self-organizing maps: applications to synoptic climatology. Climate Research, 22, 13-26, https://doi.org/10.3354/cr022013.

$\longrightarrow$, and — 2006: Consensus between GCM climate change projections with empirical downscaling: precipitation downscaling over South Africa. International Journal of Climatology, 26, 1315-1337, https://doi.org/10.1002/joc.1314.

Huang, X., and P. A. Ullrich, 2017: The Changing Character of Twenty-First-Century Precipitation over the Western United States in the Variable-Resolution CESM. J. Climate, 30, 7555-7575, https://doi.org/10.1175/JCLI-D-16-0673.1.

Johnson, N. C., and S. B. Feldstein, 2010: The Continuum of North Pacific Sea Level Pressure Patterns: Intraseasonal, Interannual, and Interdecadal Variability. Journal of Climate; Boston, 23, 851-858,860-864,866-867.

- - , and B. Tremblay, 2008: The Continuum of Northern Hemisphere Teleconnection Patterns and a Description of the NAO Shift with the Use of SelfOrganizing Maps. J. Climate, 21, 6354-6371, https://doi.org/10.1175/2008JCLI2380.1.

Kennedy, A., X. Dong, and B. Xi, 2016: Cloud fraction at the ARM SGP site: reducing uncertainty with self-organizing maps. Theoretical \& Applied Climatology, 124, 4354, https://doi.org/10.1007/s00704-015-1384-3.

Lennard, C., and G. Hegerl, 2015: Relating changes in synoptic circulation to the surface rainfall response using self-organising maps. Climate Dynamics, 44, 861-879, https://doi.org/10.1007/s00382-014-2169-6. 
Liu, Y., and R. H. Weisberg, 2011: A Review of Self-Organizing Map Applications in Meteorology and Oceanography. Self Organizing Maps - Applications and Novel Algorithm Design,.

Loikith, P. C., and A. J. Broccoli, 2014: Comparison between Observed and ModelSimulated Atmospheric Circulation Patterns Associated with Extreme Temperature Days over North America Using CMIP5 Historical Simulations. J. Climate, 28, 20632079, https://doi.org/10.1175/JCLI-D-13-00544.1.

Loikith, P. C., B. R. Lintner, and A. Sweeny, 2017: Characterizing Large-Scale Meteorological Patterns and Associated Temperature and Precipitation Extremes over the Northwestern United States Using Self-Organizing Maps. J. Climate, 30, 2829-2847, https://doi.org/10.1175/JCLI-D-16-0670.1.

Luce, C. H., J. T. Abatzoglou, and Z. A. Holden, 2013: The Missing Mountain Water: Slower Westerlies Decrease Orographic Enhancement in the Pacific Northwest USA. Science, 342, 1360-1364, https://doi.org/10.1126/science.1242335.

May, C., and Coauthors, 2018: Chapter 24 : Northwest. Impacts, Risks, and Adaptation in the United States: The Fourth National Climate Assessment, Volume II. U.S. Global Change Research Program, https://nca2018.globalchange.gov/chapter/24/ (Accessed June 5, 2019).

Mechem, D. B., C. S. Wittman, M. A. Miller, S. E. Yuter, and S. P. de Szoeke, 2018: Joint Synoptic and Cloud Variability over the Northeast Atlantic near the Azores. J. Appl. Meteor. Climatol., 57, 1273-1290, https://doi.org/10.1175/JAMC-D-17-0211.1.

Oki, T., and S. Kanae, 2006: Global Hydrological Cycles and World Water Resources. Science, 313, 1068-1072.

Radić, V., A. J. Cannon, B. Menounos, and N. Gi, 2015: Future changes in autumn atmospheric river events in British Columbia, Canada, as projected by CMIP5 global climate models. Journal of Geophysical Research: Atmospheres, 120, 9279-9302, https://doi.org/10.1002/2015JD023279.

Rana, A., and H. Moradkhani, 2016: Spatial, temporal and frequency based climate change assessment in Columbia River Basin using multi downscaled-scenarios. Clim Dyn, 47, 579-600, https://doi.org/10.1007/s00382-015-2857-x.

Reichle, R. H., Q. Liu, R. D. Koster, C. S. Draper, S. P. P. Mahanama, and G. S. Partyka, 2016: Land Surface Precipitation in MERRA-2. J. Climate, 30, 1643-1664, https://doi.org/10.1175/JCLI-D-16-0570.1.

Rupp, D. E., J. T. Abatzoglou, and P. W. Mote, 2017: Projections of 21st century climate of the Columbia River Basin. Clim Dyn, 49, 1783-1799, https://doi.org/10.1007/s00382-016-3418-7.

Rupp David E., Abatzoglou John T., Hegewisch Katherine C., and Mote Philip W., 2013: Evaluation of CMIP5 20th century climate simulations for the Pacific Northwest 
USA. Journal of Geophysical Research: Atmospheres, 118, 10,884-10,906, https://doi.org/10.1002/jgrd.50843.

Seager, R., N. Naik, and G. A. Vecchi, 2010: Thermodynamic and Dynamic Mechanisms for Large-Scale Changes in the Hydrological Cycle in Response to Global Warming. J. Climate, 23, 4651-4668, https://doi.org/10.1175/2010JCLI3655.1.

Sheridan, S. C., and C. C. Lee, 2011: The self-organizing map in synoptic climatological research. Progress in Physical Geography; London, 35, 109-119, http://dx.doi.org.ezproxy.library.ubc.ca/10.1177/0309133310397582.

Taylor, K. E., R. J. Stouffer, and G. A. Meehl, 2012: An Overview of CMIP5 and the Experiment Design. Bull. Amer. Meteor. Soc., 93, 485-498, https://doi.org/10.1175/BAMS-D-11-00094.1.

Warner, M. D., C. F. Mass, and E. P. Salathé, 2012: Wintertime Extreme Precipitation Events along the Pacific Northwest Coast: Climatology and Synoptic Evolution. Mon. Wea. Rev., 140, 2021-2043, https://doi.org/10.1175/MWR-D-11-00197.1. 


\section{Appendix}

\section{A1. Chapter 1 Supplementary Figures}

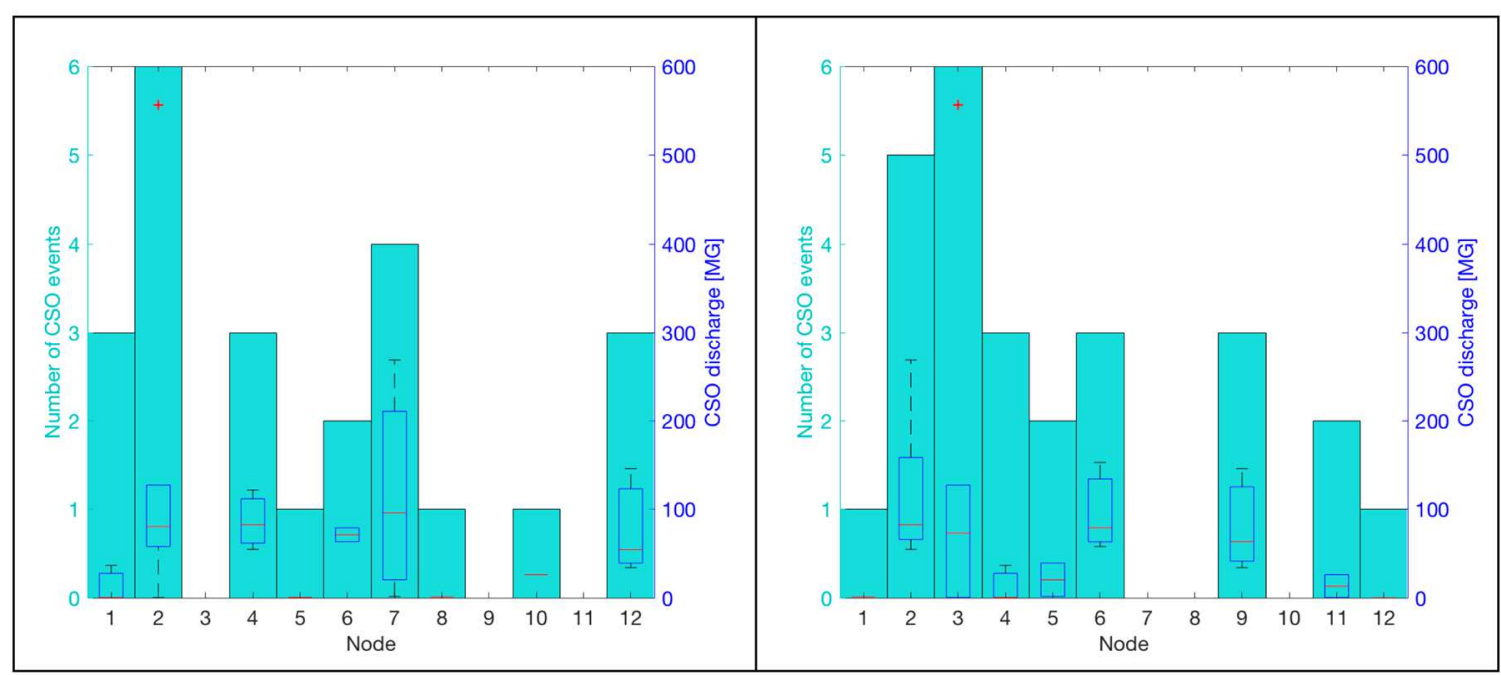

FIG. A1. CSO distribution by node for heavy total days (left) and high intensity days (right). 

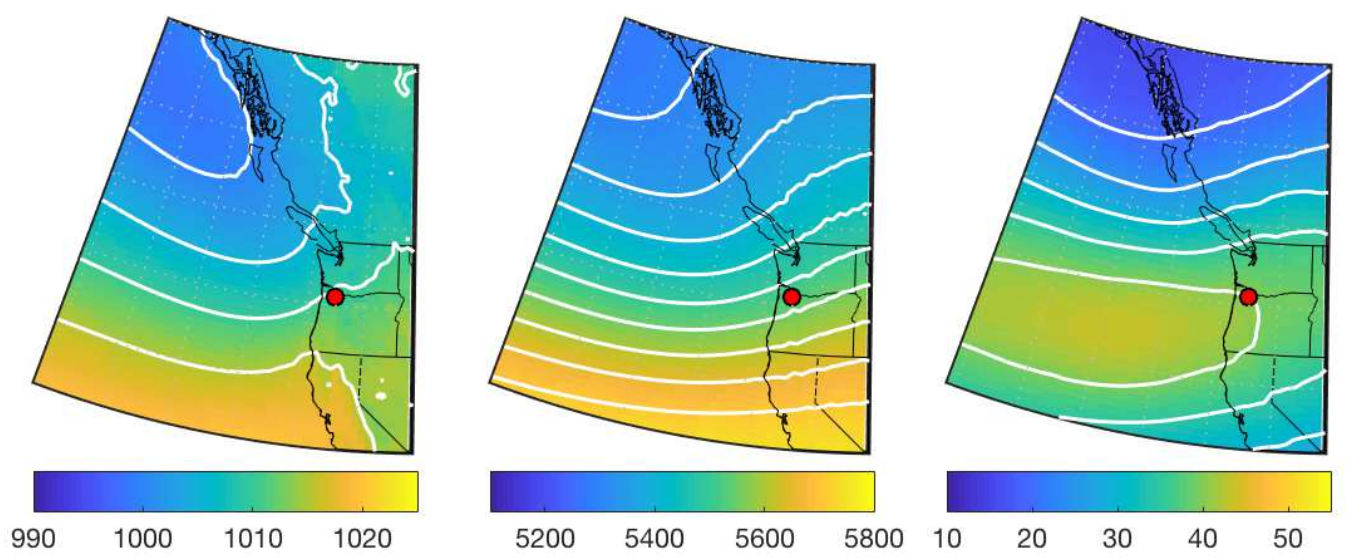

FIG. A2. Composite averages of (left) SLP [hPa] (contours at $5 \mathrm{hPa}$ spacing), (center) Z500

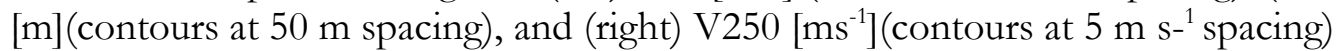
concurrent with heavy total days. Portland, OR is indicated by the red dot. 
(a)
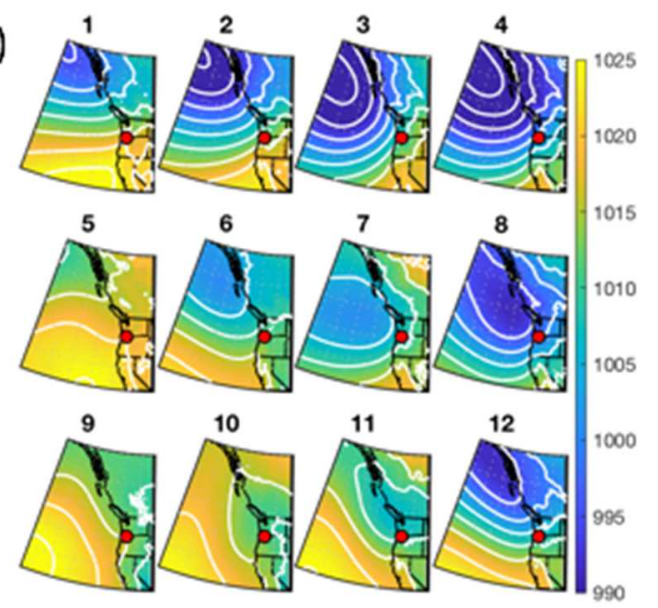

(b)
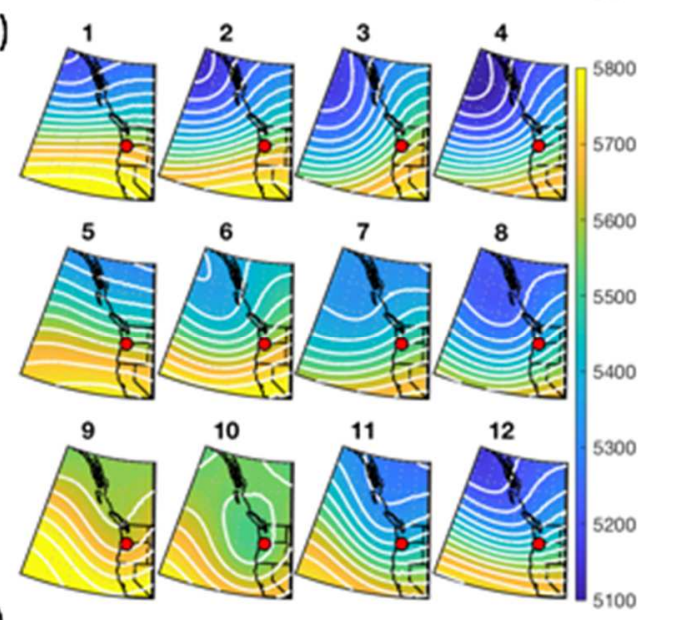

(c)

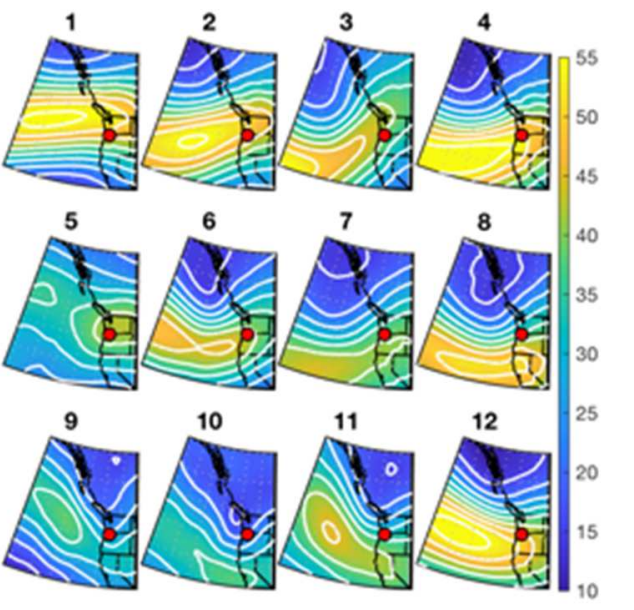

FIG. A3. 12-node SOM for the 1045 days of the heavy total days showing (a) SLP [hPa]

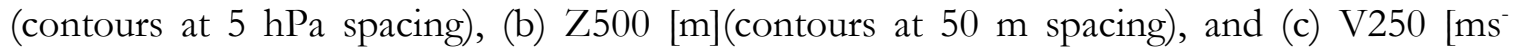
${ }^{1}$ ](contours at $5 \mathrm{~m} \mathrm{~s}^{-}{ }^{1}$ spacing) concurrent with heavy total days. Portland, OR is indicated by the red dot. 

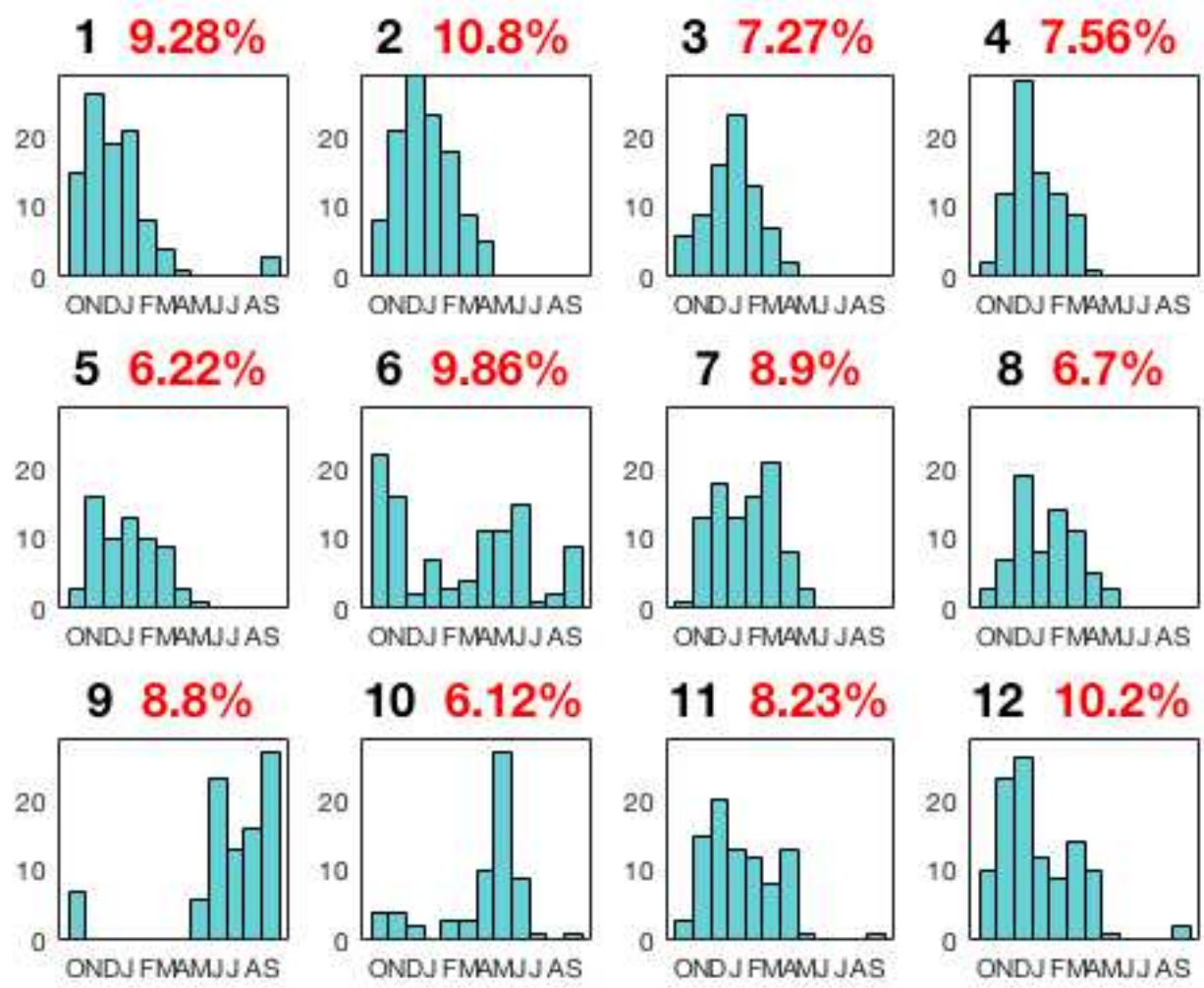

FIG. A4. Histogram showing number of days assigned to each month for each node for heavy total days. The fraction of total input days assigned to each node is indicated in red above respective histogram. 

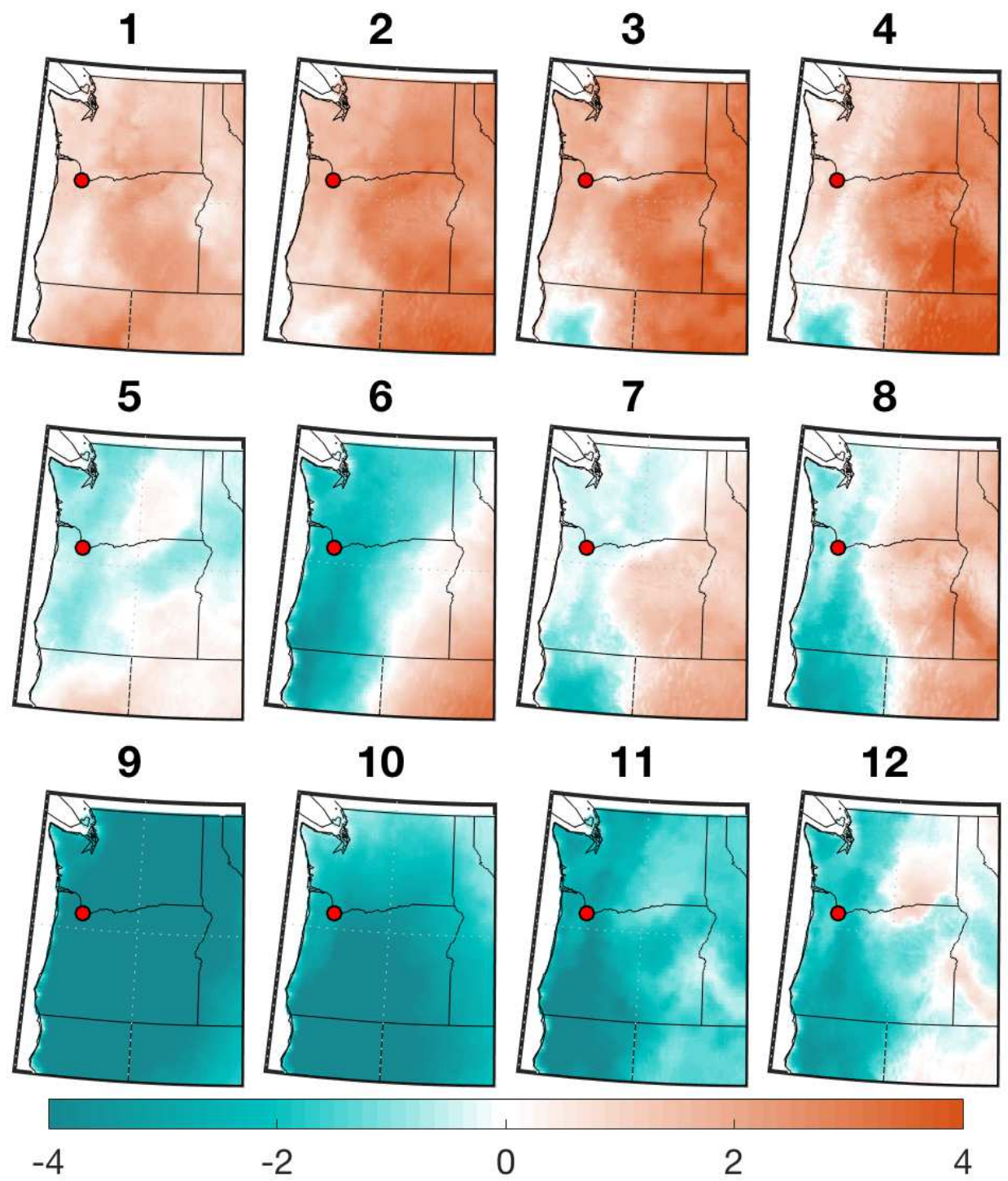

FIG. A5. Composites of daily maximum temperature anomaly $\left[{ }^{\circ} \mathrm{C}\right]$ for all days assigned to each node. Portland, OR is indicated by the red dot. 

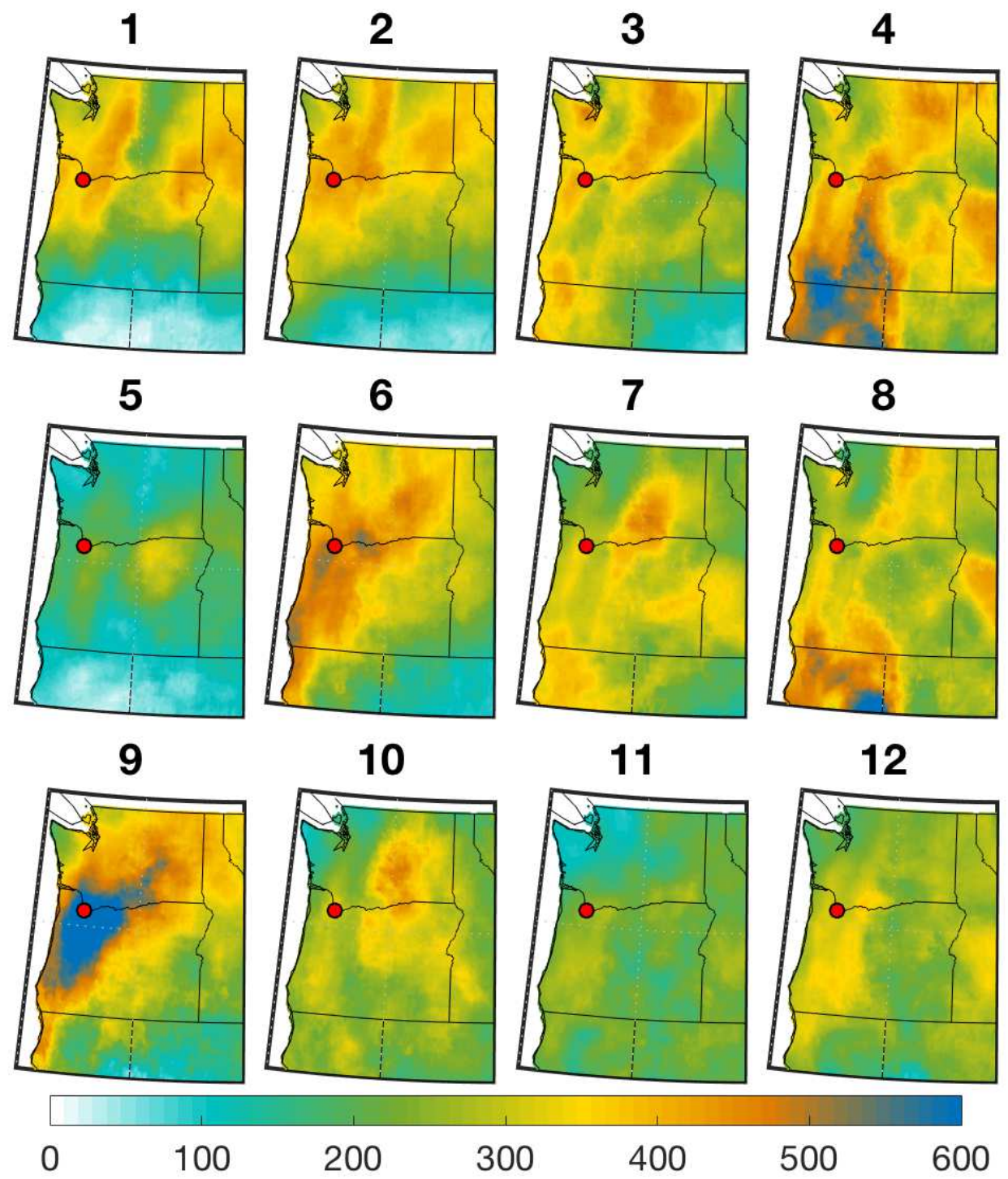

FIG. A6. Same as in Fig. 6, but for daily precipitation anomaly as percent of climatology [\%]. Portland, OR is indicated by the red dot. 

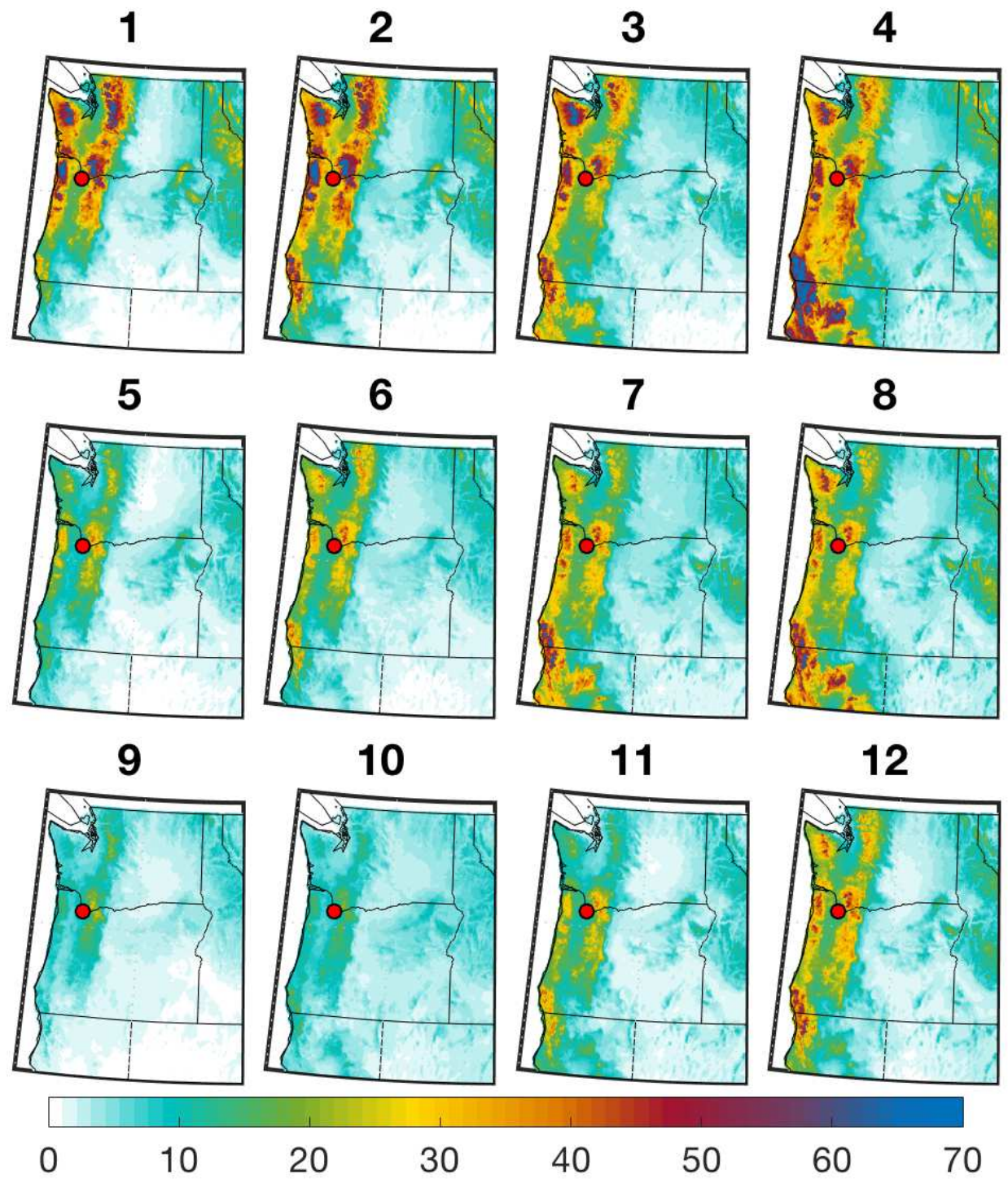

FIG. A7. Same as in Fig. 6, but for daily precipitation amount $[\mathrm{mm} /$ day]. Portland, OR is indicated by the red dot. 

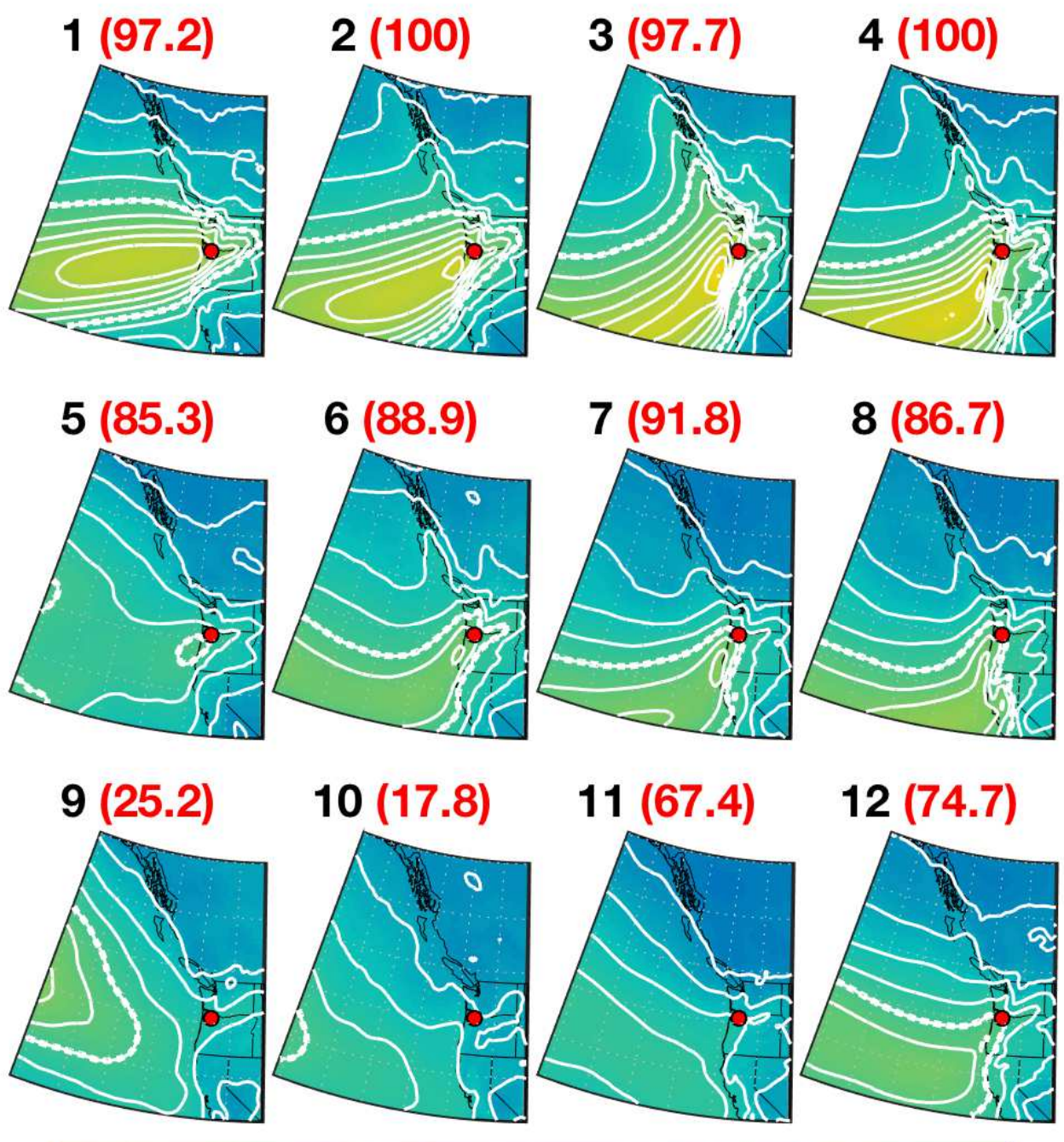

12 (74.7)
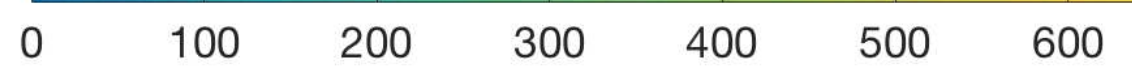

FIG. A8. Same as in Fig. 6, but for IVT $\left[\mathrm{kg} \mathrm{m}^{-1} \mathrm{~s}^{-1}\right.$; contours at $50 \mathrm{~kg} \mathrm{~m}^{-1} \mathrm{~s}^{-1}$ spacing]. Bold dashed white contour indicates the $250 \mathrm{~kg} \mathrm{~m}^{-1} \mathrm{~s}^{-1}$ threshold for AR classification. Red numbers are the percent of days in each node that are concurrent with an AR over the study area. 


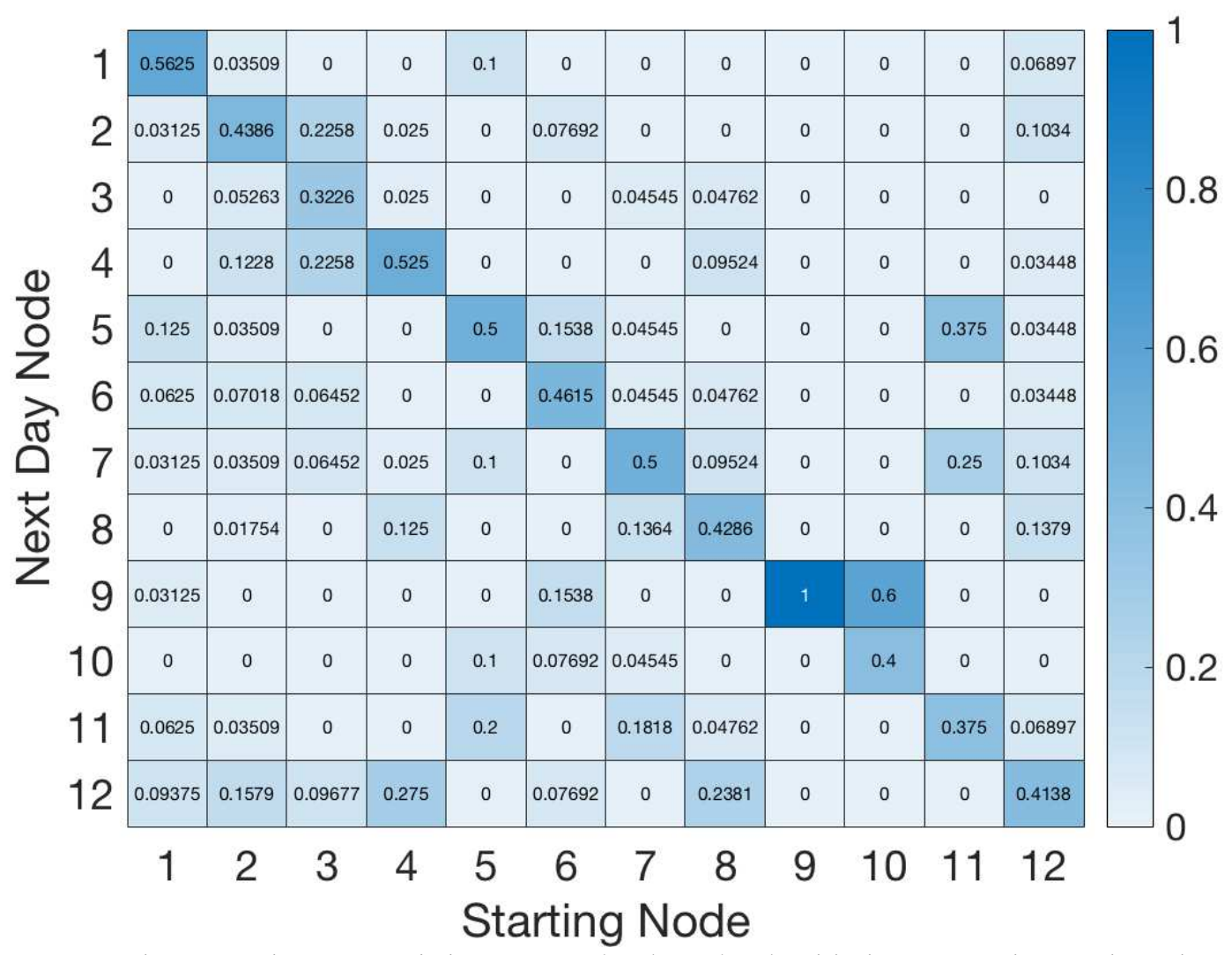

FIG. A9. When two heavy total days occur back-to-back, this heatmap shows the where in the SOMs space the second day occurs. The x-axis shows the starting node assignment and the $y$-axis shows the node assignment of the consecutive day. Heatmap values indicate the percentage of consecutive days assigned to each next-day-node for each given starting node. For example, $94 \%$ of heavy total days that were initially assigned to node 12 , were still assigned to node 12 on the second day. 


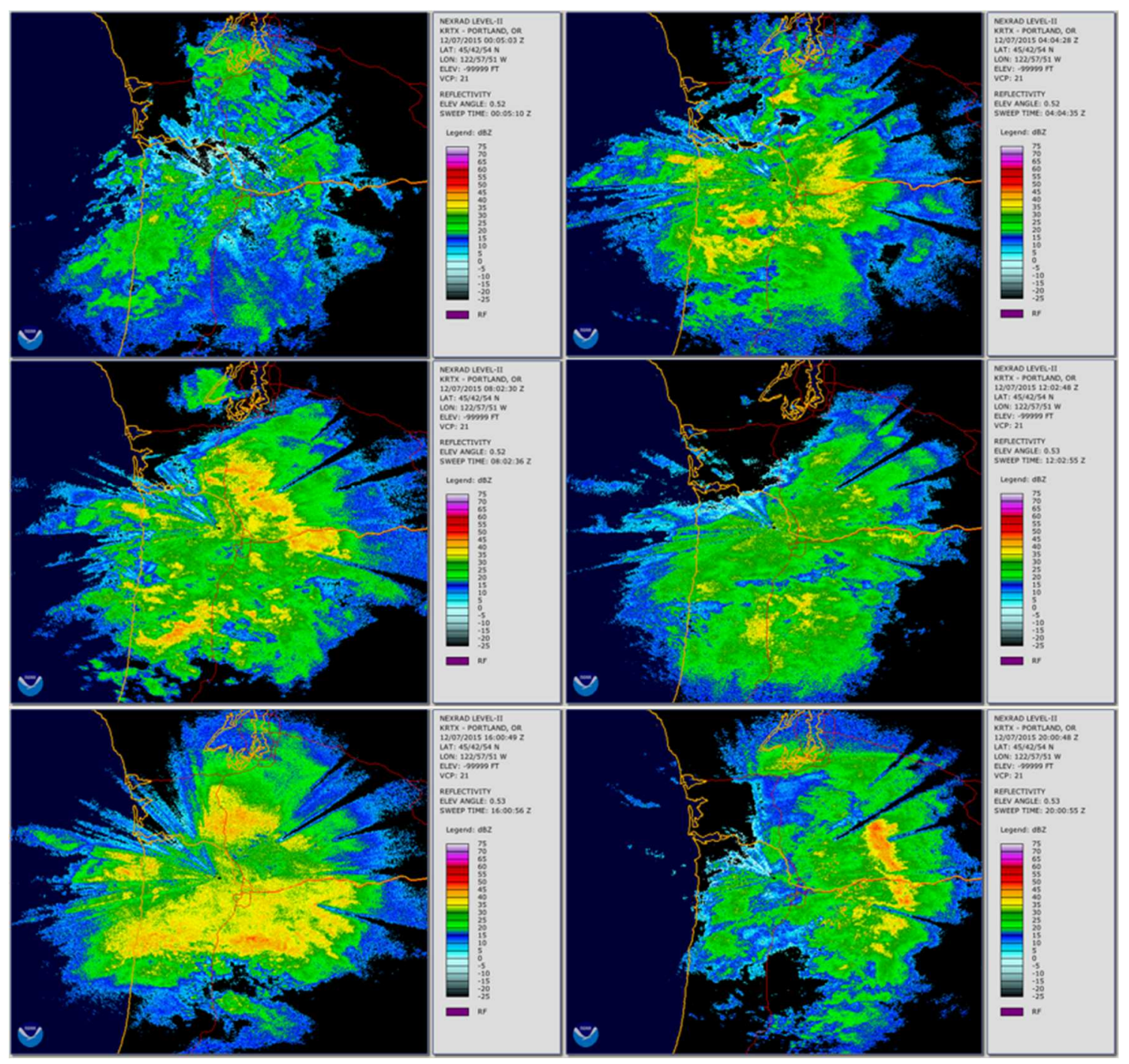

FIG. A10. NWS NEXRAD WRS-88D radar reflectivity data for December 7, 2015 shown at 4-hour time steps, from left to right and top to bottom, starting at 0Z. Portland is in the center of the image where the red lines (arterial freeways) intersect. 


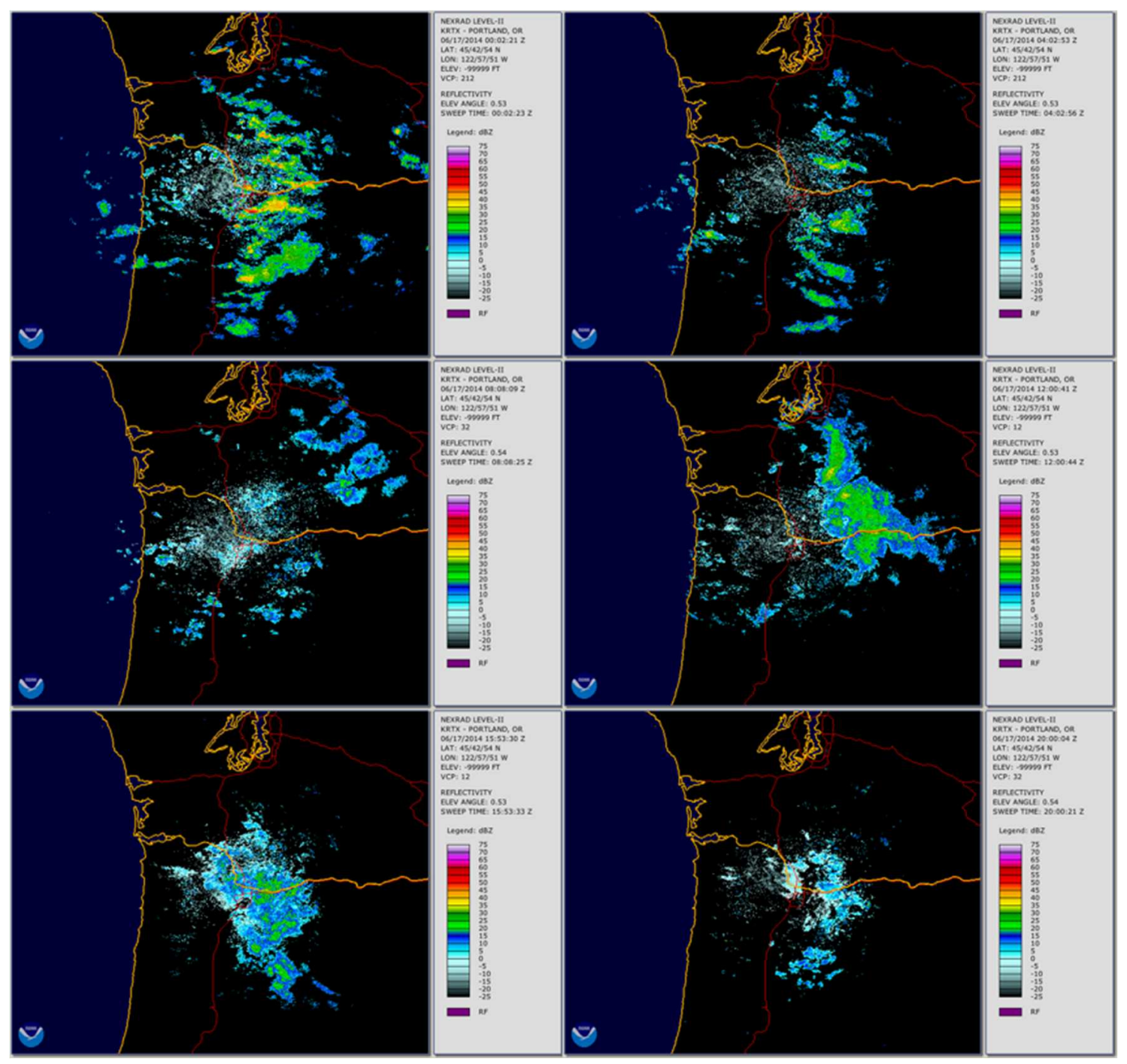

FIG. A11. As in Figure S10 June 17, 2014 shown at 4-hour time steps starting at 2Z. 


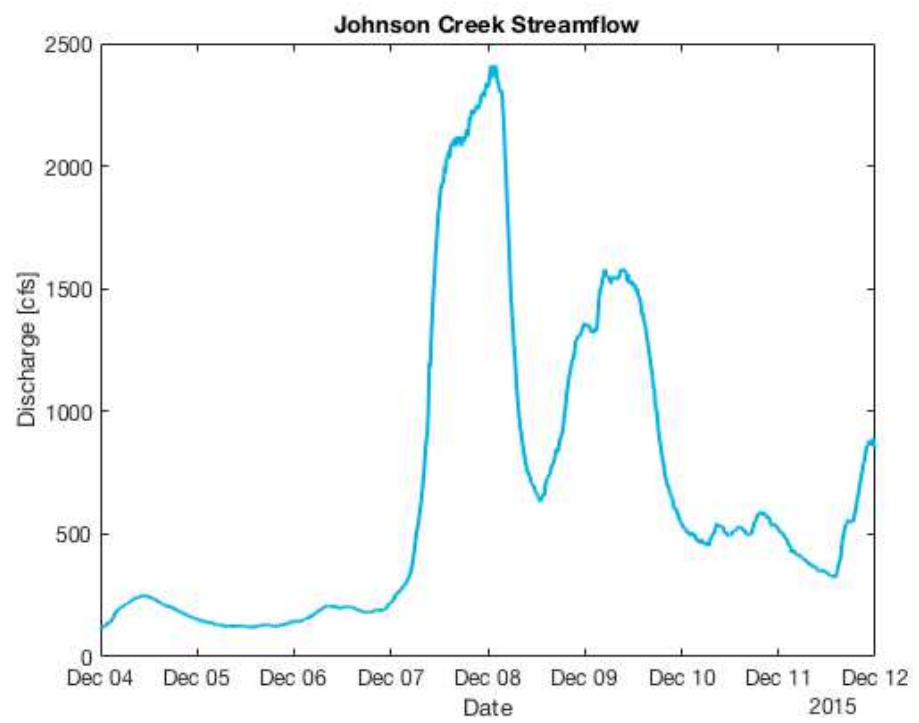

FIG. A12. Hydrograph at USGS station 14211550 on Johnson Creek in Portland for December 2017. 


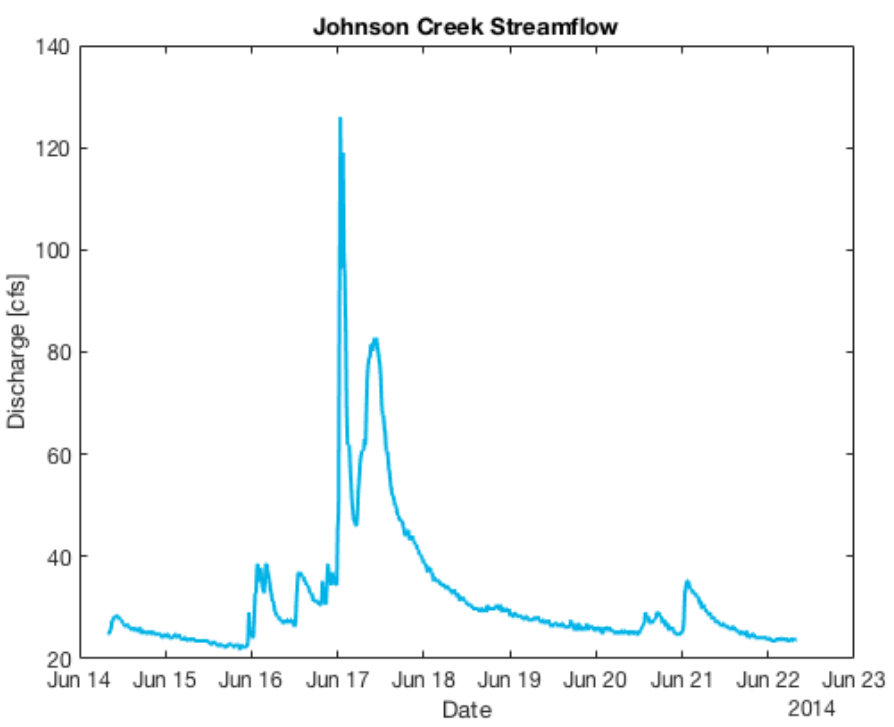

FIG. A13. As in Figure S12 but for June 2014. 